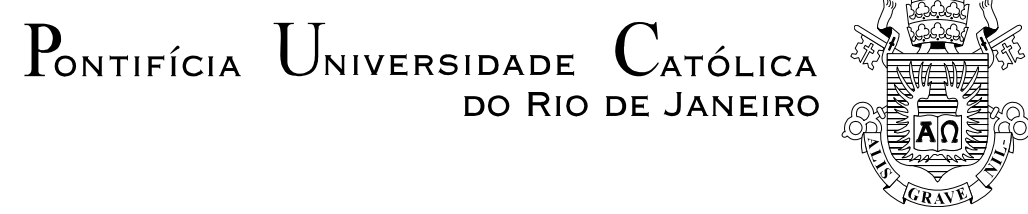

Evaristo Sidonio Junior

Integração de Redes sem Fio Utilizando o Protocolo IEEE 802.21

Dissertação de Mestrado

Dissertação apresentada como requisito parcial para obtenção do grau de Mestre pelo Programa de Pósgraduação em Engenharia Elétrica do Departamento de Engenharia Elétrica da PUC-Rio.

Orientador: Prof. José Roberto Boisson de Marca

Rio de Janeiro

Abril de 2013 


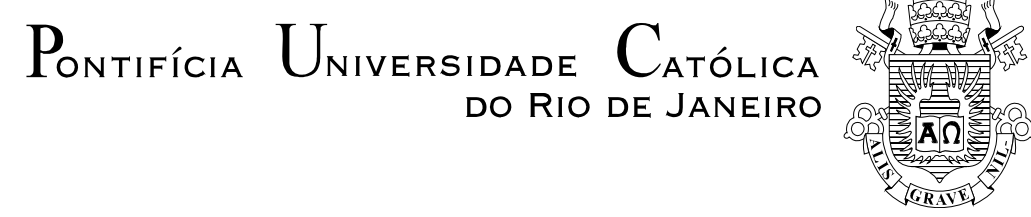

Evaristo Sidonio Junior

\section{Integração de Redes sem Fio Utilizando o Protocolo IEEE 802.21}

Dissertação de Mestrado apresentada como requisito parcial para obtenção do grau de Mestre pelo Programa de Pós-Graduação em Engenharia Elétrica do Departamento de Engenharia Elétrica do Centro Técnico Científico da PUC-Rio. Aprovada pela Comissão Examinadora abaixo assinada.

Prof. Jose Roberto Boisson de Marca

Orientador

Centro de Estudos em Telecomunicações - PUC-Rio

Prof. Gláucio Lima Siqueira

Centro de Estudos em Telecomunicações - PUC

Prof. Guilherme Dutra Gonzaga Jaime

Centro de Estudos em Telecomunicações - PUC-Rio

Prof. José Eugenio Leal

Coordenador Setorial do

Centro

Técnico Científico - PUC-Rio

Rio de Janeiro, 15 de abril de 2013 
Todos os direitos reservados. É proibida a reprodução total ou parcial do trabalho sem autorização da universidade, do autor e do orientador.

\section{Evaristo Sidonio Junior}

Graduou-se em Engenharia Elétrica com ênfase em Telecomunicações em 2010. Atuou como professor contratado no CEFET/RJ (Centro Federal de Educação Tecnológica Celso Suckow da Fonseca).

Ficha Catalográfica

Sidonio Junior, Evaristo

Integração de redes sem fio utilizando o protocolo IEEE 802.21 / Evaristo Sidonio Junior; orientador: José Roberto Boisson de Marca - 2013.

128 f.; $30 \mathrm{~cm}$

Dissertação (mestrado) - Pontifícia Universidade Católica do Rio de Janeiro, Departamento de Engenharia Elétrica, 2013.

Inclui bibliografia

1. Engenharia elétrica - Teses. 2. Protocolo 802.21. 3. Algoritmos de decisão de handover. 4. Interoperação de redes sem fio. I. Marca, José Roberto Boisson de. II. Pontifícia Universidade Católica do Rio de Janeiro. Departamento de Engenharia Elétrica. III. Título. 
Para minha família, pela formação espiritual, humana, educacional e, acima de tudo, pelo amor incondicional. 


\section{Agradecimentos}

Ao bom Deus que nos criou, a Nosso Senhor Jesus Cristo que nos salvou e ao Espírito Santo que ilumina aqueles que assim de sejam e acreditam.

A Santíssima Virgem Maria, mãe de Deus, que sempre me conduziu e orientou em tudo.

A Santa Igreja Católica Apostólica Romana por ter me concedido a graça da fé.

A minha família que, em tudo, sempre me apoiou e sustentou. Sem a participação deles, nem seria possível imaginar este trabalho.

Aos amigos ao longo destes anos, pela amizade, conselhos, força e refúgio nos momentos difíceis.

A todos os professores da PUC-Rio pela formação ao longo destes anos.

Ao CNPq pelos auxílios concedidos durante a pós-graduação e a PUC-Rio que, servindo e amando, custeou generosamente minha graduação. 


\section{Resumo}

Sidonio Júnior, Evaristo; de Marca, José Roberto Boisson (Orientador). Integração de redes sem fio utilizando o protocolo IEEE 802.21. Rio de Janeiro, 2013. 128p. Dissertação de Mestrado - Departamento de Engenharia Elétrica, Pontifícia Universidade Católica do Rio de Janeiro.

A existência de várias tecnologias para acesso a Internet é uma realidade dos nossos dias. Um subconjunto muito importante destas tecnologias, que segue em pleno desenvolvimento, é o das redes sem fio. Diante das alternativas tecnológicas e da demanda crescente por aplicações multimídia, de preferência com conexões do tipo AAA (Anyone Anywhere Anytime), a interoperação entre diferentes redes de acesso sem fio se torna bastante interessante. Seguindo esta tendência, o IEEE (Institute of Electrical and Eletronics Engineers) realizou a especificação de um protocolo que auxilia o processo de handover entre redes de diferentes tecnologias (handover vertical) chamado IEEE 802.21 conhecido também por MIH (Media Independent Handover). Esta dissertação apresenta um estudo sobre aspectos de gerência de mobilidade e do processo de handover vertical entre as tecnologias UMTS (Universal Mobile Telecommunication System), WiMax (IEEE 802.16) e WiFi (802.11) através do protocolo IEEE 802.21. Nela, é confeccionada uma proposta teórica de um algoritmo de decisão de handover vertical entre redes sem fio locais e geograficamente distribuídas para uma topologia comumente encontrada atualmente. São realizadas, através do software ns2 (Network Simulator), simulações do handover vertical envolvendo as tecnologias referidas com o suporte do protocolo IEEE 802.21. Ao final, são feitas as análises e conclusões dos resultados obtidos.

\section{Palavras-chave}

Protocolo 802.21; algoritmos de decisão de handover; interopeção de redes sem fio. 


\section{Abstract}

Sidonio Júnior, Evaristo; de Marca, José Roberto Boisson (Advisor). Wireless Internetworking using IEEE 802.21 protocol. Rio de Janeiro, 2013. 128p. MSc Dissertation - Departamento de Engenharia Elétrica, Pontifícia Universidade Católica do Rio de Janeiro.

A variety of technologies to access the Internet is a reality today. An important subset of these technologies, which follows in full development, is the wireless networks. Given the technological alternatives and increasing demand for multimedia applications, preferably with connections AAA (Anyone Anywhere Anytime), interoperation between different wireless access networks is quite interesting. Following this trend, the IEEE (Institute of Electrical and Electronics Engineers) held a protocol specification that helps the process of handover between networks of different technologies (vertical handover) called IEEE 802.21 also known as MIH (Media Independent Handover). This work presents a study on aspects of mobility management and vertical handover process between UMTS (Universal Mobile Telecommunication System), WiMax (IEEE 802.16) and WiFi (802.11) technologies using IEEE 802.21 protocol. In it, there is a theoretical proposal of a decision algorithm for vertical handover between local and geographically distributed wireless networks to a topology commonly found today. Simulations involving vertical handover in these technologies, with the support of the IEEE 802.21 protocol, are performed using the software ns2 (Network Simulator). At the end, analyzes and conclusions of results are made.

\section{Keywords}

802.21 protocol; handover decision algorithms; wireless internetworking. 


\section{Sumário}

$\begin{array}{ll}\text { 1. Introdução } & 13\end{array}$

1.1. Heterogeneidade tecnológica dos ambientes 13

$\begin{array}{ll}\text { 1.2. Interoperação } & 14\end{array}$

1.3. Descrição do problema 15

$\begin{array}{ll}\text { 1.4. Organização do texto } & 17\end{array}$

2. O Protocolo IEEE 802.21 ou MIH (Media Independent Handover) 20

2.1. Introdução 20

2.2. Objetivo e escopo e principais características do padrão IEEE $802.21 \quad 21$

2.3. SAP (Service Access Point) 25

2.4. MIHF (Media Independent Handover Function) 26

2.4.1. MIES (Media Independent Event Service) 26

2.4.2. MICS (Media Independent Command Service) 28

2.4.3. MIIS (Media Independent Information Service) 29

2.5. Gerência dos serviços da MIHF 32

2.6. Estrutura do quadro IEEE 802.21 34

2.7. Diagrama de um processo de handover assistido pelo padrão $802.21 \quad 36$

3. Algoritmos de decisão de handover vertical 4

3.1. Introdução 41

3.2. Métricas utilizadas por um algoritmo de decisão de handover 42 vertical

3.3. Parâmetros de avaliação de desempenho de um VHD 43

3.4. Taxonomia 44

3.5. Proposta teórica de um algoritmo de decisão 46

3.5.1. Classificação do algoritmo proposto e trabalhos relacionados 46

3.5.2. Sinergia entre elementos da gerência de mobilidade e do sistema 47

3.5.3. Algoritmo proposto: diagrama de fluxo e funcionamento $\quad 50$

4. Simulação e análise de desempenho

4.1. O simulador ns2 53

4.2. Limitações do ns2 e objetivos de simulação 54

4.3. Cenários e configurações de elementos $\quad 55$

4.3.1. Configuração dos Tráfegos $\quad 55$

4.3.2. Configuração das redes envolvidas $\quad 56$

4.3.3. Topologias das redes em cada cenário $\quad 57$

4.3.3.1. Cenário 1: Handover entre UMTS e 802.16 57

4.3.3.2. Cenário 2: Handover entre redes 802.16 e 802.11

4.3.3.3. Cenário 3: Handover entre redes UMTS e 802.11

4.3.4. Considerações sobre instalações do MIP e do 802.21 59

$\begin{array}{ll}\text { 4.4. Análise dos resultados } & 60\end{array}$

4.4.1. Análise dos cenários com o tráfego $1 \quad 61$

4.4.2. Análise dos cenários com o tráfego 2 
5.1. Conclusão 64

5.2. Trabalhos futuros $\quad 65$

$\begin{array}{ll}\text { Referências bibliográficas } & 67\end{array}$

Apêndice A: Tecnologias de rede sem fio $\quad 72$

A.1. Introdução

A.2. A rede UMTS (Universal Mobile Telecommunication System) 72

A.2.1. Histórico e Características Gerais $\quad 72$

A.2.2. A técnica de acesso CDMA (Code Division Multiple Access) 73

A.3. Classes de QoS definidas para a rede UMTS. $\quad 75$

$\begin{array}{ll}\text { A.4. Arquitetura da rede UMTS } & 75\end{array}$

A.4.1. UE (User Equipment)

A.4.2. CN (Core Network) 76

A.4.3. UTRAN (UMTS Terrestrial Access Network) 77

A.5. Handover e gerência de mobilidade em nível de camada de enlace $\quad 78$

A.6. Principais melhorias: o HSPA e o HSPA+ 81

A.6.1. HSDPA (High Speed Downlink Packet Access) 81

A.6.2. HSUPA (High Speed Uplink Packet Access) 81

A.6.3. Evolved HSPA (Evolved High Speed Packet Access) ou HSPA+ 82

A.7. A evolução do UMTS: o LTE (Long Term Evolution) 82

A.7.1. Considerações sobre evolução para uma arquitetura plana 83

$\begin{array}{ll}\text { A.7.2. Características gerais } & 84\end{array}$

$\begin{array}{ll}\text { A.7.2.1. Método de acesso OFDMA } & 84\end{array}$

A.7.2.2. Arquitetura plana e agendamento de pacotes no domínio da 84 frequência

A.7.2.3. Aplicação da tecnologia de antenas múltiplas $\quad 85$

A.7.2.4. Mudança de paradigma: comutação de pacotes na interface 85 aérea

$\begin{array}{lr}\text { A.7.3. Arquitetura de rede } & 85\end{array}$

A.7.3.1. SAE (System Architecture Evolution) 85

A.7.3.2. Interface aérea: a EUTRAN ou Evolved UTRAN 86

A.7.3.3. Núcleo de rede ou EPC (Evolved Packet Core) 87

A.8. Os padrões IEEE $802 \quad 87$

$\begin{array}{ll}\text { A.9. O padrão } 802.11 & 88\end{array}$

A.9.1. Histórico e Características Gerais $\quad 88$

A.9.2. Arquitetura de rede e modos de operação da camada MAC $\quad 89$

A.9.2.1. DCF (Distribute Coordination Function) 91

A.9.2.2. PCF (Point Coordination Function) 92

A.9.3. Formato dos Quadros da camada MAC 802.11 93

A.9.4. Tipos de quadro e aspectos da gerência de mobilidade $\quad 94$

A.9.5. Classes de QoS e o padrão 802.11e 96

A.9.5.1. EDCA (Enhanced Distributed Channel Access) 97

A.9.5.2. HCCA (HCF Controlled Channel Access) 98

A.9.6. Cálculo de banda residual com o auxílio da especificação 98 $802.11 \mathrm{e}$

A.10. O padrão IEEE 802.16 100

A.10.1. Histórico e Características Gerais $\quad 100$

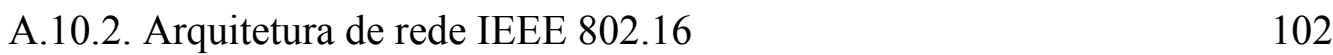


A.10.2.1. MS (Mobile Station) 102

A.10.2.2. ASN (Access Service Network) 103

A.10.2.3. CSN (Connectivity Service Network) 104

A.10.2.4. Gerência de Mobilidade 104

$\begin{array}{ll}\text { A.10.3. A camada física do IEEE 802.16 } & 105\end{array}$

A.10.3.1. A técnica de acesso OFDMA 105

$\begin{array}{ll}\text { A.10.3.2. Tecnologias de antenas múltiplas } & 107\end{array}$

A.10.3.3. Modulação Adaptativa 108

A.10.4. A camada MAC do IEEE 802.16 109

A.10.5. Classes de QoS do padrão 802.16 110

Apêndice B: Aspectos genéricos da teoria de redes sem fio 112

B.1. Introdução 112

B.2. Arquitetura genérica de uma rede sem fio 112

B.2.1. Plano de Dados 114

B.2.2. Plano de Controle $\quad 115$

B.2.3. Terminal móvel (ou Multimode Terminal) 116

B.3. O processo de handover 116

B.3.1. Definições e tipos de handover 116

$\begin{array}{ll}\text { B.3.2. Modalidades e políticas de handover } & 117\end{array}$

B.3.3. Fases do processo de handover 118

B.3.4. Gerência de Mobilidade e problemas associados ao handover $\quad 119$

B.3.4.1. O protocolo IP Móvel ou MIP (Mobile IP) 120

B.3.4.2. Ineficiências do MIP e handover transparente 123

$\begin{array}{ll}\text { B.4. Principais propostas de interoperabilidade } & 124\end{array}$

B.4.1. I-WLAN (Interworking WLAN) 124

B.4.2. GAN (Generic Access Network) 126

B.4.3. IEEE 802.21 ou MIH (Media Independent Handover) 128 


\section{Lista de figuras}

Figura 1.1: Exemplos de handovers verticais e horizontais

Figura 1.2: Móvel executando um handover vertical com uma conexão

IP em curso

Figura 2.1: Localização do 802.21 no modelo TCP/IP 22

Figura 2.2: Relacionamento entre serviços MIHF e MIHUs 24

Figura 2.3: SAPs no padrão IEEE 802.21 25

Figura 2.4: Segmentos dentro do buffer da camada MAC após um handover

Figura 2.5: Pesquisa de informações de um servidor MIH 31

Figura 2.6: Formato do cabeçalho MIHP $\quad 34$

Figura 2.7: Formato da carga útil da mensagem MIHP 35

Figura 2.8: Diagrama do processo de handover vertical 39

Figura 2.9: Diagrama do processo de handover vertical (continuação) $\quad 40$

Figura 3.1: Exemplos de métricas de um VHD 42

Figura 3.2: Localização física dos elementos PDP e PEP 48

Figura 3.3: Sinergia entre algoritmo e o padrão 802.21

Figura 3.4: Diagrama de fluxo do algoritmo proposto 51

Figura 4.1: Topologia simulada no cenário 1 2

Figura 4.2: Topologia simulada no cenário $2 \quad 58$

Figura 4.3: Topologia simulada no cenário $3 \quad 59$

Figura 4.4: Vazão média obtida com o tráfego $1 \quad 61$

Figura 4.5: Atraso médio obtido com o tráfego $1 \quad 62$

Figura 4.6: Vazão média obtida com o tráfego $2 \quad 63$

Figura 4.7: Atraso médio obtido com o tráfego 2

Figura A.1: Espalhamento espectral no DS-CDMA 74

Figura A.2: Principais elementos da arquitetura UMTS 76

Figura A.3: O UTRAN e o RNS $\quad 78$

Figura A.4: Hierarquia na gerência de mobilidade com elemento âncora $\quad 80$

Figura A.5: Processo de planificação da arquitetura $\quad 83$

Figura A.6: Visão geral da arquitetura do LTE $\quad 86$

Figura A.7: Principais elementos do EPC $\quad 87$

Figura A.8: Escopo dos padrões IEEE 802 comparados ao modelo OSI $\quad 88$

Figura A.9: Topologia de rede em modo ad-hoc $\quad 89$

Figura A.10:Topologia de rede em modo infraestrutura 90

Figura A.11: Quadro 802.11 e seu campo de controle 93

Figura A.12: Outras especificações IEEE802.11 97

Figura A.13: Arquitetura de rede IEEE 802.16 102

Figura A.14: Eficiência espectral na OFDM 105

Figura A.15: Divisão em M portadoras e minimização da ISI 106

Figura A.16: Ilustração do uso da modulação adaptativa 108

Figura A.17: Camada MAC do IEEE 802.16 109

Figura B.1: Plano de Dados e Plano de Controle $\quad 114$

Figura B.2: Móvel em uma rede estrangeira utilizando o MIP 121

Figura B.3: Arquitetura de integração I-WLAN 125

$\begin{array}{ll}\text { Figura B.4: Arquitetura de integração GAN } & 127\end{array}$ 


\section{Lista de tabelas}

Tabela 4.1: Configurações da Rede UMTS 55

Tabela 4.2: Configurações da Rede UMTS 56

Tabela 4.3: Configurações da Rede 802.16 56

Tabela 4.4: Configurações da Rede 802.11 56

Tabela 4.5: Configurações de parâmetros gerais 56

Tabela 4.6: Funcionalidades dos elementos de rede ao utilizar o MIPv4 60

Tabela A.1: Classes de QoS definidas para a rede UMTS 75

Tabela A.2: Padrões IEEE 802.11 89

Tabela A.3: Características das principais especificações 802.16 101 


\section{1 \\ Introdução}

\section{1}

\section{Heterogeneidade tecnológica dos ambientes}

A existência de várias possibilidades para acesso à internet é uma realidade dos nossos dias. Um subconjunto muito importante, que segue em pleno desenvolvimento, é o que se refere às redes de acesso sem fio.

O IMT-2000, organismo da ITU (International Telecommunication Union) responsável pela padronização dos sistemas de telefonia móvel de terceira geração, tinha em mente o atendimento da demanda de um perfil de usuário emergente à época. A expectativa dos usuários deste novo perfil era a de estar sempre conectado, independentemente de hora e local. Assim, surgiram os conceitos de conexão Always on, ABC (Always Best Connected) ou ainda AAA (Anyone Anywhere Anytime) que, até hoje, representam uma meta a ser atingida.

Dando continuidade aos passos do sistema GSM (Global System for Mobile communication) e do GPRS (General Packet Radio Service), sua versão que dá suporte à comutação de pacotes, o UMTS (Universal Mobile Telecommunication System) tornou-se o sistema $3 \mathrm{G}$ mais popular de telefonia celular, vindo a possuir a maioria esmagadora do mercado de telefonia móvel. De fato, o UMTS e suas evoluções mantêm, até hoje, esse domínio tendo ainda crescimentos notáveis no número de usuários a cada ano [1]. No Brasil, há dados que nos levam a esperar um crescimento ainda expressivo do 3G [2].

Paralelamente, outras tecnologias de redes sem fio foram sendo desenvolvidas. Com um foco no tratamento de pequenas áreas, surgiram as WLANs (Wireless Local Area Networks) cujo principal representante é a família de padrões IEEE 802.11, popularmente conhecida como redes WiFi. Essa família surgiu como uma alternativa de menor custo para prover acesso à Internet em área local. A área de cobertura de uma rede WiFi é conhecida como hotspot.

Por outro lado, percebeu-se uma espécie de "lacuna" no que diz respeito à comparação dessas duas tecnologias. Procurando preencher esta "lacuna" 
existente entre as redes $3 \mathrm{G}$ (menor velocidade e grande alcance) e as redes IEEE 802.11 (maior velocidade e pouco alcance), surgiu o padrão IEEE 802.16 que ficou popularmente conhecido como WiMax. Inicialmente proposto como alternativa de banda larga móvel, o WiMax pode também ser utilizado como backbone/backhaul para redes com ou sem fio.

Como não poderia ser diferente, as tecnologias de telefonia móvel não pararam de evoluir no UMTS. Tendo em vista o início do movimento em direção à quarta geração, há o surgimento do LTE (Long Term Evolution), uma evolução das redes UMTS. O LTE difere das evoluções HSPA e HSDPA do UMTS no que se refere à sua arquitetura de rede e de interface aérea. As evoluções mantiveram toda a essência do UMTS, enquanto o LTE rompe com ela, possuindo, entre outros aprimoramentos, um ambiente de comunicação totalmente via protocolo IP.

\section{2 \\ Interoperação}

Como se sabe, nenhuma dessas tecnologias conseguiu atender sozinha a demanda por conexões AAA de forma satisfatória. Com o notável crescimento das aplicações multimídia graças aos poderosos aparelhos (handsets) atuais, uma opção seria, ao invés de investir em uma única tecnologia, procurar tirar vantagem da heterogeneidade, isto é, da sobreposição existente entre as tecnologias. Dessa forma, seria necessário criar condições para um usuário que deseje (ou mesmo necessite) migrar de uma determinada tecnologia A para outra tecnologia B, disponível no mesmo local, porém de utilização mais conveniente, o faça de maneira suave e transparente, isto é, sem que suas aplicações sejam afetadas no processo.

A interoperação pode ser obtida através do handover vertical executado por um terminal móvel ou MN (Mobile Node). A Figura 1.1 ilustra uma situação que serviu como motivação para o estudo desta dissertação. 


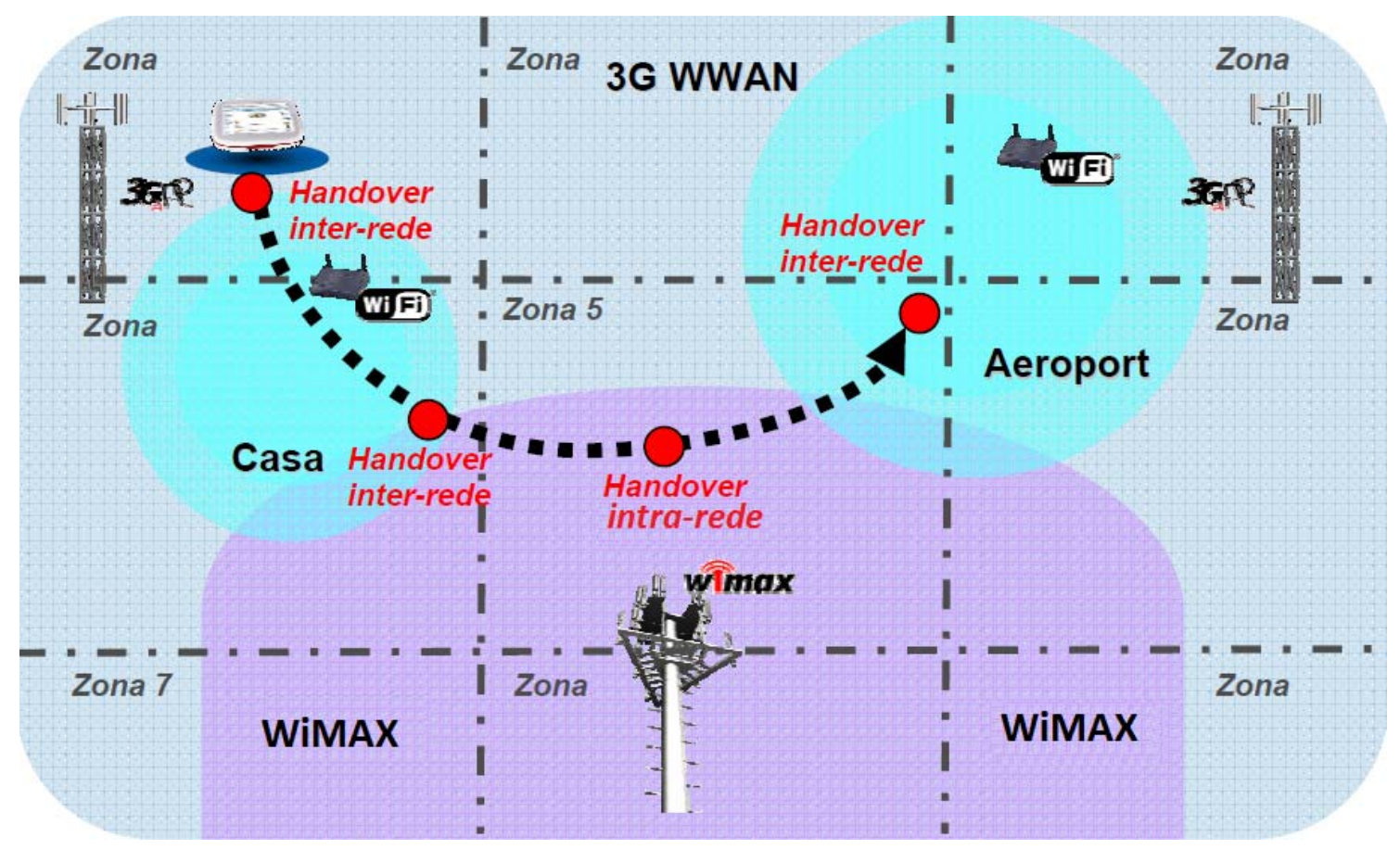

Figura 1.1: Exemplos de handovers verticais e horizontais [28]

O cenário ilustrado mostra um usuário que se move de seu domicílio até o aeroporto. Inicialmente conectado em sua WLAN doméstica, o MN, para manter sua aplicação em curso, vê a necessidade da realização de um handover vertical (inter-rede), isto é, de migrar para uma WWAN (Wireless Wide Area Network) que, no caso, pode ser uma rede $3 \mathrm{G}$ ou uma rede WiMax. Independentemente da WWAN escolhida, o $\mathrm{MN}$, ao se deslocar entre células adjacentes, tem a necessidade de realizar handovers sucessivos para não perder sua conexão. Caso estes handovers ocorram entre estações rádio base de mesma tecnologia, eles são chamados de handovers horizontais (intra-rede).

\section{3}

\section{Descrição do problema}

Dada a indiscutível tendência dominante atual por aplicações IP, supõe-se que o MN esteja executando uma ou mais dessas aplicações, estando, portanto, conectado a um servidor, em qualquer parte do mundo, ao qual será atribuído o nome genérico CN (Correspondent Node). Assim, em resumo, tem-se entre um MN e um CN, uma conexão TCP/IP corrente como mostra a Figura 1.2. Naturalmente, surgem as perguntas: como o MN consegue manter seu endereço IP 
quando troca de rede? Caso haja a troca de endereço IP do MN, como o CN irá descobrir isso? De fato, são dois os principais problemas a enfrentar: um relacionado à camada de rede e outro à camada de enlace.

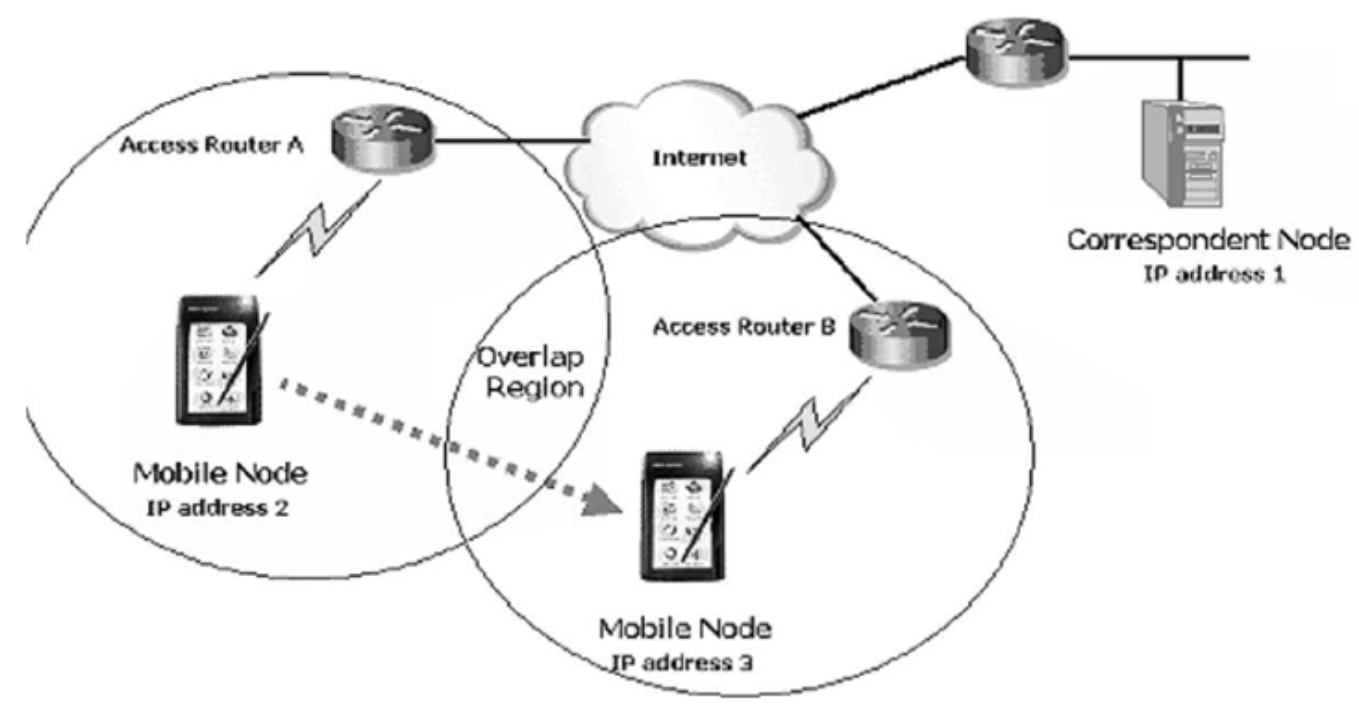

Figura 1.2: Móvel executando um handover vertical com uma conexão IP em curso [53]

Cada operadora recebe da ICANN (Internet Corporation for Assigned Names and Numbers) um conjunto de endereços IP para utilização dos usuários de sua rede. No caso da Figura 1.1, a execução de um handover horizontal não implica a necessidade de mudança do endereço IP. Mecanismos inerentes à própria tecnologia fazem com que o MN mantenha seu endereço IP visto que, como já mencionado, estão no domínio da mesma operadora. Assim, toda a operação passa despercebida (ou transparente) pelo $\mathrm{CN}$, pois quando este envia um pacote endereçado ao $\mathrm{MN}$, o roteador da operadora, que conhece todas as rotas para todos os endereços IP ativos da operadora, saberá encaminhá-lo corretamente até o MN.

O problema acontece quando o MN precisa receber um novo endereço IP e piora na medida em que este novo endereço não faça parte da faixa de endereços IP de sua rede original. Embora possa ocorrer também em um handover horizontal, esta é uma situação que tem ocorrência certa em um handover vertical e que deve ser tratada objetivamente.

O segundo problema, de natureza mais óbvia que o anterior, é a maneira desafiadora de fazer com que tecnologias com mecanismos de camada de enlace 
diferentes possam interagir entre si e também com suas respectivas camadas de rede e superiores.

Outro desafio, de natureza diferente dos dois anteriores ligados às camadas de rede e de enlace já mencionados, consiste na escolha da rede mais adequada para que o MN possa se reconectar ao executar um handover vertical. Características intrínsecas à rede como custo monetário, taxa disponível, custo energético pelo lado do usuário e balanceamento de carga e QoS (Quality of Service) disponível pelo lado do operador de rede devem ser levadas em consideração na escolha. Por exemplo, um usuário em uma rede $3 \mathrm{G}$ pode considerar um mau negócio migrar para uma rede WiFi que, embora mais veloz e de menor custo monetário, possa estar sobrecarregada de tráfego. Nesse contexto, a tarefa de escolher a rede mais adequada em cada momento é realizada por um algoritmo de decisão de handover.

Assim, retornando ao exemplo da Figura 1.1, o usuário, antes de sair de casa, tem a sua disposição a conexão com sua rede WLAN domiciliar e a rede de telefonia móvel 3G. Essa situação se repete no aeroporto lembrando que, nesse caso, a WLAN tem uma maior estrutura e, com certeza, é mais congestionada que uma WLAN domiciliar. Em casa, parece óbvio que o melhor seja permanecer na rede WLAN, porém no aeroporto já não se pode afirmar isso.

\section{4}

\section{Organização do texto}

Dentre as principais propostas de interfuncionamento entre redes sem fio, destaca-se a proposta do IEEE feita pelo padrão 802.21 também conhecido como MIH (Media Independent Handover). O MIH exige um pequeno número de modificações no funcionamento regular das tecnologias envolvidas, sendo, por isso, um elemento chave no estudo desta dissertação. Esse protocolo possui grande versatilidade, pois pode, a princípio, funcionar com qualquer tecnologia existente ou futura fazendo-se para isso pequenas adaptações. O MIH é apresentado no capítulo dois em suas principais características e interações com as diferentes camadas, tendo como referência o modelo OSI de camadas de rede.

No capítulo três, são abordados os algoritmos de decisão de handover cujo objetivo é o de escolher a rede ótima dentre todas as disponíveis para execução de 
um handover vertical. São vistas sua definição, estrutura e como ele se relaciona com os diversos elementos e protocolos nas diversas entidades de rede.

Neste capítulo é feita também a proposta de um algoritmo de decisão de handover vertical baseado em informações do protocolo MIH. Este algoritmo foi concebido para atender um cenário de baixa mobilidade bem parecido com o que se pode ter na casa do usuário ou no aeroporto como representado na Figura 1.1. Assim, o algoritmo foi elaborado para funcionar, aproveitando-se da sobreposição de redes WWAN e WLAN em vários ambientes tão comuns nos dias atuais.

Já no capítulo quatro, são realizadas simulações de handovers verticais entre as redes UMTS, WiMax e Wi-Fi tendo como protagonista o protocolo IEEE 802.21. É feita inicialmente uma breve introdução ao simulador utilizado, o ns2 (Network Simulator). Em seguida são abordadas algumas limitações e dificuldades gerais encontradas na simulação, bem como os objetivos gerais a serem atingidos.

Uma observação importante a fazer é sobre a escolha da rede UMTS para a simulação. Dois foram os fatos que levaram a esta escolha. O primeiro, de caráter mais prático, foi a inexistência de um módulo confiável da tecnologia LTE para o simulador ns2. O segundo, já comentado brevemente no tópico inicial deste capítulo introdutório, diz respeito à larga utilização e seu grande potencial de crescimento ainda existente, o que, de fato, justifica ações muito concretas nas redes UMTS por parte dos operadores do setor de comunicações móveis.

Quanto a simulação, são apresentados três cenários em que dois tipos de tráfego são utilizados. A ideia é avaliar a eficácia de ação do handover vertical através do auxilio do protocolo MIH nos cenários, bem como seu desempenho através das métricas de taxa de transferência ou vazão média (throughput), e atraso médio (delay).

Por fim, o capítulo cinco apresenta as conclusões gerais do trabalho e procura também indicar novos caminhos possíveis na continuidade do estudo que, obviamente, não se esgotará tão cedo na literatura.

Com o propósito de uma enumerar algumas características básicas presentes no estudo das redes sem fio, uma revisão de conceitos gerais e outros aspectos julgados relevantes ao tema de redes de comunicação sem fio são apresentados sob a forma de dois apêndices após a conclusão do texto. 
Sendo as redes UMTS, 802.11 e 802.16 as três principais tecnologias utilizadas nesse trabalho, o Apêndice A versa sobre suas principais características de arquitetura e de operação, bem como funcionalidades específicas citadas neste estudo. No Apêndice B são apresentados aspectos teóricos genéricos de arquitetura de uma rede sem fio. São vistos os conceitos de planos de rede, o processo global do handover e, por fim, são examinadas brevemente outras propostas de interoperação de redes sem fio paralelas a proposta do IEEE 802.21. 


\section{O Protocolo IEEE 802.21 ou MIH (Media Independent Handover)}

\section{1 Introdução}

Logo após o advento da tecnologia 2G GSM e de sua associação à comutação de pacotes com o GPRS, iniciou-se o interesse por um sistema de comunicação móvel que fosse capaz de oferecer roaming mundial e também, além de voz, uma vasta gama de serviços. De fato, essa tendência influenciou a concepção dos sistemas $3 \mathrm{G}$ de telefonia móvel e o acrônimo AAA (Anyone Anywhere Anytime) foi criado a partir do IMT 2000 como comentado no capítulo de introdução.

Como se sabe, os sistemas de telefonia móvel se desenvolveram bastante, mas não são capazes de atender a essa demanda totalmente. Contudo, a solução pode vir não de uma só tecnologia que domine todo o espaço de forma onipresente, mas sim pela utilização de várias tecnologias que, se complementando, pudessem atingir um nível de conectividade AAA. A capacidade de realização do handover vertical torna-se então requisito fundamental no contexto de interoperabilidade e da exigente expectativa de experiência dos usuários das redes sem fio.

Neste capítulo, a proposta de interoperação de redes sem fio dada pelo IEEE é vista em seus detalhes. A discussão se volta para a camada de enlace e, especialmente, para como o IEEE 802.21 auxilia o processo de handover vertical melhorando, deste modo, o nível de satisfação do usuário móvel. Assim, o objetivo é estudar o que ocorre na camada de enlace, sobretudo no que diz respeito ao handover vertical. Já os desafios enfrentados pelo processo de handover relativos à camada de rede, que complementam os da camada de enlace, são apresentados no Apêndice B. 


\section{2}

\section{Objetivo, escopo e principais características do padrão IEEE 802.21}

O objetivo principal do padrão 802.21 é permitir que os usuários móveis e a operadora da rede consigam extrair todas as vantagens inerentes às várias sobreposições de diferentes tipos de rede sem fio existentes hoje em dia através da realização de handovers verticais. O padrão provê um framework (conjunto de operações) para a descoberta de novas redes candidatas em potencial ao handover vertical e que auxilia sua operação em nível da camada de enlace com possibilidade de interação com camadas superiores [31].

Comparativamente, o MIP (Mobile Internet Protocol) foi citado como a solução mais comum para o gerenciamento de mobilidade no contexto da camada de rede atendendo handovers horizontais e verticais (vide Apêndice B). No caso do handover horizontal, cada tecnologia já possui suas próprias especificações de camada de enlace como pode ser visto no Apêndice A. O padrão 802.21 entra aqui como proposta de especificação genérica para o gerenciamento de mobilidade em nível de camada de enlace para o caso específico do handover vertical, embora possa, no futuro, atender handovers horizontais. Ao fazer tal análise, é interessante esclarecer as funcionalidades que estão fora do escopo das especificações do padrão 802.21.

- Handover horizontais (em princípio) [31];

- $\quad$ Políticas de handover;

- Mecanismos de segurança;

- Melhorias na camada de enlace de tecnologias específicas ao utilizar o padrão IEEE 802.21;

- Melhorias nas camadas de rede e superiores. 


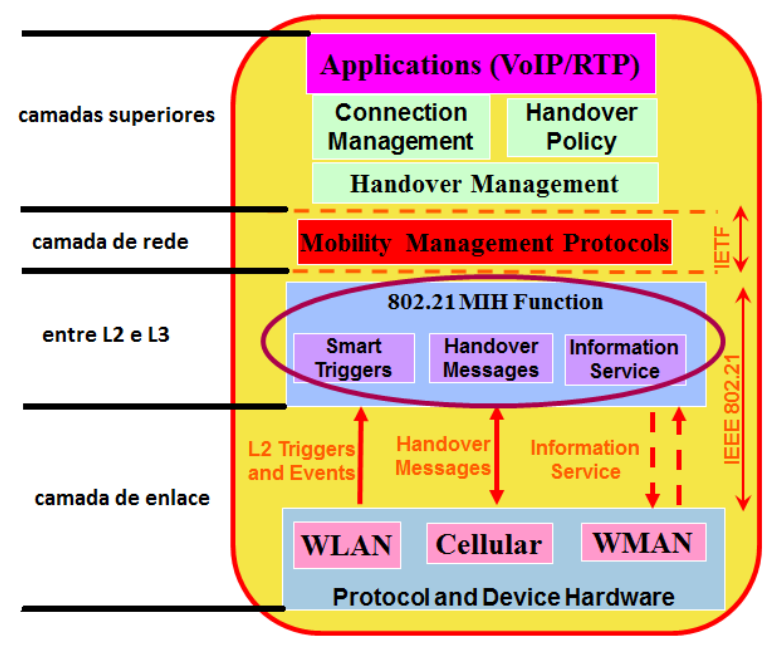

Figura 2.1: Localização do 802.21 no modelo TCP/IP [54]

O padrão 802.21 define um conjunto de serviços que ficam localizados em uma entidade lógica chamada de MIHF. A MIHF (MIH Function) é responsável por coletar e disponibilizar as informações necessárias entre as entidades pertencentes às redes envolvidas que executam o padrão 802.21. Assim, a MIHF é o coração das ações do protocolo 802.21.

Na Figura 2.1, observa-se que o protocolo 802.21 se situa exatamente entre as camadas de rede e de enlace. Segundo este posicionamento, entidades lógicas requisitantes dos serviços da MIHF pertencentes a camadas superiores são denominados de MIHU (MIH Users). Por exemplo, um algoritmo de decisão que atua na segunda fase do processo de handover é um MIHU. O algoritmo pode receber parte dos valores para os parâmetros empregados por suas métricas de decisão através dos serviços oferecidos pela MIHF. É exatamente esta a abordagem feita na proposta de algoritmo de decisão no capítulo três desta dissertação.

Os três serviços que a MIHF dispõe são:

- MIES (Media Independent Event Service): este serviço fornece relatórios sobre todos os eventos ocorridos na rede. Um evento se caracteriza pela mudança de valor ou de status de alguma configuração de um enlace. A disponibilidade do enlace, mudanças dinâmicas que podem vir a ocorrer nele como nível e qualidade do sinal são exemplos de informações destes relatórios. Os eventos podem ser locais (no próprio elemento de rede em 
que se executa a MIHF) ou remotos (em outro elemento da própria ou de outra rede qualquer).

- MICS (Media Independent Command Service): este serviço permite, através de um conjunto de comandos, que os MIHUs façam a gerência e o controle dos parâmetros relacionados ao comportamento do enlace ou de um handover. As informações obtidas pelo MICS são todas dinâmicas, ou seja, sempre sujeitas a mudanças. Os comandos do MICS podem ser locais ou remotos a exemplo do que ocorre com o MIES.

- MIIS (Media Independent Information Service): o MIIS permite que os MIHUs obtenham informações estáticas sobre as características e serviço da rede de conexão atual (rede de origem) e de todas as redes possíveis candidatas ao handover (ou redes alvo) que estejam ao alcance do terminal móvel. Retornando ao exemplo já mencionado, o MIIS é o serviço que pode auxiliar um algoritmo de decisão fornecendo-lhe parte das métricas necessárias à tomada de decisão (a outra parte vem das políticas de handover da rede). Feita a escolha da rede alvo, o MIIS também pode atuar na preparação antecipada de recursos antes da fase de execução do handover. Todas essas informações são obtidas através de queries (pesquisas) em bases de dados localizadas, ou em um servidor de informações presente na rede de origem ou no próprio terminal móvel.

A opção da utilização de um servidor, chamado Information Server, bem como o relacionamento entre os três serviços da MIHF e seus MIHUs se encontram na Figura 2.2. 


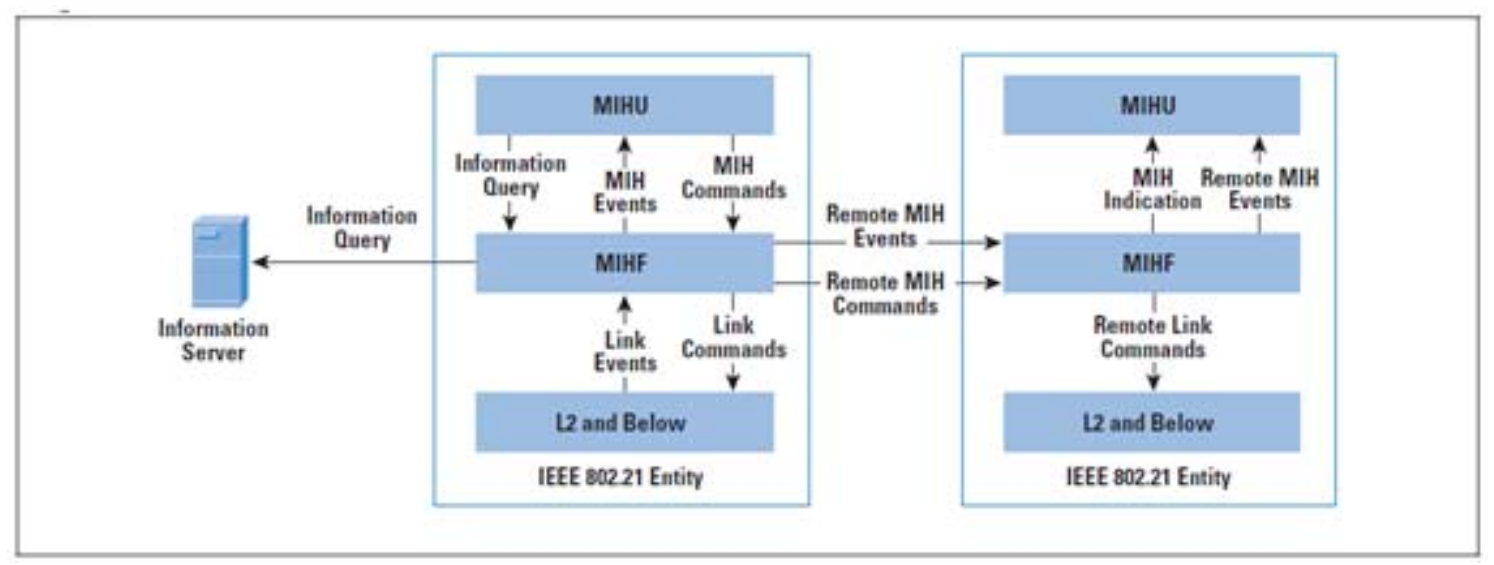

Figura 2.2: Relacionamento entre serviços MIHF e MIHUs [30]

Na Figura 2.2, são visualizados os relacionamentos entre os elementos de rede que executam a MIHF, chamados entidades IEEE 802.21, os serviços da MIHF e os MIHUs. Uma entidade IEEE 802.21 pode ser uma estação radio base, chamada na terminologia do padrão de PoA (Point of Attachment), um terminal móvel ou MN (Mobile Node) ou qualquer outro elemento no qual o 802.21 é executado. No caso específico em que uma entidade IEEE 802.21 troca mensagens diretamente com um MN que também executa o protocolo 802.21, a entidade recebe o nome de PoS (Point of Service). Ou seja, na prática, um PoS geralmente é também um PoA. Duas entidades lógicas MIHF que se comunicam são chamadas pares MIHF (MIHF peers).

Na parte esquerda da Figura 2.2, a entidade lógica MIHF de um elemento de rede interage com a de outro elemento que pode fazer parte da própria rede (local) ou de outra rede (remoto) através dos serviços MIHF. Ressaltam-se também as direções das setas que representam os serviços MIES e MICS. Observe que ambos podem ser horizontais (remotos) ou verticais (locais) como já mencionado.

A arquitetura do protocolo 802.21 pode ser dividida em quatro partes básicas: os SAPs que constituem as interfaces de relacionamento com todos os outros protocolos, a entidade lógica MIHF, a gerência dos serviços oferecidos pela MIHF e um protocolo que estrutura o formato das mensagens trocadas entre os entes que executam o padrão 802.21 [30]. 


\section{3}

\section{SAP (Service Access Point)}

Em redes de computadores, um serviço de rede é especificado por um conjunto de pequenas operações chamadas primitivas [32]. São elas que, formalmente, executam ou relatam a ação dos serviços entre entidades pares (entidades que se comunicam).

No contexto do padrão 802.21, define-se SAP (Service Access Point) como uma interface que associa primitivas entre a entidade lógica MIHF, os MIHUs e os demais protocolos com que o 802.21 se relaciona. O SAP é o elemento chave que permite que um MIHU tenha acesso aos serviços da MIHF.

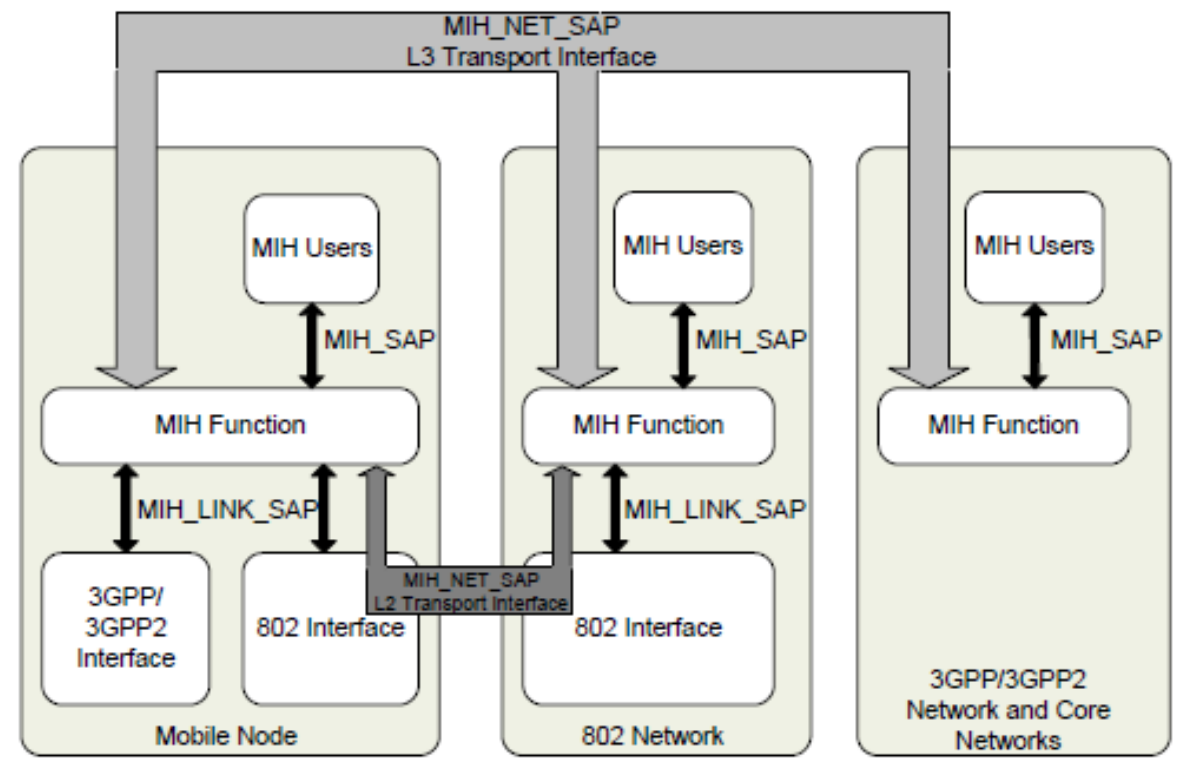

Figura 2.3: SAPs no padrão IEEE 802.21 [33]

Como mostra a Figura 2.3, há três tipos principais de SAPs que se comunicam com MIHUs distintos dependendo do protocolo envolvido.

- MIH_SAP: é a interface entre a MIHF e MIHUs específicos como, por exemplo, protocolos de gerência de mobilidade, políticas de handover, algoritmos de decisão e demais aplicações.

- MIH_LINK_SAP: são as interfaces entre a MIHF e a tecnologia específica de acesso da camada de enlace. Notam-se na Figura as principais famílias 802 (com e sem fio), 3GPP e 3GPP2. Portanto, são estes SAPs que 
viabilizam a comunicação com as WNICs (Wireless Network Interface Card) dos MNs, processo fundamental no processo de handover vertical.

- MIH_NET_SAP: são as interfaces entre a MIHF local e as camadas de rede e de enlace de entidades $\mathrm{MIH}$ remotas.

\section{4}

\section{MIHF (Media Independent Handover Function)}

Neste tópico, serão detalhados os três serviços oferecidos pela MIHF: MIES, MICS e o MIIS [30].

\subsection{1}

\section{MIES (Media Independent Event Service)}

O MIES indica o comportamento das transmissões na L1 (camada física) e/ou na L2 (camada de enlace). Se alguma mudança ocorrer, um evento é gerado. Por isso, de uma maneira geral, um evento é o agente responsável pela busca de redes candidatas à conexão (Network Discovery) e pelos procedimentos de handover. Dependendo de sua origem, podem ser agrupados de duas formas:

1) Eventos de Enlace (Link Events): quando o evento se origina na camada de enlace.

2) Eventos MIH (MIH Events): quando o evento se origina em uma entidade MIHF local ou remota.

- Eventos Locais se propagam da L2 para as camadas superiores através da MIHF.

- Eventos Remotos ocorrem em outra entidade de rede e são transmitidos por um par MIHF até a MIHF local. A Figura 2.2 ilustra esse processo. 
Os Eventos podem ser classificados em cinco tipos distintos:

1) Eventos de Mudança de Estado em L1 e L2 (MAC and PHY State Change events): indicam mudanças na subcamada MAC e na camada física. Exemplos de primitivas:

- Link_Up / Link_Down: conexão é feita/desfeita em um PoA.

- Link_Detected: indica descoberta de um PoA.

2) Evento de Parâmetros de Enlace (Link Parameter events): indicam mudanças nos parâmetros da L2. Exemplo de primitiva:

- Link_Parameters_Report: Acontece quando um limiar pré estabelecido é atingido. Por exemplo, no IEEE 802.11, caso o limiar RSSI (Received Signal Strength Indicator) seja atingido, este evento é disparado para que o MIHU responsável tome as providências devidas. Este evento é usado também para transmitir o estado dos enlaces periodicamente.

3) Eventos de Predição (Predictive events): indicam a possibilidade de problemas ocorrerem no enlace num futuro próximo. Podem até estimar o tempo até essa ocorrência. Exemplo de primitiva:

- Link_Going_Down: pode acionar um MIHU a considerar a possibilidade de handover para outras redes disponíveis ao alcance.

4) Eventos de Handover de Enlace (Link Handover events): indicam a ocorrência de handover. Exemplo de primitivas:

- Link_Handover_Imminent: notifica a iminência de um handover.

- Link_Handover_Complete: notifica que a mudança de PoA foi bem sucedida.

5) Eventos de Transmissão (Link Transmission events): apresentam o status de transmissão de um PDU (Protocol Data Unit) específico de uma camada superior qualquer passando pela camada de enlace. Camadas superiores podem melhorar a gerência do buffer da L2 no caso de perda de 
quadros. Estes eventos permitem que camadas superiores possam identificar pacotes perdidos e recuperá-los sem esperar a expiração do tempo de retransmissão.

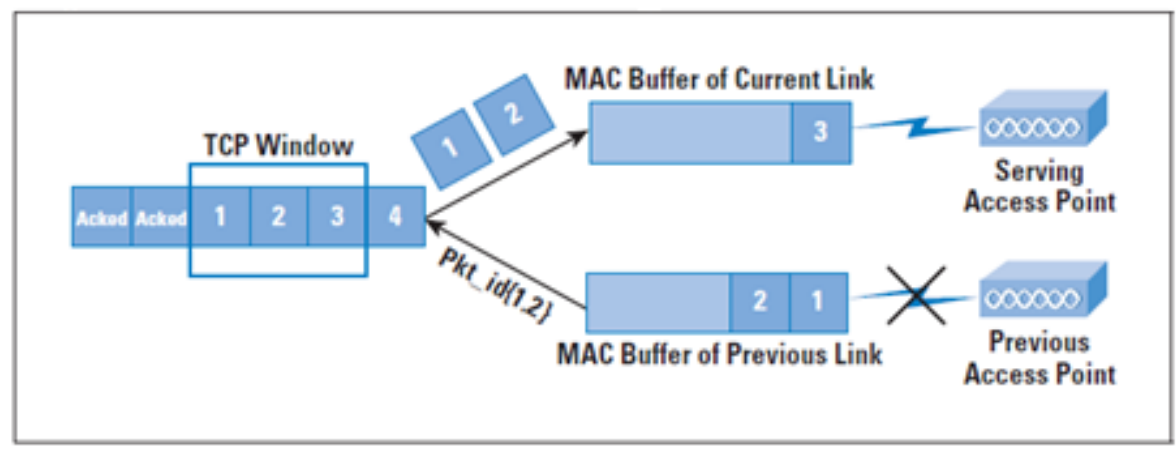

Figura 2.4: Segmentos dentro do buffer da camada MAC após um handover [30]

De fato, uma seção TCP pode ser muito afetada durante o tempo de queda e restabelecimento do enlace em um handover. Com o 802.21, a camada MAC pode reter em seu buffer quadros compostos por segmentos que, saindo do módulo ARQ (Automatic Repeat reQuest) local, não foram entregues com sucesso a seu destino pela ausência momentânea do enlace. Esta situação é ilustrada na Figura 2.4.

Nesse caso, o protocolo TCP pode utilizar informações advindas do Evento de Transmissão para identificar quais segmentos necessitam ser reenviados (após o término do handover) através da nova rede como mostra a Figura 2.4 para os segmentos de números um e dois. É importante salientar que o protocolo 802.21 não define um identificador para transmissão confiável. Ele somente informa o tamanho do quadro ficando a cargo do processamento local determinar como diferentes tipos de mensagens serão localmente identificadas.

\subsection{2}

\section{MICS (Media Independent Command Service)}

O MICS permite que as camadas superiores (MIHUs) controlem o fluxo de eventos que se origina nas camadas inferiores através de comandos específicos, permitindo, assim, que os MIHUs configurem, controlem e tenham acesso a 
informações oriundas das camadas inferiores. São definidos dois subconjuntos de comandos:

- Comandos MIH (MIH Commands): originam-se nos MIHUs e tem como destino as camadas inferiores locais ou camadas inferiores de entidades MIHF remotas. Por isso, os Comandos MIH podem ser locais ou remotos. São utilizados tipicamente para seleção de rede e para gerência de handover porque permitem que as camadas superiores possam iniciar, preparar e executar handovers.

Comandos MIH também são utilizados para configurar limiares (Thresholds) em parâmetros da camada de enlace. Por exemplo, uma vez ultrapassado um limiar, gera-se um evento e o MIHU responsável será notificado pelo Evento de Parâmetros de Enlace (Link Parameter events).

- Comandos de Enlace (Link commands): originam-se na própria entidade MIHF e tem como destino as camadas inferiores locais com a finalidade de controlar sua operação. Por isso, os Comandos de Enlace só podem ser locais. No entanto, podem ser executados em nome de um MIHU local, ao qual poderia agir em consequência de informações recebidas de um par MIHF remoto.

Comandos de Enlace são frequentemente executados por MIHUs. Por exemplo, um MIHU pode enviar a uma entidade local o Comando MIH MIH_Get_Link_Parameters. Este, quando recebido pela entidade lógica MIHF local, levará a geração do Comando de Enlace Link_Get_Parameters (vide Figura 4.2). Desta maneira, a MIHF descobre o valor atualizado dos parâmetros de todos os enlaces ativados e, assim, pode informá-los ao MIHU solicitante.

\subsection{3}

\section{MIIS (Media Independent Information Service)}

Este serviço permite a um MN verificar, em seu entorno, a existência e a disponibilidade de redes que possam ser candidatas a uma nova conexão utilizando a conexão de sua rede atual. Ou seja, utiliza-se de troca de informações para descobrir redes alvo. Estas informações são em sua grande maioria estáticas e raramente mudam. 
A troca de informações MIIS pode ocorrer na L2 ou na L3. Portanto, todas as informações necessárias relacionadas à L2 ou às superiores são coletadas antes que um MN se conecte a um novo PoA, ou seja, informações são coletadas antes que ocorra o handover vertical. Dessa forma, conclui-se que as informações MIIS dão suporte somente às fases de iniciação e de decisão do handover.

Exemplos de informações prestadas pelo serviço MIIS:

- Detalhes de necessários ao estabelecimento de conexão como endereço e localização de um PoA;

- Mecanismos de segurança utilizados na rede candidata;

- Garantia sobre a QoS que pode ser oferecida pela rede candidata.

O MIIS define um conjunto de elementos chamados IEs (Information Elements) que permitem a seleção de uma rede candidata, isto é, podem fornecer métricas ao algoritmo de decisão na segunda fase do handover. Os IEs são classificados em três grupos:

- Elementos de informações gerais e elementos de redes de acesso específicas (General Information Elements and Access Network Specific Information): este grupo fornece uma visão geral sobre as redes vizinhas existentes, como, por exemplo:

o Relatórios de redes disponíveis e suas respectivas operadoras, com contratos de roaming e custo associado a sua utilização;

o Mecanismos de segurança e QoS disponíveis.

Este IE pode ser utilizado pelo $\mathrm{MN}$ ou pelo operador da rede. Isso irá depender do tipo de política de handover adotado (vide Apêndice B). Por exemplo, supondo um MCHO (Mobile Controlled Handover), caso a operadora de uma das redes de acesso candidatas a handover tarifa seus usuários baseando-se no volume de tráfego $(\mathrm{R} \$ / \mathrm{kB})$, então o $\mathrm{MN}$ poderá não considerar realizar o handover vertical para esta rede quando estiver utilizando um serviço de alta taxa de transmissão como o IPTV. 
- Informações específicas do PoA (PoA-Specific Information): referem-se a informações específicas de cada PoA disponível. Exemplos:

o Localização e endereço do PoA;

o Taxas de transmissão permitidas;

o Camadas Física e de Enlace utilizadas;

o Ocupação em termos de usuários;

o Parâmetros para otimização de conectividade em nível de enlace.

O Gerenciamento de Mobilidade do MN pode, por exemplo, utilizar a informação da posição geográfica de um PoA e compará-la com a atual posição dele baseando-se em seus próprios modelos de mobilidade. Com um planejamento adequado e de posse desta informação, os MNs podem reduzir o número de handovers e também otimizar o uso dos recursos de rede.

- Outras informações (Other Informations): este IEs são utilizados para informações de detalhes específicos do fabricante dos equipamentos de rede envolvidos.

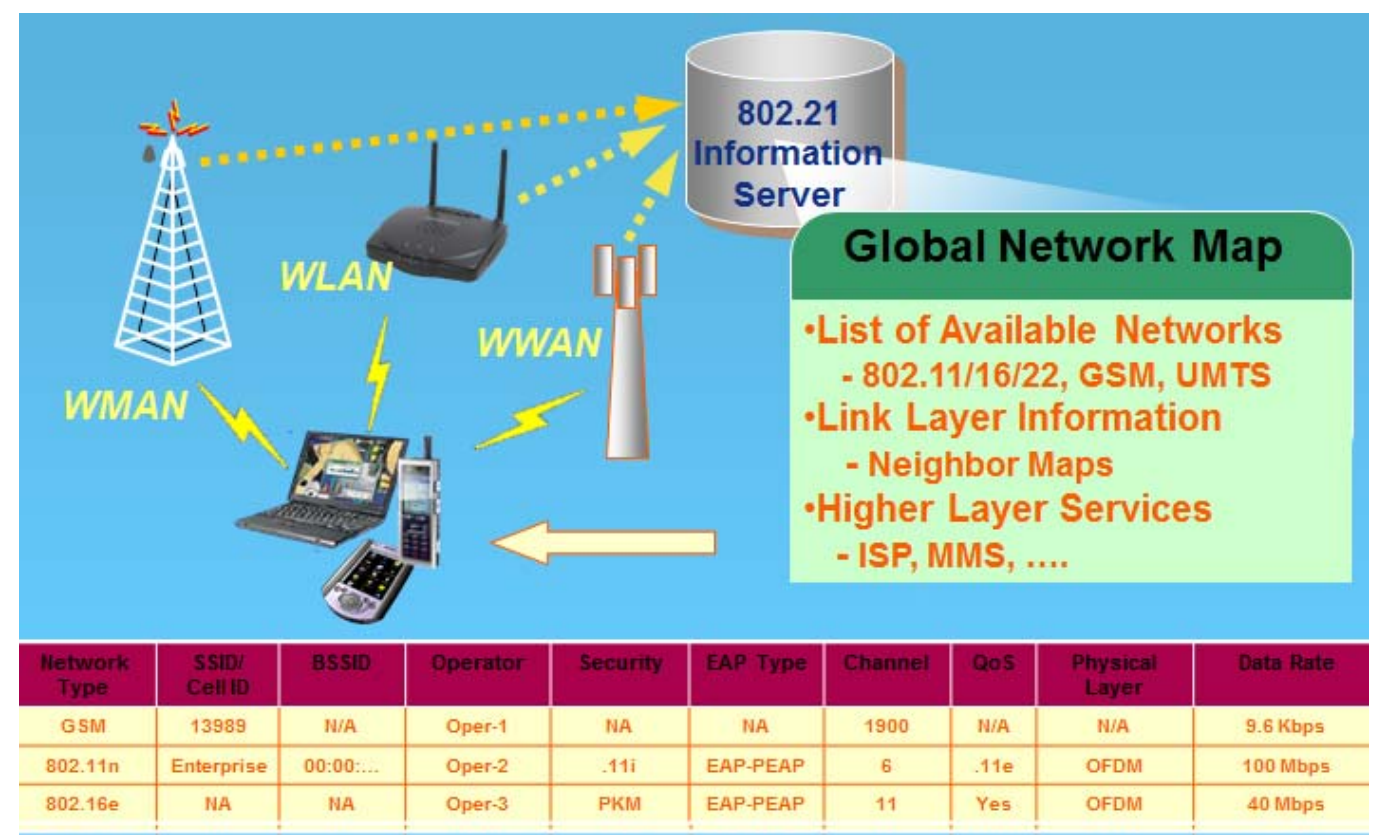

Figura 2.5: Pesquisa de informações em um servidor MIH [54] 
Como é realizada, na prática, a consulta de informações feita pelos IEs?

O MIIS provê mecanismos para que os IEs possam enviar e receber informações através de pesquisas em uma base de dado (chamada em alguns contextos de query) localizada no próprio MN ou em um Servidor de Informações MIH na rede nativa (de origem). A MIHF tem acesso a este servidor através de um PoS (Point of Service). Além disso, o PoS também possui informações sobre outros possíveis PoSs pertencentes a uma rede estrangeira chamados roaming partners. Se o Servidor de Informação da rede nativa não possui informações sobre a rede estrangeira ou se qualquer outro problema ocorrer, uma query MIIS é dirigida ao par MIHF da rede estrangeira, ao qual consegue acesso ao Servidor de Informações da rede estrangeira. Os IEs e seus relacionamentos são capturados em um esquema de Serviço de Informação que, por sua vez, define a estrutura da informação. O padrão IEEE 802.21 especifica que a informação, ao passar por redes de diferentes tecnologias, deve ser padronizada em um formato livre (open format) e comum, como o XML ou o TLV (Type Length Value).

\section{5}

\section{Gerência dos serviços da MIHF}

As diversas entidades lógicas MIHF presentes nos nós da rede devem ser devidamente configuradas para que possam utilizar os serviços MIHF adequadamente. Para tal, são definidos três procedimentos para a gerência dos serviços:

- Capacidade de descoberta de entidades MIH (MIH capability discovery):

Este procedimento permite que uma entidade lógica MIHF possa descobrir outras entidades MIHF e suas capacidades. Dependendo da informação obtida, uma entidade MIHF local determina a qual par MIHF ela irá se registrar. Este procedimento utiliza o MIHP (Protocolo MIH) comentado adiante e pode acontecer em nível de camada de enlace ou de rede. Também são permitidas mensagens em broadcast de tecnologias específicas de camada de enlace. Por exemplo, uma MIHF pode "escutar" mensagens em broadcast de tecnologias 
específicas como Quadros de Beacon do padrão 802.11. Há também uma mensagem gerada pelo próprio padrão 802.21 que, na verdade, constitui uma mensagem em broadcast independente de tecnologia chamada MIH_Capability_Discover. Essa mensagem é enviada periodicamente por entidades MIHF para anunciar sua existência e suas capacidades.

Uma MIHF pode também enviar mensagens de solicitação como MIH_Capability_Discover de modo unicast ou multicast para detectar algum par MIHF.

De fato, uma MIHF pode enviar uma solicitação de modo unicast para obter capacidades de um elemento 802.21 específico da rede. Nesse caso, somente este elemento deve responder esta solicitação.

- $\quad$ Registro MIH (MIH registration):

O registro MIH é um procedimento simétrico feito por dois pares MIHF nos quais ambos se autenticam entre si e, dessa forma, se comunicam de uma maneira mais confiável. Este registro não é necessário para obter um nível mínimo de serviço de um par MIHF. Sem registro e autenticação, somente um subconjunto das informações disponíveis são compartilhadas entre os pares. Porém, após o registro, os dois pares podem, simetricamente, requisitar todos os serviços entre si.

- Inscrição em um evento MIH (MIH event subscription):

A inscrição em um evento permite que um MIHU tenha acesso somente aos eventos que lhe interessam em particular, sejam eles locais ou remotos. Para inscrever-se, uma entidade MIHF deve se registrar e conhecer as capacidades de seu par MIHF. É importante notar que os originadores de eventos não são necessariamente capazes de fornecer todos os eventos que um MIHU solicitante tenha interesse. Cada solicitação de evento é seguida por uma mensagem de confirmação oriunda da entidade que originou o evento.

Neste ponto, pode-se fazer uma sucinta comparação entre o 802.21 e o protocolo IP móvel e entender como o primeiro pode ser de grande valia para a 
otimização do processo de handover também na camada três. As mensagens de gerência MIH_Capability_Discover e MIH registration do padrão 802.21 possuem, em essência, grande similaridade com as mensagens Agent Advertisement/Agent Solicitation e Registration Request/ Registration Reply do protocolo MIP. Ou seja, o que o MIP faz em nível de rede, o 802.21 faz em nível de enlace antecipadamente, podendo, dependendo de sua configuração, enviar as informações necessárias ao MIP de forma mais eficiente.

\section{6}

\section{Estrutura do quadro IEEE 802.21}

O protocolo MIHP (Media Independent Handover Protocol) é o responsável por especificar as regras de comunicação entre pares MIHF. Ele define o formato das mensagens, o cabeçalho e a forma de codificação das informações.

As mensagens MIHP são formadas de um cabeçalho e de uma carga útil cifrada em formato TLV (Type Lenght Value). Estas mensagens podem ser encaminhadas através de quadros de gerência ou de dados da camada de enlace ou de pacotes da camada de rede. O cabeçalho das mensagens é composto de oito octetos como mostra a Figura 2.6 abaixo. Os números entre parêntesis representam o tamanho dos campos em bits.

\begin{tabular}{|c|c|c|c|c|c|c|c|c|c|}
\hline \multirow{2}{*}{$\begin{array}{l}\text { Version } \\
\text { (4) }\end{array}$} & \multirow{2}{*}{$\begin{array}{c}\text { Ack } \\
\text { Req } \\
\text { (1) }\end{array}$} & \multirow{2}{*}{$\begin{array}{c}\text { Ack } \\
\text { Res } \\
\text { (1) }\end{array}$} & \multirow{2}{*}{$\begin{array}{l}\text { UIR } \\
\text { (1) }\end{array}$} & \multirow{2}{*}{$\begin{array}{l}M \\
\text { (1) }\end{array}$} & \multirow{2}{*}{$\begin{array}{l}\mathrm{FN} \\
\text { (7) }\end{array}$} & \multirow{2}{*}{$\begin{array}{l}\text { Rsvd } \\
\text { (1) }\end{array}$} & \multicolumn{3}{|c|}{$\begin{array}{c}\text { MIH Message ID } \\
\text { (16) }\end{array}$} \\
\hline & & & & & & & $\begin{array}{l}\text { SID } \\
\text { (4) }\end{array}$ & $\begin{array}{l}\text { Opcode } \\
\text { (2) }\end{array}$ & $\begin{array}{l}\text { AID } \\
\text { (10) }\end{array}$ \\
\hline $\begin{array}{l}\text { Rsvd } \\
\text { (4) }\end{array}$ & \multicolumn{6}{|c|}{$\begin{array}{c}\text { Transaction ID } \\
\text { (12) }\end{array}$} & \multicolumn{3}{|c|}{$\begin{array}{l}\text { Variable Load Length } \\
\text { (16) }\end{array}$} \\
\hline
\end{tabular}

Figura 2.6: Formato do cabeçalho MIHP [30]

- Version: versão do padrão 802.21 utilizada;

- Ack Req e Ack Res: mensagens de confirmação MIH (ACK MIH messages) não são obrigatórias. Mesmo assim, o MIHP oferece suporte a 
confirmações que assegurem confiabilidade à troca de suas mensagens. A entidade MIHF emissora pode configurar o campo Ack Req para que a receptora venha a respondê-la através do campo Ack Res. A identificação de mensagem MIH e a identificação de transação, campos vistos adiante, devem ser iguais nas mensagens de solicitação e de confirmação. Uma mensagem de confirmação pode ou não ter carga útil.

- UIR (Unathenticated Information Request): é um campo do tipo flag que sinaliza que a mensagem de resposta deve ser enviada com um tamanho limitado. Se este bit for igual a um, a informação de resposta não é completa. Isto significa que as entidades MIHF que trocam estas mensagens não se registraram.

- M (More Fragments) e FN (Fragment Number): usados para mensagens de fragmentação.

- MIH Message ID: três subcampos:

o SID (Service Identifier): indica a qual serviço MIHF a mensagem pertence: MIES, MICS, MIIS ou de gerência de serviços MIHF.

o Opcode (Operation Code): especifica se a mensagem é uma solicitação ou resposta.

o AID (Action Identifier): relacionado com o SID: se o SID indica o serviço MIES, então o AID identifica o tipo do evento.

- Variable Load Lenght: indica o tamanho total da carga útil (payload) codificada em TLV.

- Transaction ID: é um identificador que auxilia a associar cada requisição, resposta ou indicação à sua respectiva confirmação.

- Rsvd: reservado para uso futuro.

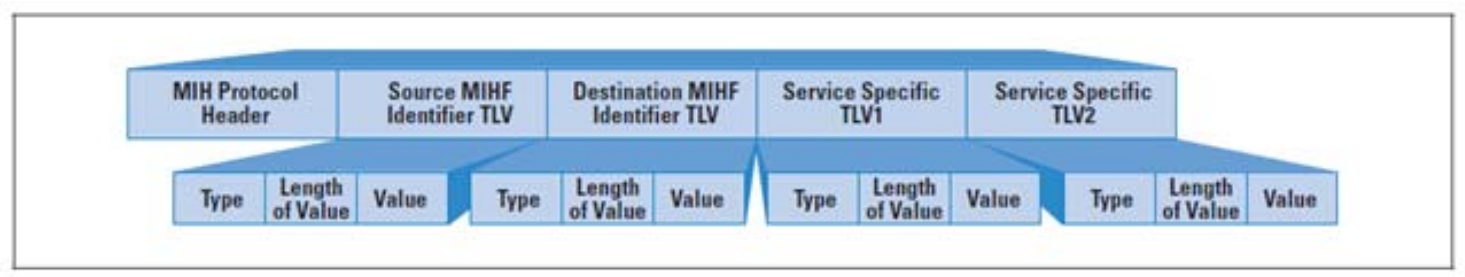

Figura 2.7: Formato da carga útil da mensagem MIHP [30]

A carga útil da mensagem MIHP é composta por: 
- Source Identfier and Destination Identifier: devem apresentar o mesmo valor do campo MIHF ID. Cada entidade lógica MIH deve possuir um único MIHF ID. Ele é designado a cada entidade no momento de sua configuração e anexado junto com a carga útil de cada mensagem que solicita a identificação do destino. Sua utilização ocorre durante a fase de registro da gerência dos serviços da MIHF. Em mensagens de broadcast, o identificador de destino é definido com tamanho zero.

\section{7}

\section{Diagrama de um processo de handover vertical assistido pelo padrão} 802.21

Finalizando este capítulo, segue-se um diagrama de fluxo que exemplifica como o padrão 802.21 pode auxiliar as fases de iniciação (ou preparação) e de decisão do processo de handover vertical. O exemplo mostra o procedimento que ocorre com total controle do terminal móvel ou MCHO.

Todos os passos estão ilustrados nas Figuras 2.8 e 2.9. A descrição deles é feita da seguinte forma $[33,34]$ :

1. O MN está conectado à sua rede de origem através de seu PoS atual. Por esta conexão, o móvel pode ter acesso às informações de um servidor MIH como o citado na Figura 2.5.

2. O MN solicita ao servidor, através de uma query, informações sobre as redes que se encontram no entorno de sua localização. Esta solicitação (query) é enviada pela a mensagem MIH_Get_Information request. O servidor responde com a mensagem $M I H \_G e t \_I n f o r m a t i o n$ response.

2.1 Caso não haja um servidor MIH, a entidade lógica MIHF, presente no MN, pode enviar mensagens genéricas MIH_Capability_Discover, em broadcast, procurando pela entidade MIHF presente no PoS de uma outra rede (chamada estrangeira) em seu entorno. Assim, as mensagens MIH_Get_Information request e MIH_Get_Information response serão 
trocadas entre o $\mathrm{MN}$ e os PoSs das redes alvos (estrangeiras) no entorno.

3. Segundo algum critério (por exemplo, a diminuição da magnitude do sinal oriundo da estação radio base em comparação com um limite preestabelecido), o MN começa a fase de iniciação do processo de

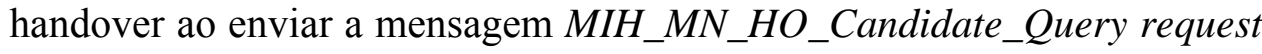
ao seu PoS atual. Nesta mensagem, estão contidas as redes alvo nas quais existe um interesse em potencial ao handover.

4. O PoS atual verifica a disponibilidade de recursos ao enviar a mensagem MIH_N2N_HO_Query_Resources request para os respectivos PoSs de cada uma das redes alvo.

5. Cada um dos PoSs das redes alvo candidatas respondem ao PoS atual do MN através da mensagem MIH_N2N_HO_Query_Resources response e o PoS, por sua vez, envia todos os resultados ao MIHU do MN pela mensagem MIH_MN_HO_Candidate_Query response.

6. Agora, entra em cena o algoritmo de decisão presente no MN. Escolhida a rede alvo, o MN notifica essa decisão ao seu PoS através da mensagem MIH_MN_HO_Commit request. O PoS atual do MN envia, ao PoS da rede alvo escolhida, a mensagem $M I H \_M N \_H O \_C o m m i t$ request requisitando a alocação de recursos. O PoS da rede alvo escolhida responde com a mensagem MIH_MN_HO_Commit response.

7. O MN também inicializa a interface de rede correspondente à rede escolhida, através da MIHF, pelo envio da primitiva MIH_Link_Actions.request e obtém a resposta MIH_Link_Actions.confirm.

8. A conexão com a rede escolhida é estabelecida e, a partir de agora, já se podem iniciar os procedimentos de gerência de mobilidade entre o $\mathrm{MN}$ e a rede estrangeira em nível de camada de rede (vide Link up indication na Figura 2.9). 
8.1 Caso o protocolo utilizado seja o MIP, o endereço CoA (Care of Address) pode ser recebido já diretamente pelo MN permanecendo ainda com a conexão de rede de origem ativa. Portanto, o MN pode notificar o CoA recebido para o seu HA (Home Agent) através da rede de origem.

8.2 Neste momento ressalta-se o fato de que o $\mathrm{MN}$ tem conectividade com a rede estrangeira somente em nível de camada de rede (vide IP connectivity restored na Figura 2.9). Para que o MN consiga enviar dados (isto é, seja iniciada uma seção TCP/UDP) é necessária a interrupção da seção TCP existente com sua rede de origem porque um socket TCP não consegue utilizar dois endereços IP ao mesmo tempo $[26,10]$. O MN, para estabelecer uma seção TCP nova, já utilizando o CoA, tem duas opções: ou ele mesmo desconecta sua conexão, em nível de enlace, com a rede de origem ou espera que esta conexão se interrompa por si só à medida que vai deixando a área de cobertura da rede de origem, acarretando também a perda da conexão de enlace. Em ambos os casos, o endereço IP de origem deve ser descartado e, somente após isso, uma nova conexão TCP/UDP, com o endereço CoA, pode ser feita. Este processo é descrito na Figura 2.9 coma mensagem Higher layer handover execution.

Assim, na prática, o tempo total, isto é, a latência do handover vertical, é contabilizado a partir da interrupção da conexão em nível de enlace até a chegada do primeiro segmento inédito através da nova seção TCP realizada com o endereço CoA, tendo em vista o que ocorre no buffer da camada MAC como explicado na Figura 2.4 do tópico 2.2.1. Na Figura 2.9, isso é sinalizado na mensagem Traffic flow re-established.

9. O MN envia ao seu novo PoS a mensagem MIH_MN_HO_Complete request. O novo PoS, por sua vez, envia a mensagem MIH_N2N_HO_Complete request ao antigo PoS para que este remova os recursos na rede de origem. Após confirmada a desalocação de recursos na rede de origem, o novo PoS envia a mensagem $M I H \_M N \_H O \_C o m p l e t e$ response ao $\mathrm{MN}$ indicando o término do processo. 


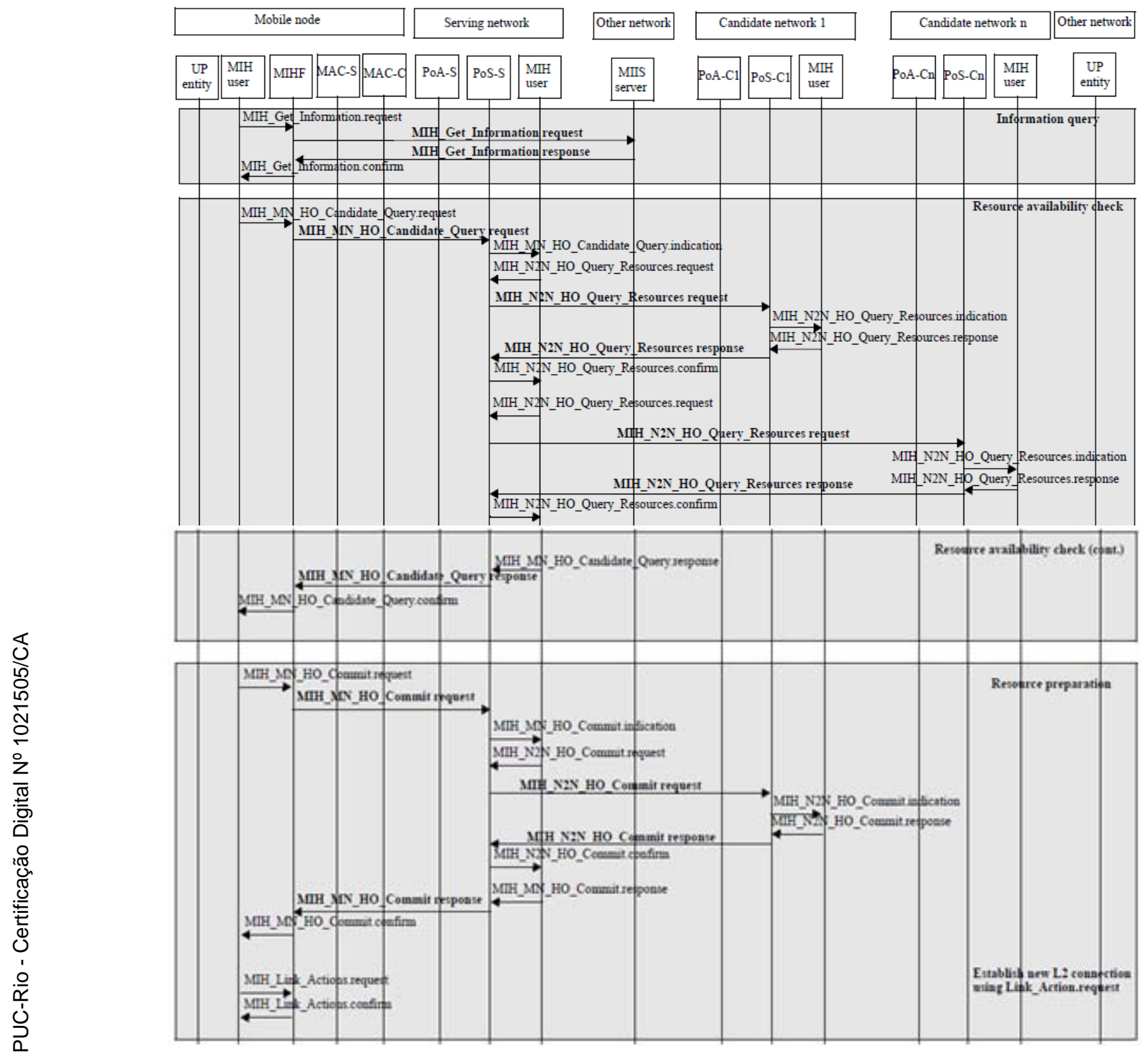

Figura 2.8: Diagrama do processo de handover vertical [34] 


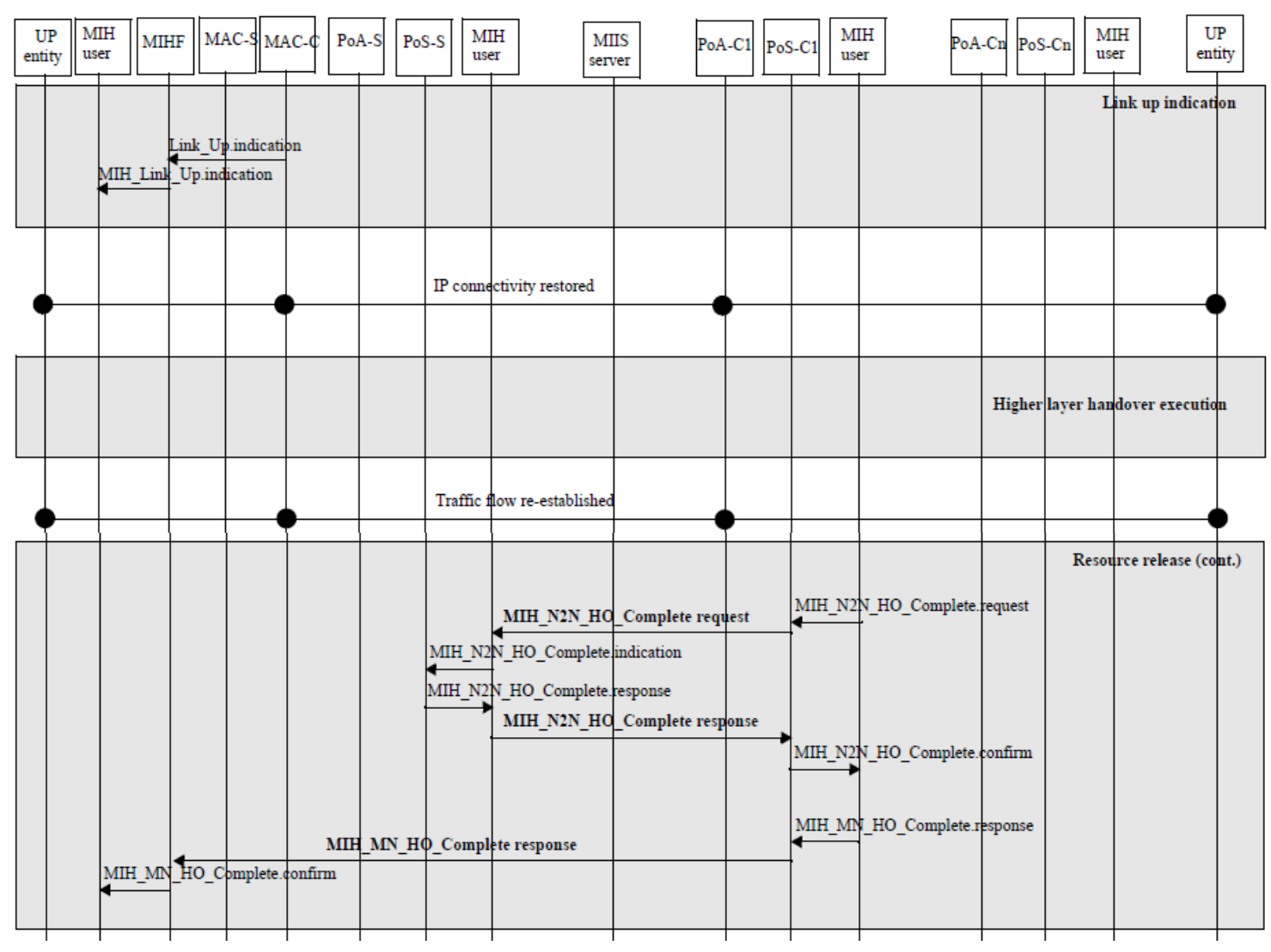

Figura 2.9: Diagrama do processo de handover vertical (continuação) [34] 


\section{Algoritmos de decisão de handover vertical}

\section{1}

\section{Introdução}

Em um ambiente de redes sem fio homogêneas, a fase de decisão e a fase de iniciação do handover acontecem praticamente juntas, pois, como não há mudança na tecnologia de rede, a iniciação ocorre pela decisão de trocar ou não de estação radio base segundo algum critério, sendo o mais comum deles, a diminuição da intensidade do sinal oriundo da estação radio base em comparação com um limite (threshold) preestabelecido.

Entretanto, no processo global do handover vertical, existem duas decisões a tomar: a primeira na fase de iniciação, que consiste na decisão do momento de real necessidade para dar início ao processo e a segunda, que consiste na escolha da rede mais adequada para migrar.

No contexto desta segunda decisão importante surge o algoritmo de decisão de handover vertical ou VHD (Vertical Handover Decision). Ele desempenha um papel extremamente importante no processo global do handover. No Apêndice B encontram-se as diferentes fases do processo de handover de maneira geral e, no capítulo anterior, foi descrito como o padrão IEEE 802.21 pode auxiliar este processo, oferecendo meios de compartilhamento de informações preciosas entre os protocolos e elementos da gerência de mobilidade das redes.

Neste capítulo, as atenções são voltadas para os algoritmos de decisão que atuam em handovers verticais. Inicialmente são brevemente comentados alguns critérios para que o processo de handover vertical seja iniciado. Depois são apresentadas algumas métricas importantes para a comparação do desempenho de diferentes tipos de algoritmos e, em seguida, é apresentada uma taxonomia dos VHDs existentes e sua interação com outros elementos associados à gerência de mobilidade. Ao final, é apresentada uma proposta teórica de um algoritmo de decisão baseada no suporte que o padrão 802.21 pode oferecer. 


\section{2}

\section{Métricas utilizadas por um algoritmo de decisão de handover vertical}

Quando se trata especificamente de handovers verticais, há uma quantidade maior de critérios a considerar para que se possa iniciar o processo global do handover. De fato, o VHD procurará realizar a escolha da rede ótima segundo alguns critérios como exemplificado na Figura 3.1.

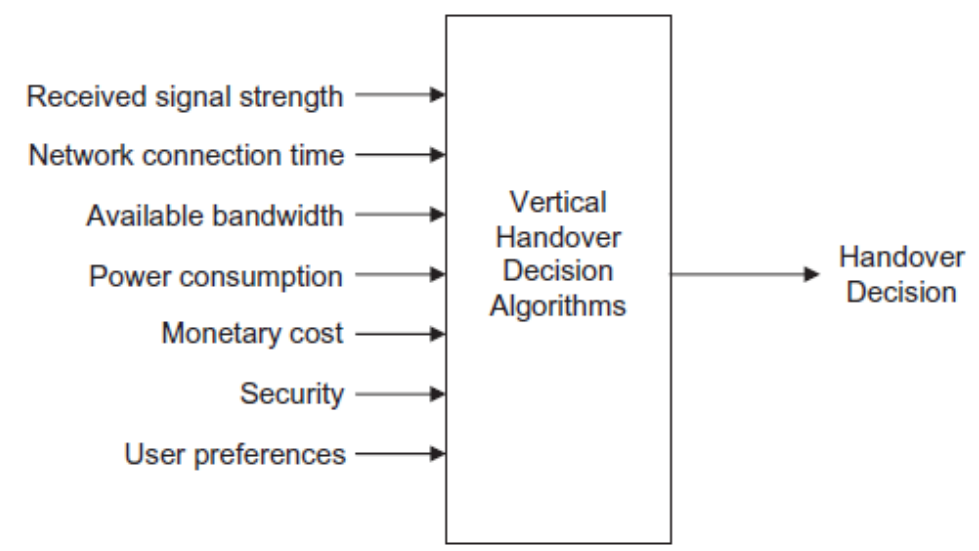

Figura 3.1: Exemplos de métricas de um VHD [35]

- Potência de sinal recebido:

Reflete o efeito da distância do aparelho móvel à estação radio base na qualidade do serviço. É uma métrica utilizada, essencialmente, em handovers horizontais e também considerada nos handovers verticais.

- Tempo de conexão na rede:

Reflete o tempo no qual o móvel permanece conectado a uma mesma rede. Isto é importante para que o handover não ocorra cedo demais, fazendo com que sejam desperdiçados recursos na rede alvo, ou tarde demais, causando uma falha no processo de handover por falta de recursos disponíveis na rede alvo.

- Largura de banda disponível:

Reflete a quantidade de banda que pode ser utilizada na rede alvo sem gerar sobrecarga nela. É um bom indicador para caracterizar as condições de tráfego e especialmente importante para aplicações sensíveis ao atraso. 
- Consumo de energia:

Indica se uma determinada rede possui estações radio base que necessitam de menores índices de energia do aparelho móvel, fazendo com que sua bateria dure mais tempo.

- Custo monetário:

Indica o custo monetário dos serviços que a operadora da rede oferece a seus usuários.

- Segurança:

Indica o nível de confiabilidade e integridade oferecido aos dados pela rede.

- Preferências do usuário:

De utilidade totalmente subjetiva, indica uma rede arbitrada como preferencial pelo usuário.

\section{3}

\section{Parâmetros de avaliação de desempenho de um VHD}

Quando utilizados em cenários e condições equivalentes, diferentes algoritmos de decisão podem ser comparados tendo como parâmetros as seguintes métricas:

- Tempo ou latência de execução do handover:

Refere-se à duração entre o início do processo (fase de iniciação) do handover até sua conclusão. A complexidade do algoritmo de decisão é um fator que influencia bastante o tempo de execução de um handover.

- Número de handovers:

A permissão de um pequeno número de handovers é uma característica desejável em um algoritmo de decisão. Recursos nas redes podem ser dramaticamente desperdiçados caso haja um número excessivo de 
handovers ocorrendo. De fato, o handover de um móvel para uma rede sobrecarregada e que venha a ter necessidade de retornar à rede anterior é considerado um handover supérfluo.

- Probabilidade de falha de handover

Uma falha ocorre quando, após o início do processo de handover, a rede alvo não possua mais recursos para alocar o tráfego requerido pelo nó móvel ou quando o móvel sai totalmente da área de cobertura da rede atual antes de completar todo o processo de handover.

- Vazão (Throughput)

Refere-se ao acréscimo na taxa de dados que o móvel consegue ao realizar o handover com sucesso, sendo, portanto, um grande indicador de QoS oferecida.

\section{4}

\section{Taxonomia}

Uma questão muito importante é a da QoS envolvida no processo de handover vertical. De fato, a definição dada para um handover vertical suave e transparente apresentada no Apêndice B menciona indiretamente essa questão: tornar o processo imperceptível para o usuário significa não só manter o serviço, mas mantê-lo em níveis aceitáveis com as premissas do usuário (QoS). Por isso, como já mencionado, o tempo que um algoritmo de decisão leva em sua execução é um parâmetro que também deve ser considerado na latência do processo global de handover.

Dessa forma, o desafio encontra-se no desenvolvimento de um algoritmo que trate o problema da maneira mais abrangente possível, isto é, de maneira que atenda à situações de várias topologias de rede, às políticas de handover e à experiência de satisfação do usuário, o que está diretamente relacionado com a questão de QoS (Quality of Service) e de QoE (Quality of Experience).

Em [35], os VHDs são agrupados em quatro grandes grupos segundo os critérios utilizados na decisão, complexidade e eficiência: 
- Algoritmos baseados no sinal recebido (RSS based VHD Algorithms): são algoritmos que comparam o nível de sinais advindos de várias estações radio base (RSS-Receiver Sinal Strength) e selecionam aquele de maior magnitude. Sua maior característica é a simplicidade de hardware necessária para implementação.

- Algoritmos baseados em largura de banda (Bandwidth based VHD Algorithms): são algoritmos que consideram como objetivo manter uma determinada largura de banda para o usuário antes de realizar o handover. Por isso, um desafio importante é como estimar a largura de banda residual nas redes envolvidas.

- Algoritmos baseados em função de custo (Cost function based VHD Algorithms): são algoritmos cuja decisão depende do valor obtido em uma função de custo. Essa função pode incluir vários parâmetros que, na verdade, são métricas que exprimem as preferências (inclusive de QoS) do usuário. Essa função deve ponderar diferentes parâmetros refletindo a importância de cada um deles de acordo com o objetivo do serviço Por exemplo, se a prioridade é o custo, coloca-se um peso maior nesse parâmetro a fim de que ele sobressaia sobre outras métricas como largura de banda e consumo da bateria do aparelho móvel. Os algoritmos desta classe encontram-se entre os mais populares VHDs existentes.

- Algoritmos combinados (Combination Algorithms): esta classe é, na verdade, uma extensão dos algoritmos baseados em função de custo. A diferença básica se encontra no fato de que os pesos atribuídos às métricas mais importantes ou a própria função de decisão, ou ambas, podem ser baseadas em técnicas de pesquisa operacional (OP-Operation Research), redes neurais (ANN-Artificial Neural Networks) ou lógica fuzzy (FL-Fuzzy Logic). É a categoria mais completa de algoritmos, pois conseguem combinar o maior número de métricas e situações topológicas, priorizando todas as aplicações ativas no momento. Por outro lado, sua complexidade e o tempo gasto no processamento são alguns de seus inconvenientes. Os 
exemplos mais conhecidos são os métodos SAW (Simple Additive Weighting), MEW (Multiplicative Exponent Weighting), GRA (Gray Relational Analysis) e TOPSIS (Technique for Order Preference by Similarity to Ideal Solution). Em [36], há uma comparação interessante entre eles.

\section{5}

\section{Proposta teórica de um algoritmo de decisão}

\subsection{1}

\section{Classificação do algoritmo proposto e trabalhos relacionados}

O algoritmo proposto foi concebido para funcionamento em um cenário de baixa mobilidade em que exista uma superposição de redes sem fio distintas. Este tipo de cenário é bastante comum hoje em dia. Um exemplo pode ser uma área onde coexistam as redes IEEE 802.11 e UMTS como comentado na Figura $1.1 \mathrm{ou}$ ainda em um campus de uma universidade.

Procurou-se oferecer um tratamento adequado à economia de energia, visando aumentar o tempo de utilização da bateria do aparelho móvel. E com relação à experiência de utilização do usuário, procurou-se, sempre que possível, melhorar - ou ao menos manter - a QoS a cada nova rede a se conectar.

Como será visto em detalhes, a utilização do protocolo IEEE 802.21 é imprescindível para o funcionamento do algoritmo proposto. Em [42,43 e 52] podem ser vistas outras propostas que enfatizam esta abordagem de relacionamento de VHDs e o protocolo IEEE 802.21.

Em resumo, podem ser destacadas as seguintes características gerais do algoritmo proposto:

- Cenários de baixa mobilidade: exemplo campus de uma universidade.

- Economia de energia/custo de bateria.

- Implementação:

o Simplicidade e rapidez:

- Comparando com algoritmos baseados em pesquisa operacional, lógica fuzzy e redes neurais. 
- Minimização da latência no processo global de handover vertical.

o Objetividade:

- Maior restrição para aplicações é a largura de banda. Por isso, procura-se maximizá-la em todo o tempo através da melhor conexão possível.

- Preferência explícita pela conexão com uma WLAN e por tráfego de tempo real.

o Flexibilidade:

- Decisão de handover centrada no $\mathrm{MN}$ : usuário paga por serviço.

- Parceria como o padrão IEEE 802.21: pode ser adaptado para outras tecnologias com poucas mudanças.

\begin{abstract}
Diante destas características, pode-se denominar o algoritmo proposto como possuindo uma classificação híbrida dentro da taxonomia apresentada no tópico 3.4. O VHD proposto apresenta características como as dos algoritmos baseados em RSS e em largura de banda, essencialmente pelo tratamento de QoS, e, por outro lado, se distancia desses pela participação do protocolo IEEE 802.21 como principal elemento agregador de métricas para auxiliá-lo na tomada de decisão.
\end{abstract}

\title{
3.5 .2
}

\section{Sinergia entre elementos da gerência de mobilidade e do sistema}

O algoritmo toma sua decisão baseado em informações advindas de diferentes elementos lógicos do sistema. Deve existir uma base de dados onde possam ser armazenadas as políticas de handover da rede [37].

Estes elementos lógicos podem se apresentar em formatos distintos e sua localização física também pode depender das modalidades de handover quanto à participação da rede na decisão de handover conforme pode ser visto no Apêndice B. No caso do handover vertical, os dois elementos mais importantes são o PDP (Policy Decision Point) e o PEP (Point Enforcement Point) [38]: 
- Ponto de decisões de política ou PDP: decisões para handovers verticais são tomadas no PDP de acordo com os parâmetros recebidos pela política de handover (simbolizada na Figura como Policy Database). Na prática, é onde se encontra o algoritmo de decisão, mas também pode ser usado para outras funcionalidades como autenticação e tarifação.

- Ponto de execução de política ou PEP: é o elemento que efetivamente dispara a execução do handover após receber a saída do PDP. Ou seja, representam uma série de funcionalidades que devem ser realizadas pelas estações radio base em conjunto com o terminal móvel.
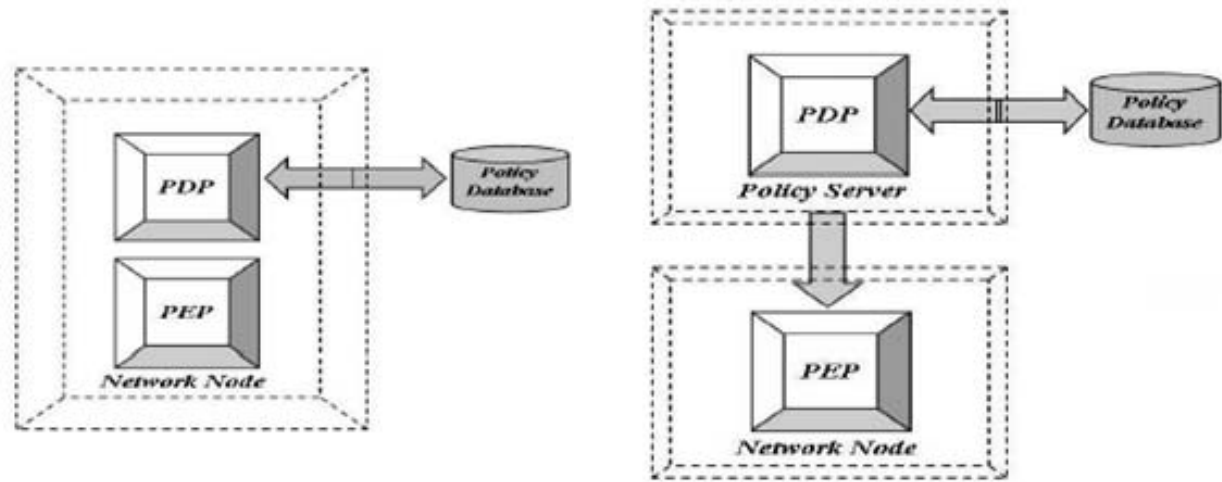

Figura 3.2: Localização física dos elementos PDP e PEP [38]

O lado esquerdo da Figura 3.2 representa a situação em que o tipo de handover é o NCHO (Network Controlled Handover), isto é, a rede possui o controle sobre a decisão. Por isso, PDP e PEP estão localizados em um mesmo elemento de rede excluindo-se o terminal móvel. No lado direito, PDP e PEP estão em locais físicos distintos, pois esta situação representa a modalidade MCHO (Mobile Controlled Handover), ou seja, o terminal móvel possui o controle sobre a decisão. Dessa forma, o PDP encontra-se no terminal móvel e o PEP em outro elemento de rede.

Uma sinergia entre a base de dados e o SO (sistema operacional) do sistema é bem vinda nesta situação. Assim, o usuário, através de uma interface amigável disponibilizada pelo $\mathrm{SO}$, poderia configurar suas preferências, habilitando ou desabilitando métricas, de modo que sejam levadas em consideração nos parâmetros de entrada do algoritmo de decisão. 


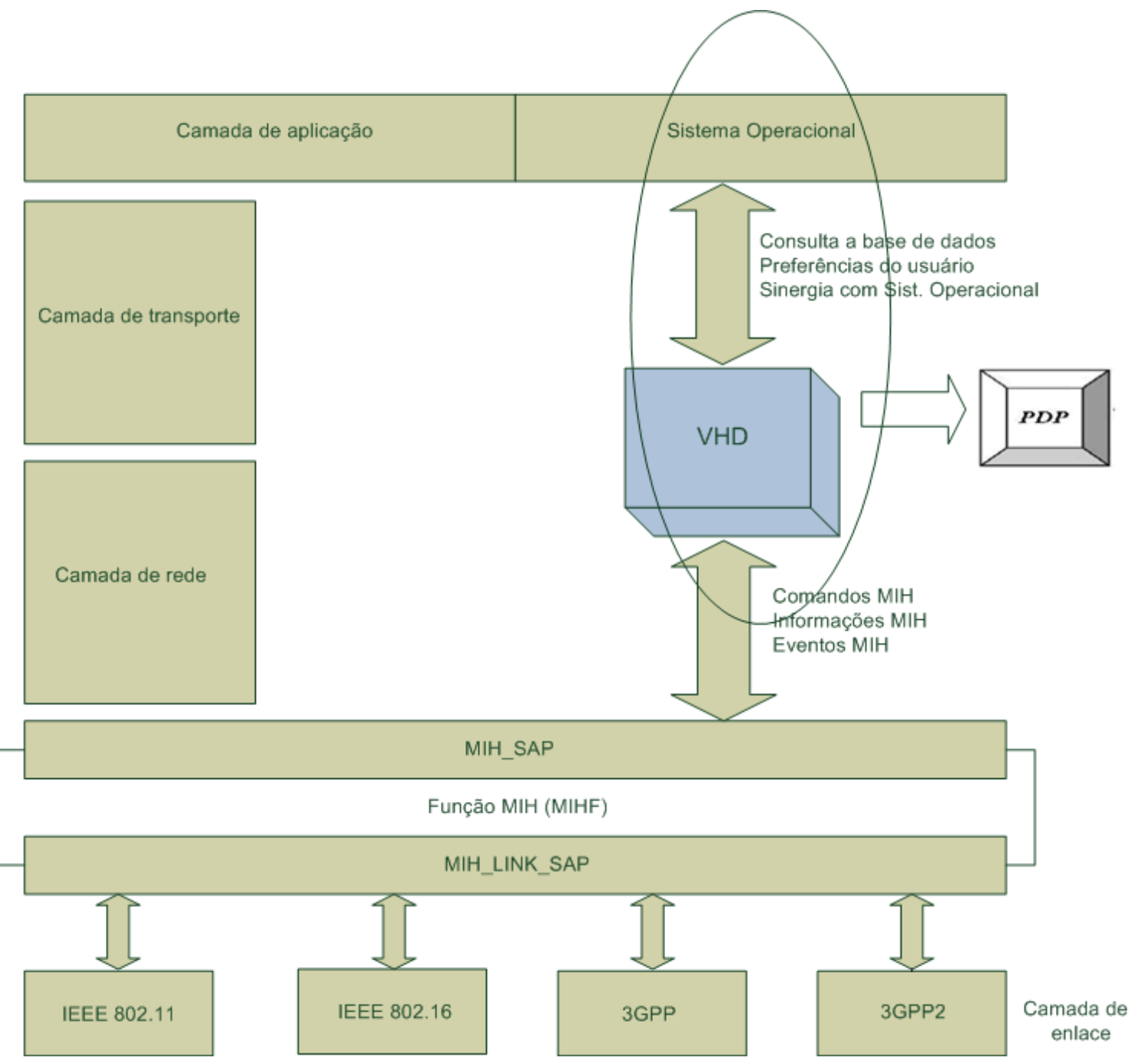

Figura 3.3: Sinergia entre algoritmo e o padrão 802.21

O relacionamento global entre o algoritmo de decisão, as demais entidades da gerência de mobilidade e do sistema é apresentado na Figura 3.3 do ponto de vista da pilha de protocolos TCP/IP. Nela, somente o PDP se encontra no terminal móvel, sugerindo uma modalidade $\mathrm{MCHO}$ de handover. O PEP, sendo responsável pela execução ou trigger, se encontra na estação radio base e, como já comentado no capítulo dois, não faz parte da especificação do padrão 802.21, apesar de poder ser acionado por ele como o diagrama no tópico 2.7 no fim do capítulo precedente mostrou.

O algoritmo de decisão recebe parte das informações da base de dados onde estão as políticas de handover (preferências do usuário e do operador de rede) e parte da MIHF. A MIHF recolhe todas as informações e eventos ocorridos em nível de enlace pelos SAPs que fazem interface com as diferentes tecnologias de acesso repassando-os aos respectivos MIHUs. Ela também realiza o mesmo no 
sentido oposto, isto é, transmitindo ordens de MIHUs (como o algoritmo de decisão) para as camadas inferiores executarem através de comandos.

\section{5 .3}

\section{Algoritmo proposto: diagrama de fluxo e funcionamento}

Tendo como referência a figura 3.4, o MIH verifica, periodicamente, a existência de novas redes no entorno do MN. Ao mesmo tempo, o MIH também realiza o monitoramento do sinal recebido pelo PoA (RSS - Received Signal Strength) e a largura de banda residual ( $R B$ - Residual Bandwidth) da rede WLAN e, pelo lado da WWAN, monitora a relação sinal ruído (SINR - Signal-toNoise Ratio) e também seu RSS.

$\mathrm{O}$ algoritmo tem por preferência fazer com que o $\mathrm{MN}$ permaneça conectado à WLAN sempre que puder, pois ela é uma rede de menor custo, de maior capacidade e geralmente, menos congestionada. Por exemplo, caso seja considerada a rede 802.11 como WLAN, o MIH poderá executar buscas periódicas por ela, seja por mensagens de brodcast genéricas buscando um PoS, seja "escutando" quadros de beacon. Portanto, a conexão com a WWAN só ocorre por falta de sinal de uma WLAN ou por degradação das condições de largura de banda/ sinal recebido pelo $\mathrm{MN}$. 


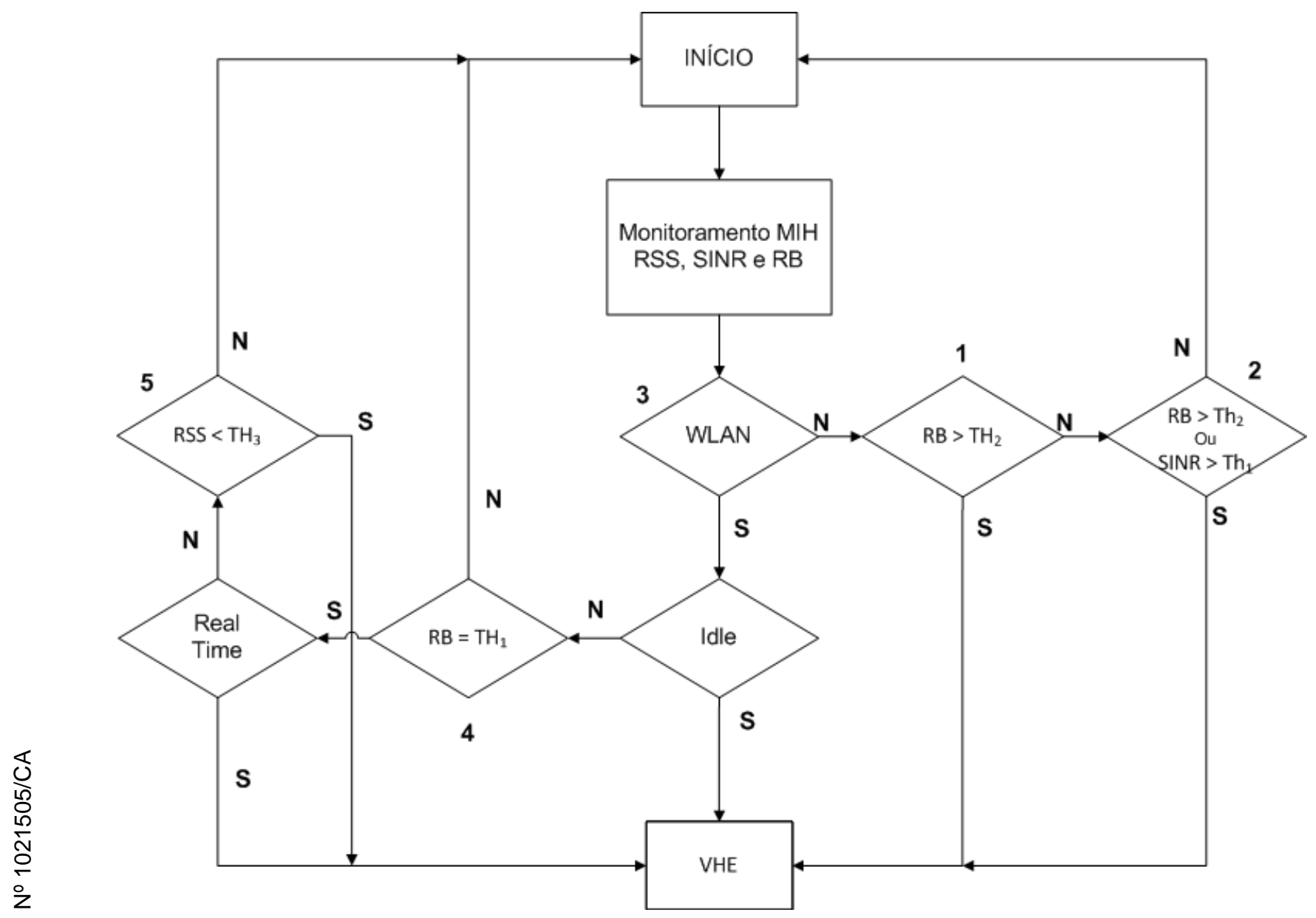

Figura 3.4: Diagrama de fluxo do algoritmo proposto

1. Caso o MN esteja conectado na WWAN e o valor de RB (Residual Bandwidth) na WLAN exceda um valor limite igual a $\mathrm{TH}_{2}$, significando que a largura de banda que a WLAN tem a oferecer é, no momento, maior que a da WWAN, decide-se pelo VHE (Vertical Handover Execution).

2. Também se decide pelo VHE caso o valor do sinal recebido pelo MN caia drasticamente (grande obstrução ou borda de célula) ou ainda tenha sua SINR bastante deteriorada. Este último caso, supondo redes UMTS, pode ocorrer em razão dos mesmos motivos anteriores ou ainda em razão do número de usuários no nodeB em questão ser grande tendo como consequência a "respiração" (breathing) da célula. Qualquer uma das situações fará com que a largura de banda disponível na WWAN seja afetada. $\mathrm{O}$ valor de $\mathrm{Th}_{1}$ é o valor no qual a SINR faz a célula respirar bastando, portanto, atingi-lo. 
3. Caso o MN esteja conectado na WLAN, mas não esteja utilizando nenhuma aplicação (estado idle), faz-se a opção pelo handover, pois, neste estado, a rede WWAN consome menos energia da bateria [6].

4. Caso o MN esteja utilizando alguma aplicação e a RB na WLAN atingir um valor limite $\mathrm{TH}_{1}$, significando que sua ocupação está próxima da saturação, verifica-se a natureza da aplicação. Se for uma aplicação que necessite tratamento de tempo real, opta-se pelo handover para salvaguardar a aplicação.

5. Caso a aplicação não seja de tempo real, o handover só ocorrerá se a RSS da WLAN atingir um valor crítico abaixo de $\mathrm{Th}_{3}$, significando uma zona com obstáculos ou de borda da sua ESS.

Obtenção dos parâmetros de comparação:

Todos os parâmetros de comparação são obtidos pelos serviços MIIS e MIES. O valor de $\mathrm{Th}_{1}(\mathrm{~dB})$ é o valor limite para que a célula respire, o que contabiliza indiretamente o número de usuários no nodeB. Uma consulta ao servidor IS ou ao PoS da WWAN pode obter esse valor. Os valores $\mathrm{Th}_{2}(\mathrm{dBm})$ e $\mathrm{Th}_{3}(\mathrm{dBm})$ representam, respectivamente, os limiares de RSS das redes WWAN e WLAN. No caso em que esses valores caem por causa da proximidade à borda de célula, o evento MIH_link_going_down também pode ser configurado, o que se torna uma segunda opção de implementação dessa parte do algoritmo. O mesmo pode se dizer da utilização do Evento de Parâmetros de Enlace com relação o valore de $\mathrm{Th}_{1}$. (vide capítulo dois tópico 2.4.1) $\mathrm{O}$ valor $\mathrm{TH}_{2}$ é a maior taxa de transmissão que a WWAN pode oferecer.

Já os valores de $\mathrm{TH}_{1}$ e de $\mathrm{RB}$ exigem um cálculo adicional. $\mathrm{O}$ valor RB é calculado conforme explicado no tópico A.9.6 do Apêndice A. Uma vez determinado o valor $\mathrm{RB}$, determina-se o valor $\mathrm{TH}_{1}$ a partir da taxa de transferência da WLAN que caso seja, por exemplo, a 802.11g, é de 54 Mbps. Assim:

\section{$T K_{1}=54-\operatorname{RB}(M b p s)$}




\section{Simulação e análise de desempenho}

\section{1}

\section{O simulador ns2}

Como dito no capítulo de introdução, o simulador utilizado neste trabalho foi o ns (Network Simulator) versão dois. O ns2 dá suporte a um vasto número de protocolos de diversos tipos de rede com ou sem fio. Por apresentar um código livre, há um grande número de voluntários que contribuem com o desenvolvimento de novos modelos e bibliotecas pra o ns2 o que o justifica ser, talvez, o simulador de eventos discreto para redes mais popular existente. Atualmente, quem gerencia seu desenvolvimento é a DARPA (Defense Advanced Research Projects Agency) através do SAMAN (Simulation Augmented by Measurement and Analysis for Networks) e pela NSF através do CONSER (Collaborative Simulation for Education and Research) [39].

$\mathrm{O}$ ns2 trabalha, basicamente, com duas linguagens de programação que possuem papéis distintos em sua arquitetura. Ele funciona como um interpretador de scripts orientados a objeto de uma linguagem desenvolvida pelo MIT (Massachusetts Institute of Technology) chamada Otcl (Object-oriented Tool Command Language), porém, em seu núcleo, a linguagem utilizada é a $\mathrm{C}++$.

Uma simulação no ns2 é escrita em Otcl, pois esta linguagem apresenta simplicidade e rapidez na alteração de seu código, mas, carecendo de rapidez computacional, não é adequada para a construção dos objetos (entes aos quais implementam, de fato, todas as funcionalidades dos protocolos e de ferramentas de análise de uma rede como um todo no software). Por esse motivo, o núcleo do ns é implementado como uma estrutura modular em $\mathrm{C}++$ pois, apesar de possuir uma complexidade maior em sua aprendizagem e, por conseguinte, lentidão em alterações no código, essa linguagem apresenta um bom rendimento computacional. [40]

Em suma, tem-se o Otcl como a interface principal entre o usuário e o ns2 sendo nela a configuração dos principais protocolos e o agendamento dos eventos 
que se desejam simular. Já para a criação e/ou alteração de componentes bem como funcionalidades novas de qualquer tipo no ns2, é necessário um certo grau de proficiência na linguagem $\mathrm{C}++$.

A versão atual do simulador disponível é a ns2.35. Entretanto, não há módulos para simulação de redes UMTS, 802.16 e do protocolo 802.21 no pacote de programas de sua versão original. Buscando uma alternativa para estas lacunas, o NIST (National Institute of Standards and Technology) desenvolveu um módulo independente para a compilação em separado no ns2 chamado Mobility Package. Este módulo, além de adicionar as bibliotecas necessárias às simulações de redes 802.16, UMTS e o protocolo 802.21, ainda realiza algumas adaptações e melhorias nas bibliotecas da camada MAC da rede 802.11 já existentes. O download deste módulo do NIST encontra-se disponível em [41].

O módulo do NIST, essencial para este trabalho, foi desenvolvido especialmente para a versão ns2.29 o que justifica a utilização desta versão um pouco mais antiga ao invés da atual nesta dissertação.

O ns2 pode ser instalado e operado através dos sistemas operacionais Windows ou Linux. Optou-se pela plataforma Linux na realização deste trabalho por sua estabilidade e pela menor dificuldade de instalação dos diversos pacotes necessários que compõem o simulador ns2. A distribuição Linux utilizada foi a Ubuntu 10.10 Lucid Linx.

\section{2}

\section{Limitações do ns2 e objetivos de simulação}

Como comentado no tópico anterior, o módulo desenvolvido pelo NIST é o responsável por permitir a realização de simulações envolvendo as redes UMTS e 802.16 juntamente com o protocolo IEEE 802.21. Entretanto, sendo um módulo de compilação em separado do código do ns2, ele ainda apresenta alguma carências, sobretudo no que diz respeito à implementação do protocolo MIH.

Inicialmente, nem todas as funcionalidades do protocolo IEEE 802.21 foram realmente implementadas. O serviço MIIS, por exemplo, de fundamental importância na comunicação das várias partes do sistema com o algoritmo de decisão apontadas no capítulo anterior, não possui implementação no módulo do NIST. Portanto, a simulação do VHD proposto tornou-se inviável. 
Outro ponto a se destacar se refere ao funcionamento do ns2 após a adição do módulo do NIST. Após a compilação dos dois códigos, a ferramentas do ns2 responsável por gerar gráficos apresentou bugs em suas respostas. Dessa forma, optou-se por extrair todos os resultados numéricos em um arquivo separado e, assim, utilizar o programa Microsoft Excel para apresentar os resultados.

Sendo assim, as simulações, detalhadas logo em seguida, tem por objetivo mostrar a eficácia da utilização do protocolo IEEE 802.21 no processo de handover vertical entre as redes UMTS, IEEE 802.16 e IEEE 802.11.

\section{3}

\section{Cenários e configurações de elementos}

\subsection{1}

\section{Configuração dos Tráfegos}

O primeiro tipo de tráfego a ser simulado neste trabalho possui uma taxa de 12 kbps servindo como um exemplo de aplicação de voz que se enquadra na classe de QoS Conversational da rede UMTS tendo como correspondente, na classificação de QoS da redes 802.16, a classe UGS (Apêndice A).

Já o segundo possui um taxa de 5 Mbps e serve como exemplo de uma aplicação do tipo streaming em que, por exemplo, áudio e vídeo podem ser transferidos simultaneamente. Este tráfego se enquadra na classe de QoS Streaming da rede UMTS que tem como correspondente a classe rtPS na rede 802.16 .

A tabela 4.1 descreve as principais configurações empregadas pelos dois tipos de tráfego:

Tabela 4.1: Configurações da Rede UMTS

\begin{tabular}{|l|c|c|}
\hline & Tráfego 1 & Tráfego 2 \\
\hline Classe de QoS UMTS & Streaming & Conversational \\
\hline Classe de QoS WiMax & rtPS & UGS \\
\hline Taxa de transmissão & $5 \mathrm{Mbps}$ & $12 \mathrm{Kbps}$ \\
\hline Protocolo de transporte & UDP & UDP \\
\hline Tipo de aplicação no ns2 & CBR & CBR \\
\hline
\end{tabular}




\subsection{2}

\section{Configuração das redes envolvidas}

As tabelas 4.2, 4.3 e 4.4 apresentam as configurações utilizadas nos principais elementos e nos enlaces que compõem, respectivamente, as redes UMTS, 802.16 e 802.11 simuladas. Foram mantidos todos os valores padrão presentes no simulador. Em seguida, a tabela 4.5 apresenta como estão configurados parâmetros gerais dos elementos envolvidos.

Tabela 4.2: Configurações da Rede UMTS

\begin{tabular}{|l|c|c|}
\hline \multicolumn{1}{|c|}{ Enlaces } & Velocidade & Atraso de propagação \\
\hline Interface aérea (nó móvel-NodeB) & $2 \mathrm{Mbps}$ & $0,4 \mathrm{~ms}$ \\
\hline Interface lub (NodeB-RNC) & $622 \mathrm{Mbps}$ & $0,2 \mathrm{~ms}$ \\
\hline Interface lu-PS (RNC-SGSN) & $622 \mathrm{Mbps}$ & $0,4 \mathrm{~ms}$ \\
\hline Interface Gn (SGSN-GGSN) & $622 \mathrm{Mbps}$ & $10 \mathrm{~ms}$ \\
\hline Interface Gp (GGSN-Roteador) & $100 \mathrm{Mbps}$ & $15 \mathrm{~ms}$ \\
\hline Roteador-Nó Fixo & $100 \mathrm{Mbps}$ & $30 \mathrm{~ms}$ \\
\hline
\end{tabular}

Tabela 4.3: Configurações da Rede 802.16

\begin{tabular}{|l|c|c|}
\hline \multicolumn{1}{|c|}{ Enlaces } & Velocidade & Atraso de propagação \\
\hline Interface aérea (nó móvel-bs 802.16) & $4 \mathrm{Mbps}$ & $0,4 \mathrm{~ms}$ \\
\hline Roteador-bs 802.16 & $100 \mathrm{Mbps}$ & $15 \mathrm{~ms}$ \\
\hline Roteador-Nó Fixo & $100 \mathrm{Mbps}$ & $30 \mathrm{~ms}$ \\
\hline
\end{tabular}

Tabela 4.4: Configurações da Rede 802.11

\begin{tabular}{|l|c|c|}
\hline \multicolumn{1}{|c|}{ Enlaces } & Velocidade & Atraso de propagação \\
\hline Interface aérea (nó móvel-bs 802.11) & $11 \mathrm{Mbps}$ & $0,4 \mathrm{~ms}$ \\
\hline Roteador-ap 802.11 & $100 \mathrm{Mbps}$ & $15 \mathrm{~ms}$ \\
\hline Roteador-Nó Fixo & $100 \mathrm{Mbps}$ & $30 \mathrm{~ms}$ \\
\hline
\end{tabular}

Tabela 4.5: Configurações de parâmetros gerais

\begin{tabular}{|l|c|c|c|}
\hline & UMTS & 802.16 & 802.11 \\
\hline Modulação & QPSK & OFDM/QPSK & DQPSK \\
\hline Modelo de propagação & TwoRayGround & TwoRayGround & TwoRayGround \\
\hline Roteamento sem fio & UMTSRouting & DSDV & DSDV \\
\hline Tipo dos enlaces & duplex & duplex & duplex \\
\hline Tipo de buffer & DropTail (FIFO) & DropTail (FIFO) & DropTail (FIFO) \\
\hline
\end{tabular}




\subsection{3}

\section{Topologias das redes em cada cenário}

Cada um dos dois tipos de tráfego foi simulado em três cenários distintos. A seguir, são tratados os detalhes das topologias dos cenários.

\subsubsection{1}

\section{Cenário 1: Handover entre UMTS e 802.16}

No primeiro cenário, o handover acontece entre as redes UMTS e 802.16 e é controlado totalmente pelo nó móvel. A Figura 4.1 mostra uma visão da tela de simulação do ns2 que mostra os elementos das redes envolvidos.

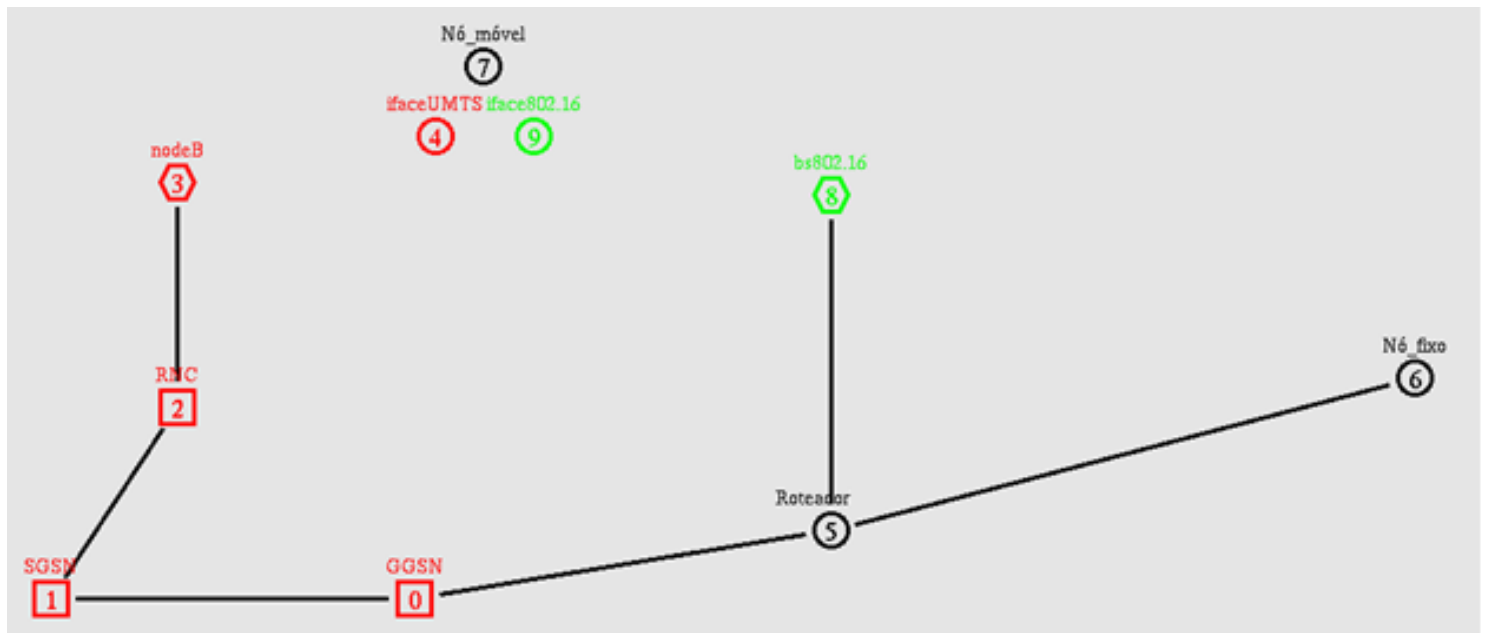

Figura 4.1: Topologia simulada no cenário 1

Os elementos principais da rede UMTS aparecem na cor vermelha e, na cor verde, os elementos da rede 802.16. Duas interfaces associadas ao terminal móvel são vistas na figura. Elas representam as interfaces lógicas que simulam as interfaces físicas específicas de cada tecnologia (WNICs - Wireless Network Interface Card) que, por dificuldades no processamento de sinal, ainda não coexistem em uma só placa [25]. Na terminologia utilizada no ns2, um nó que utiliza mais de uma interface é chamado de multiface node. O 802.21 deve ser instalado no multiface node e interage com as duas interfaces ao longo do tempo. 


\subsubsection{2}

\section{Cenário 2: Handover entre redes 802.16 e 802.11}

No segundo cenário, o handover acontece entre as redes automaticamente, isto é, como uma necessidade do nó móvel ao perceber que o nível de sinal oriundo da estação base a qual está atrelado começa a cair drasticamente ao chegar à borda de sua área de cobertura.

Neste cenário, o handover ocorre entre as redes 802.16 e 802.11. A Figura 4.2 mostra uma visão da tela com os principais elementos das redes envolvidos.

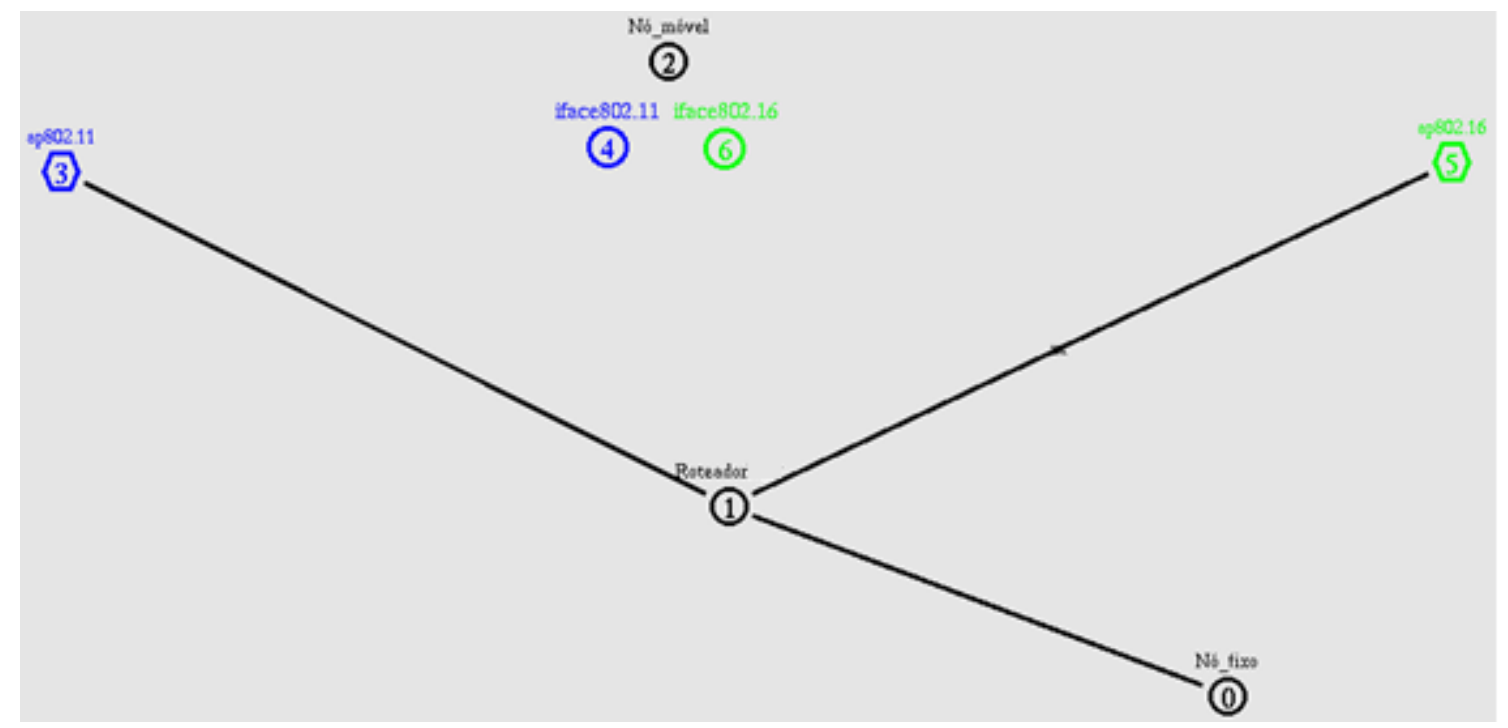

Figura 4.2: Topologia simulada no cenário 2

Tem-se, neste caso, os elementos de rede 802.11 na cor azul e, na cor verde, os da rede 802.16. Assim como no caso anterior, o nó móvel contém as duas interfaces lógicas das redes 802.16 e 802.11 .

\subsubsection{3}

\section{Cenário 3: Handover entre redes UMTS e 802.11}

Neste cenário procurou-se por um funcionamento híbrido do handover. Aqui, o handover acontece, de maneira controlada pelo nó móvel, primeiramente entre as redes UMTS e 802.11. Em um segundo momento, o handover ocorre da rede 802.11 de volta para a rede UMTS, porém de forma automática. 
Procurou-se criar neste cenário uma situação comum hoje. Por exemplo, um usuário de uma rede WWAN (UMTS, no caso) que chega a um ambiente (por exemplo, na PUC-Rio) onde exista uma rede 802.11 segura e estável procurará, caso possa, permanecer conectado a esta última enquanto puder. A Figura 4.3 mostra a tela do simulador com os principais elementos das redes envolvidos.

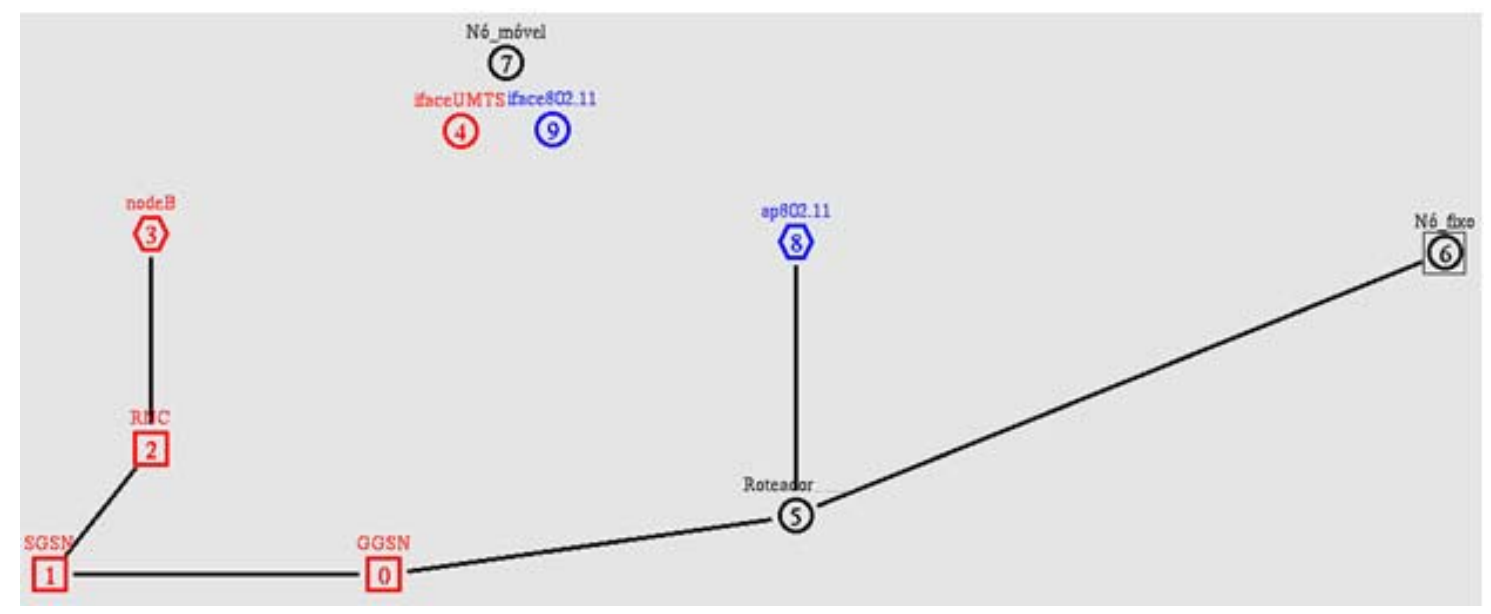

Figura 4.3: Topologia simulada no cenário 3

Mantendo-se a codificação das cores, tem-se os elementos da rede UMTS, bem como sua respectiva interface lógica no nó móvel na cor vermelha e, na cor azul, os elementos da rede 802.11 juntamente com sua respectiva interface lógica no nó móvel.

\subsection{4}

\section{Considerações sobre instalações do MIP e do 802.21}

Em todos os cenários, o protocolo utilizado para a solução do problema de camada de rede no processo do handover é o MIPv4 (Mobile IPv4) que está presente na versão original do ns2.29.

O módulo Mobility Package do NIST faz uma pequena modificação no protocolo MIPv4 adicionando a ele um módulo chamado ND (Neighbor Discover) que faz parte, na verdade, da implementação do MIPv6. O módulo ND é o responsável por implementar, no ns2, a criação do endereço CoA na rede estrangeira e também, como seu próprio nome diz, por anunciar a presença da rede estrangeira [41]. 
Pela rede UMTS, o protocolo MIPv4 é instalado no RNC uma vez que este elemento é o principal gestor das funcionalidades de radio da rede. Pelo lado da rede 802.16, o MIP é instalado na estação base (BS) uma vez que o ns2 não implementa outros elementos dessa rede. Já na rede 802.11, o MIP é instalado no AP.

Para cada cenário, as funcionalidades de HA (Home Agent) e FA (Foreign Agent) são designadas com mostra a tabela seguinte:

Tabela 4.6: Funcionalidades dos elementos de rede ao utilizar o MIPv4

\begin{tabular}{|c|c|c|c|}
\hline Elemento de rede & Cenário 1 & Cenário 2 & Cenário 3 \\
\hline RNC & HA & - & HA \\
\hline AP 802.11 & - & FA & FA \\
\hline BS 802.16 & FA & HA & - \\
\hline
\end{tabular}

Todos os cenários consistem na simulação de uma conexão entre um $\mathrm{CN}$ (Correspondent Node), chamado de Nó_fixo, que é o transmissor de conteúdo, e um terminal móvel ou Nó_móvel como designado nas figuras.

$\mathrm{O}$ roteador, presente em todos os cenários, pode ser enxergado como a própria internet, pois sua função é tão somente interligar o núcleo das redes envolvidas assim como comentado no capítulo três na discussão sobre arquiteturas genéricas de redes sem fio.

O protocolo 802.21 é instalado em todos os nós das redes excetuando-se o roteador (pelo exposto acima), o GGSN, o SGSN e, obviamente, o Nó_fixo.

\section{4}

\section{Análise dos resultados}

Nesta seção, avalia-se a condição de handover nos cenários descritos adotando-se como métricas os valores de vazão média (throughput) e atraso médio fim a fim (end-to-end delay).

O tempo total de simulação foi de 170 segundos. Os valores das métricas foram coletados pelo simulador a cada 0.9 segundos. Os resultados para os três cenários foram agrupados para o tráfego 1 e para o tráfego 2. 


\subsection{1}

\section{Análise dos cenários com o tráfego 1}

As próximas figuras representam a visualização gráfica dos resultados obtidos para a vazão e atraso médios nos três cenários ao utilizar o tráfego 1.

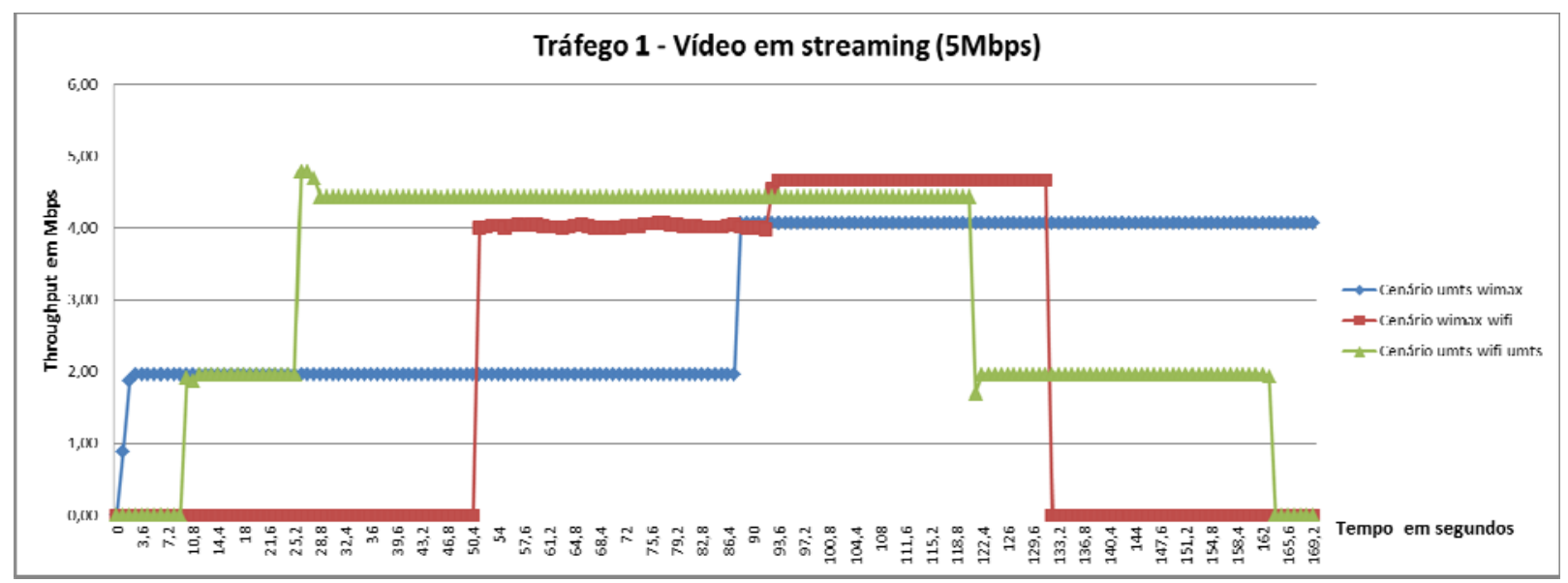

Figura 4.4: Vazão média obtida com o tráfego 1

O início do tráfego ocorre nos instantes, $0,5 \mathrm{~s}, 50 \mathrm{~s}$ e $9 \mathrm{~s}$ respectivamente para os cenários 1, 2 e 3. Observando a Figura 4.4, percebe-se a mudança abrupta no valor da vazão do nó móvel caracterizando os instantes nos quais o handover ocorre nos três cenários.

Destacam-se também os valores de saturação obtidos. Na rede UMTS, os valores chegam próximo da capacidade máxima de 2 Mbps e são estáveis em todo o processo. A esta estabilidade atribui-se o fato de que não há outros nós se comunicando (tráfego de background) razão pela qual a interferência no sistema CDMA é nula.

Já na rede 802.16, nota-se o limite em torno dos $4 \mathrm{Mbps}$. Isso ocorreu porque a modulação utilizada na simulação foi a QPSK em vez da modulação padrão original de 16QAM. Esta mudança na modulação foi necessária para que se pudesse observar bem o momento no qual o handover ocorre, bem como sua comparação com as outras tecnologias.

E a rede 802.11, sendo a rede de maior taxa de transferência, obteve o melhor desempenho como esperado. 


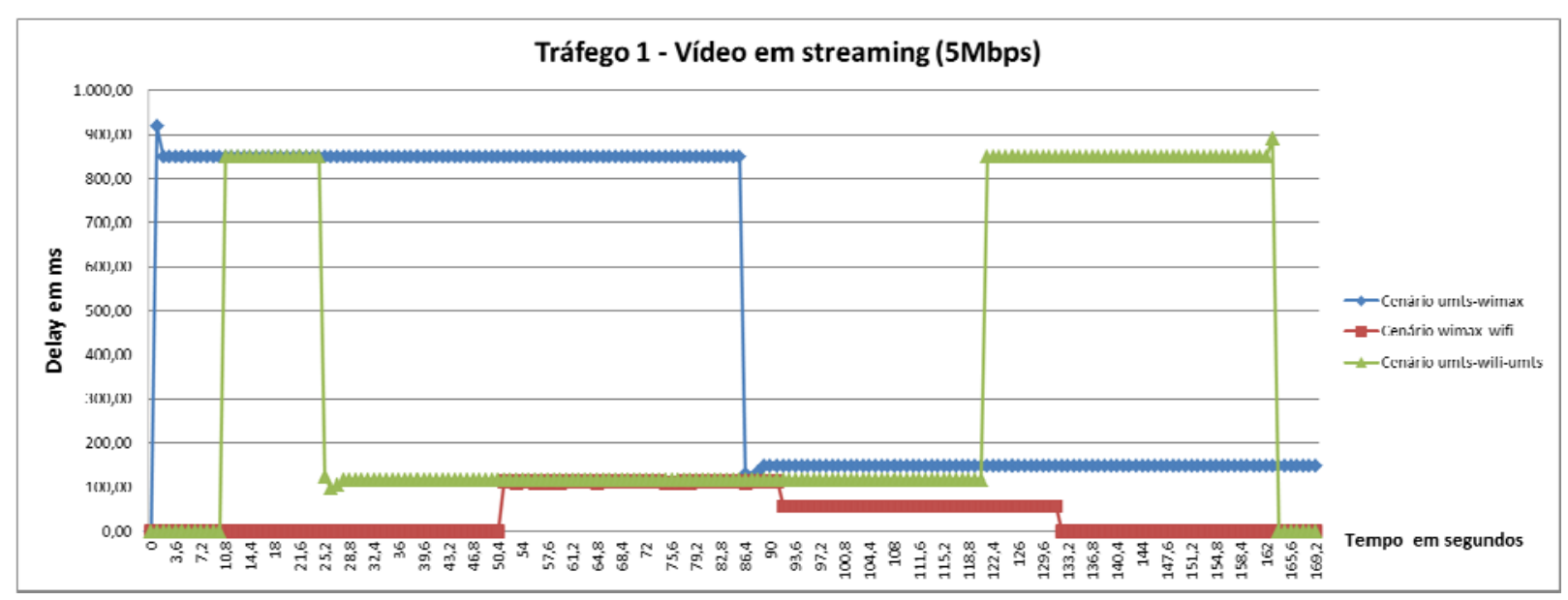

Figura 4.5: Atraso médio obtido com o tráfego 1

Pode-se perceber na Figura 4.5, nos mesmos instantes de tempo da Figura 4.4, que o efeito abrupto na mudança dos valores ocorre também para o atraso médio. Como esperado, a magnitude do atraso diminui quando o nó móvel passa para uma rede de maior capacidade de transferência e aumenta quando ocorre o oposto.

\subsection{2}

\section{Análise dos cenários com o tráfego 2}

As próximas Figuras representam a visualização gráfica dos resultados obtidos para a vazão e para o atraso médio nos três cenários ao utilizar-se, desta vez, o tráfego 2.

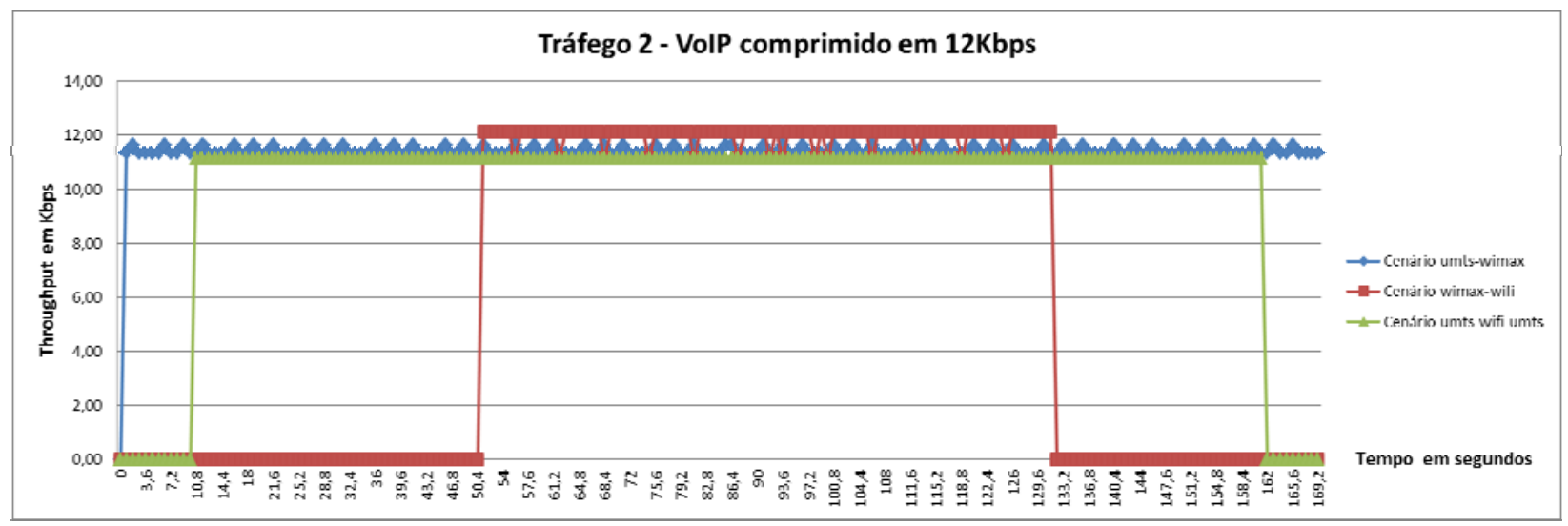

Figura 4.6: Vazão média obtida com o tráfego 2 
$\mathrm{Na}$ Figura 4.6 observa-se que, devido a taxa do tráfego 2 ser consideravelmente baixa para a capacidade das três tecnologias, elas praticamente se equivalem em termos de vazão. Por esse motivo, não se consegue observar os instantes nos quais o handover acontece como visto na Figura 4.4 para o tráfego 1.

Entretanto, algo diferente ocorre na Figura 4.7 onde são visualizados os valores para o atraso médio.

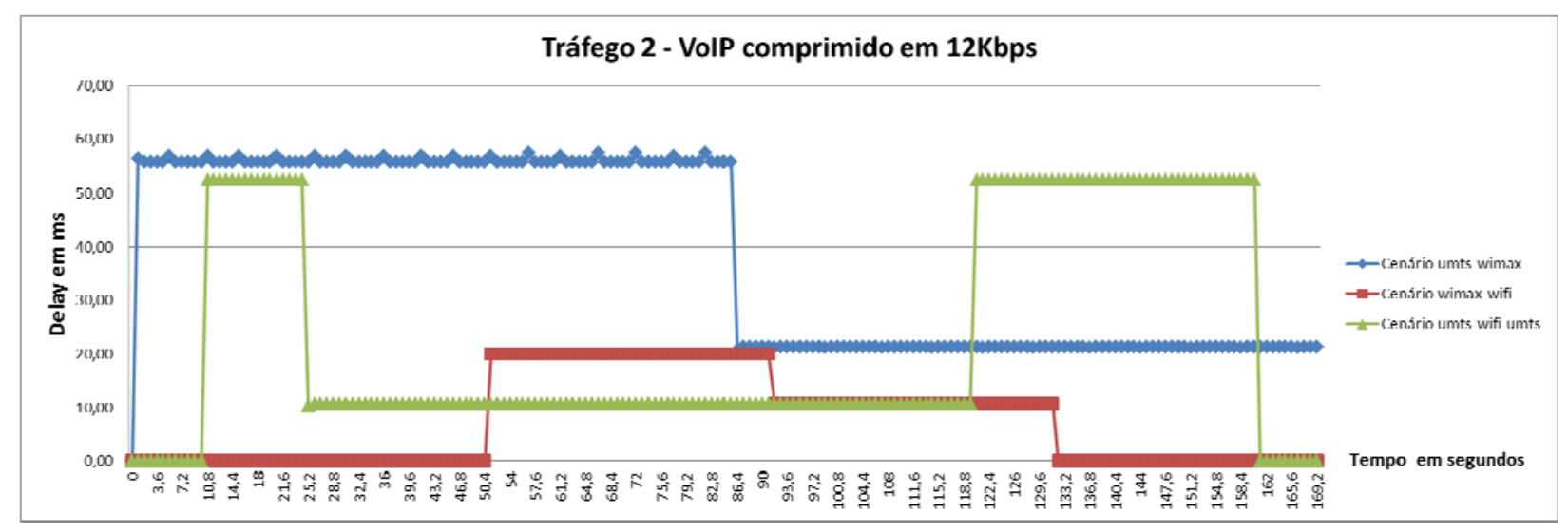

Figura 4.7: Atraso médio obtido com o tráfego 2

Na Figura 4.7, pode-se observar as mudanças abruptas nos valores na magnitude do atraso que caracterizam os instantes da ocorrência do handover. Nisto, observa-se a diferença na eficiência da entrega e tratamento dos pacotes das camadas física e MAC das redes UMTS e as 802.16 e 802.11. A utilização de várias portadoras que ocorre no OFDMA e a ausência de concorrência de comunicação com o AP 802.11 devido a inexistência de outros nós transmitindo fazem com que as tecnologias 802.16 e 802.11 superem a rede UMTS com seu método de acesso WCDMA.

Uma última consideração se refere à ação do buffer em cada um dos cenários de simulação. Uma perda de pacotes deveria ocorrer devido ao tempo de desconexão momentâneo que o Nó_móvel experimenta no instante handover como comentado na seção 2.7. Entretanto, tal fato não ocorreu na simulação devido à ação do buffer presente no HA que retém os pacotes enquanto o processo de handover não se encerra. 


\section{Conclusão e trabalhos futuros}

\section{1}

\section{Conclusão}

O número crescente de usuários que demandam serviços de alta mobilidade impulsiona a busca por novas soluções e um constante desenvolvimento das tecnologias de rede. Neste sentido, as redes UMTS/LTE, IEEE 802.16 e IEEE 802.11 desempenham certo protagonismo, sendo as principais tecnologias de rede sem fio atuais. Entretanto, a utilização delas de forma isolada não atende as expectativas atuais dos usuários que desejam estar conectados a todo o momento e em todo lugar.

Esta dissertação procurou investigar as possibilidades de atendimento desse novo tipo de demanda através da integração das redes disponíveis por meio da execução de handovers verticais. Dentre as principais possibilidades de integração, optou-se pela proposta dada pelo IEEE através do protocolo IEEE 802.21 ou MIH (Media Independent Handover). O objetivo principal deste padrão é auxiliar o processo de handover vertical de forma que ele seja imperceptível para o usuário móvel.

O elemento chave desta dissertação é o protocolo IEEE 802.21. Ele foi discutido em detalhes explicando-se seus principais objetivos, partes, elementos e funções visando-se com isso o entendimento de um exemplo de sua aplicação em conjunto com o protocolo MIPv4.

Um estudo mais específico da fase de decisão de handover foi feito ao serem apresentados os algoritmos de decisão de handover. Foram vistos seus objetivos, suas classificações quanto a complexidade empregada em sua elaboração, suas principais métricas de avaliação de desempenho e seu relacionamento com outras partes do sistema como um todo.

No campo de uma contribuição teórica, foi proposto um algoritmo de decisão que tem por finalidade atender uma topologia particular, porém bastante comum no cotidiano. Ele tem como principais características a utilização de 
vários serviços oferecidos pelo $\mathrm{MIH}$ e uma baixa complexidade em sua implementação.

Finalizando o trabalho, foram realizadas simulações de handovers verticais entre as tecnologias UMTS, 802.16 e 802.11 utilizando-se o protocolo 802.21 como protagonista do processo. Verificou-se a eficácia do processo de handover em três cenários distintos onde, em cada um deles, dois tipos de tráfego foram utilizados. Observou-se a melhor eficiência da tecnologia 802.11 e 802.16 sobre a rede UMTS, principalmente da interface aérea no que diz respeito ao atraso médio dos pacotes. Desta forma, pode-se constatar a eficácia do apoio às várias etapas do processo de handover vertical que o protocolo IEEE 802.21 pode oferecer.

\section{2}

\section{Trabalhos futuros}

O mundo das redes sem fio é imenso e complexo com vários desafios e caminhos para serem trilhados ainda. Sua evolução permanente promete revolucionar ainda mais a vida de toda a sociedade através de um uso integrado das tecnologias. Particularmente, no âmbito deste trabalho, podem ser enumerados alguns caminhos a percorrer, principalmente no tocante a execução de um handover vertical suave e transparente.

Investigações adicionais sobre a condição de suavidade e transparência do handover vertical devem ainda ser realizadas. A latência do processo, utilizandose outros tipos de tráfegos e métricas, deve ser verificada como condição primeira de suavidade e transparência do processo. Para tal, novos objetos e outras ferramentas adicionais devem ser desenvolvidas no núcleo do simulador ns2 que permitam tais experiências.

Nesse sentido, retomando a discussão sobre o problema de gerência de mobilidade apresentado no Apêndice B, pode-se investigar as possibilidades que o protocolo mSCTP (mobile Stream Control Transmission Protocol) apresenta.

Simulações envolvendo o mSCTP, o MIP e suas melhorias demonstraram a melhoria na latência de handover ao utilizar o mSCTP [42]. Entretanto, o principal desafio na utilização do $\mathrm{mSCTP}$ é a configuração de uma regra específica para realizar o trigger entre os IPs, isto é, descobrir o momento ótimo de realizar a troca do IP de origem pelo CoA de maneira minimizar a latência e o 
tamanho de memória buffer no processo global de handover. Uma regra que pode ser usada é utilizar o momento no qual o endereço IP de origem se torna inativo. A inatividade só acontece quando a conectividade em nível de camada física e de enlace se perde à medida que o terminal móvel saia totalmente da área de cobertura da rede de origem. Ou seja, esta informação pode ser dada pelas camadas física e de enlace [26]. Este esquema constitui o que se chama de um projeto de cross-layer (cross-layer design) entre as camadas de transporte e de enlace. Um facilitador desse esquema de cross-layer é o protocolo 802.21. O protocolo 802.21 não foi concebido para resolver esse desafio em específico, porém, consegue oferecer este tipo de informação como visto no capítulo dois desta dissertação.

O módulo SCTP (Stream Control Transmission Protocol), implementado na versão original do ns2, contém a versão original do protocolo cujo objetivo é aplicar um grau a mais na confiabilidade da comunicação no contexto de redes cabeadas. Assim, modificações no núcleo do ns2 se fazem necessárias para o desenvolvimento de sua versão para redes móveis que é o mSCTP.

Outro caminho a ser seguido refere-se à simulação do algoritmo proposto e do estudo dos ajustes comentados no capítulo três. A rede utilizada para avaliação da expressão de cálculo de banda residual (vide Apêndice B) foi a 802.11 b, porém não foi mostrado por [21] até que ponto esta expressão retrata a realidade prática, principalmente se utilizarmos outras especificações como $802.11 \mathrm{~b}$ e $802.11 \mathrm{n}$. Uma modificação de desenvolvimento no módulo do protocolo 802.21 produzido pelo NIST deve também ser feita no intuito de implementar as primitivas das funcionalidades de obtenção dos parâmetros $T h_{1}, T_{2}$ e $T h_{3}$ necessários ao monitoramento do algoritmo.

A implementação do ns2 realizada pelo NIST não fornece suporte a um servidor de informações MIH cuja existência é de fundamental importância para o serviço MIIS do protocolo 802.21 devendo, portanto, ser realizada também no código do ns2. 


\section{Referências bibliográficas}

[1] Disponível em <http://appleinsider.com/articles/13/01/22/chinas-3gsubscribers-grow-83-in-2012-reach-233m>. Acesso em 11/03/2013.

[2] Disponível em $<\underline{\text { http://www.hojeemdia.com.br/noticias/economia-e- }}$ negocios/usuarios-de-3g-devem-crescer-70-em-2012-diz-ministro-1.69261>. Acesso em 11/03/2013.

[3] JESZENSKY, Paul Jean Etiene. Sistemas Telefônicos. Editora Manole, 2004.

[4] SILVA MELLO, Luis Alencar. Notas de aula ELE 2614 - Planejamento de Sistemas Celulares e de Radio Acesso - PUC-Rio, 2011.

[5] 3GPP- TS 22.105 V8.4.0 (Release 8) Technical Specification Group Services and System Aspects Service aspects; Services and service capabilities. Institute of Electrical and Eletronics Engineers, 2007.

[6] HOLMA, Harri; TOSKALA, Antti. WCDMA for UMTS HSPA Evolution

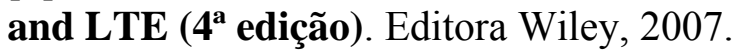

[7] DE MARCA, J.R.B. Notas de aula ELE 2606 - Redes de Comunicações Móveis e Pessoais - PUC-Rio, 2010.

[8] AGRAWAL, Rajeev; BEDEKAR, Anand. Network Architectures for 4G: Cost Considerations. Communications Magazine IEEE, 2007, p.76-81.

[9] Disponível em <http://www.ieee.org/about/index.html $>$. Acesso em $\underline{11 / 03 / 2013 .}$

[10] KUROSE, Jim; ROSS, Keith. Redes de computadores e a Internet. $5^{\text {a }}$ edição. Editora Pearson, 2010.

[11] SOBRINHO, João Luís; DE HAAN, Roland; BRÁZIO, José Manuel. Why RTS-CTS is not your ideal wireless LAN multiple access protocol. Wireless Communications and Networking Conference, IEEE, p.81-87 (Vol.1), 2005.

[12] KUMAR, Anurag; MANJUNATH, D.; KURI, Joy. WIRELESS NETWORKING. Editora Elsevier, 2008.

[13] BULHMAN, Haroldo José; CABIANCA, Luis Antonio. Redes LAN/MAN Wireless II: Funcionamento do Padrão 802.11. Tutorial disponível em $<\underline{\text { http://www.teleco.com.br/tutoriais/tutorialrwlanman2/pagina 4.asp }>\text { Acesso em }}$ $\underline{11 / 03 / 2013 .}$ 
[14] RAMACHANDRAN, Iyappan; ROY, Sumit. On the Impact of Clear Channel Assessment on MAC Performance. Department of EE, University of Washington, Seattle, WA 98105. Disponível em $<$

http://www.ee.washington.edu/research/funlab/Publications/2006/CCA on MAC. pdf $>$ Acesso em 11/03/2013.

[15] 802.11-2012 - IEEE Standard for Information technology-Telecommunications and information exchange between systems Local and metropolitan area networks--Specific requirements. Part 11: Wireless LAN Medium Access Control (MAC) and Physical Layer (PHY) Specifications IEEE Std 802.11 ${ }^{\mathrm{TM}}-2012$ (Revision of IEEE Std 802.11-2007). Institute of Electrical and Eletronics Engineers, 2012.

[16] MÜLLER, Martin. IEEE 802.16m Technology Introduction Application Note. White paper ROHDE \& SCHWARZ IEEE 802.16m Technology, 2010.

[17] SESIA, Stefania; TOUFIK, Issam; BAKER, Matthew. The Long Term Evolution from theory to practice. Editora Wiley \& sons 1td, 2011.

[18] ETEMAD, Kamran. Overview of Mobile WiMAX Technology and Evolution. IEEE Communications Magazine, IEEE, p.31-40, 2008.

[19] LIMA, Luciana dos Santos; SOARES, Luiz Fernando Gomes, ENDLER, Markus WiMAX: Padrão IEEE 802.16 para Banda Larga Sem Fio. Departamento de Informática, PUC-Rio, 2004.

[20] 802.16f-2005 - IEEE Standard for Local and Metropolitan Area Networks Part 16: Air Interface for Fixed Broadband Wireless Access Systems. Institute of Electrical and Eletronics Engineers, 2005.

[21] LEE, Cheng Wei; CHEN, Li Ming; CHEN, Meng Chang; SUN, Yeali ny. A Framework of Handoffs in Wireless Overlay Networks Based on Mobile IPv6, Department of Informatics Taiwan University, Taipei, Taiwan. IEEE Journal (Volume 2), p.2118-2128, 2005.

[22] Disponível em <http://www.vivasemfio.com/blog/tag/beacon-frame/>. Acesso em 11/03/2013.

[23] FERRUS, Ramon; SALLENT, Oriol; AGUSTI, Ramon. Interworking in heterogeneous wireless networks: comprehensive framework and future trends - Universitat Politecnica de Catalunya. Wireless Communications, IEEE (Volume 17), p. 22-31, 2010.

[24] LAMPROPOULOS, George; PASSAS, Nikos; MERAKOS, Lazaros; KALOXYLOS, Alexandros. Handover management architectures in integrated wlan / cellular networks. Communications Surveys \& Tutorials, IEEE (Volume 7), p.30-44, 2005. 
[25] GOLDSMITH, Andrea. Stanford University. Palestra proferida na PUC-Rio no dia 13/10/2011.

[26] BCHINI, Tarek; TABBANE, Nabil; CHAPUT, Emmanuel; TABBANE, Sami; BEYLOT, André-Luc. Interconnection \& Handover between IEEE 802.16e \& UMTS. International Journal of Advancements in Computing Technology Volume 1, 2009.

[27] SOARES, João Monteiro. Desempenho de Redes de Acesso Heterogéneas com Suporte de Mobilidade. Dissertação de mestrado. Universidade de Aveiro, 2009.

[28] DA SILVA, Anderson Oliveira; COLCHER, Sérgio. Evolução da Otimização do Handoff no Mobile IP. Monografias em Ciência da Computação. Departamento de Informática, PUC-Rio, 2008.

[29] 3GPP TS 23.234 V11.0.0 (2012-09): Technical Specification Group Services and System Aspects; 3GPP system to Wireless Local Area Network (WLAN) interworking; System description (Release 11). Third Generation Partnership, 2012.

[30] PIRI, Esa; PENTIKOUSIS, Kostas. IEEE 802.21: Media-Independent Handover Services. VTT Technical Research Centre of Finland. The Internet Protocol Journal volume 12, número 2, p. 7- 27, 2009.

[31] SIMSEK, Burak; JOHANN, Jens; ZÚÑIGA, Juan Carlos; KHATIBI, Farrokh; JEE, Junghoon; BAE, Byungjun. IEEE 802.21 Broadcast handovers. Disponível em: < http://www.ieee802.org/21/Tutorials/21-08-0199-03-0000broadcast-handovers-tutorial.pdf $>$. Acesso em 11/03/2013.

[32] TANENBAUM, Andrew S. Computer Networks. 4 edição. Editora Campus, 2002.

[33] DE LA OLIVA, Antonio; MELIAT, Telemaco; BANCHS, Albert; SOTO, Ignacio; VIDAL, Albert. IEEE 802.21 (Media Independent Handover services) Overview. Departamento de Engenharia em Telematica. Universidade Carlos III, Madrid, Spain, 2008.

[34] IEEE Standard for Local and metropolitan area networks. Part 21: Media Independent Handover Services. Institute of Electrical and Eletronics Engineers, 2009.

[35] YAN, Xiaohuan; SEKERCIOG, Y. Ahmet; NARAYANAN, Sathya. A survey of vertical handover decision algorithms in Fourth Generation heterogeneous wireless networks. Computers Networks, Volume 54, p. 1848$1863,2010$.

[36] NAVARRO, E. Stevens; Wong V. Comparison between vertical handoff decision algorithms for heterogeneous wireless networks. Proceedings of IEEE Vehicular Technology Conference (VTC-Spring), Volume. 2, p. 947-951, 2006. 
[37] A Framework for Policy-based Admission Control. . YAVATKAR R; PENDARAKIS, D; GUERIN R. RFC 2753, 2000.

[38] RIZVI, Safdar; AZIZ, Asif; SAAD, N.M. An Overview of Vertical Handoff Decision Policies for Next Generation Wireless Networks. Department of Electrical and Electronic Engineering, University Technology. Circuits and Systems (APCCAS), IEEE Asia Pacific Conference on, p. 88-91, 2010

[39] Disponível em < http://www.isi.edu/nsnam/ns/> Acesso em 11/03/2013.

[40] BUDZISZ, Lukasz. Stream Control Transmission Protocol (SCTP), a proposal for seamless handover management at the transport layer in heterogeneous wireless networks. $\mathrm{PhD}$ Thesis. Universitat Politécnica de Catalunya - Department of Signal Theory and Communication Radio Communication Group. Barcelona, 2009.

[41] Disponível em < $<$ http://www.nist.gov/index.html $>$ Acesso em 11/03/2013.

[42] REHAN, Maaz; YOUSAF, Muhammad; QAYYUM, Amir; MALIK, Shahzad. A Crosslayer User Centric Vertical Handover Decision Approach based on MIH Local Triggers. Second IFIP WG 6.8 Joint Conference, WMNC 2009, Gdańsk, Polônia, p. 359-369, 2009.

[43] JUNIOR, Warley M.V.; JAILTON, José; CARVALHO, Tassio; DIAS, Kelvin Lopes. Aprovisionamento de QoS e QoE em Redes Sem Fio Heterogêneas com Suporte a Balanceamento de Carga. Disponível em < http://sbrc2011.facom.ufms.br/files/workshops/wgrs/ST02_3.pdf $>$. Acesso em $11 / 03 / 2013$.

[44] BECVAR, Zdenek; ZELENKA, CZECH Jan. Handovers in the Mobile WiMAX Research in Telecommunication Technology (RTT 2006), Brno, Czech Republic, p. 147-150, 2006.

[45] CASAGNI, Alessandro; KAEMPER, Michael. How to implement WiMax in a mobile network. Siemens White paper, 2005.

[46] STORCK, Carlos R.; RIBEIRO, Anna Izabel J.T.; FIGUEIREDO, Fátima de L.P. Duarte. CAC-RD: Controle de Admissão de Chamadas Para Redes UMTS. $26^{\circ}$ Simpósio Brasileiro de Redes de Computadores e Sistemas Distribuídos, p. 371-383, 2008.

[47] STRACCIALANO, André L. Segurança em redes 3G - UMTS. Disponível em $<$ http://www.wirelessbrasil.org/wirelessbr/artigos/seguranca-umtsgeral.pdf $>$. Acesso em 11/03/2013.

[48] 3GPP TS 25.401 V11.1.0 (2012-12): Technical Specification Group Radio Access Network; UTRAN overall description (Release 11). Third Generation Partnership, 2012. 
[49] BRUNO, R.; CONTI, M.; GREGORI, E. WLAN technologies for Mobile ad hoc Networks. Consiglio Nazionale delle Ricerche Istituto (CNUCE). Conference on System Sciences. Proceedings of the 34th Annual Hawaii International, 2001.

[50] DUJOVNE, Diego; TURLETTI, Thierry; FILALI, Fethi. A Taxonomy of IEEE 802.11 Wireless Parameters and Open Source Measurement Tools. Communications Surveys \& Tutorials, IEEE (Volume 12), p. 249-262, 2010.

[51] PACK, Sangheon; CHOI, Jaeyoung, KWON, Taekyoung; CHOI, Yanghee. Fast-handoff support in IEEE 802.11 wireless networks. Communications Surveys \& Tutorials, IEEE (Volume 9), p. 2-12, 2007.

[52] FERNANDES, Stenio; KARMOUCH, Ahmed. Vertical Mobility Management Architectures in Wireless Networks: A Comprehensive Survey and Future Directions. Communications Surveys \& Tutorials, IEEE (Volume 14), p. 45-63, 2012.

[53] KOH, Seok Joo; CHANG, Moon Jeong, LEE, Meejeong. mSCTP for Soft Handover in Transport Layer. IEEE Communications letters (Volume 8), p. 189-191, 2004.

[54] GUPTA, Vivek. IEEE 802.21 MEDIA INDEPENDENT HANDOVER Tutorial.. Disponível em $<$ http://www.docstoc.com/docs/3784153/JointOpening-Plenary-IEEE-80221-Media-Independent-Handover $>$. Acesso em $11 / 03 / 2013$.

[55] LESCUYER, P.; LUCIDARME, T. Evolved Packet System (EPS): the LTE and SAE evolution of 3G UMTS. Editora Wiley, 2008.

[56]

Disponível

em $<$ http://www.dcc.fc.up.pt/ pbrandao/aulas/0405/TAR/relatorios/0304-t1 mip.pdf $>$ Acesso em 11/03/2013. 


\section{Apêndice A: Tecnologias de rede sem fio}

\section{A.1 \\ Introdução}

Neste apêndice, serão abordadas às três tecnologias de redes sem fio utilizadas neste trabalho: a rede UMTS, que corresponde a rede de telefonia móvel mais utilizada no mundo, a família de redes 802.11, conhecida popularmente como WiFi, que constitui o padrão dominante de redes locais sem fio e a rede 802.16, também conhecida como WiMax, que surgiu como alternativa aos acessos cabeados oferecendo banda larga sem fio. Serão vistas suas principais características como arquiteturas e elementos de rede, métodos de acesso e aspectos da gerência de mobilidade.

\section{A.2 \\ A rede UMTS (Universal Mobile Telecommunication System)}

\section{A.2.1}

\section{Histórico e características gerais}

Embora os sistemas móveis de telefonia da segunda geração pudessem oferecer serviços de voz e dados, estes eram extremamente limitados seja em termos de taxa de transferência, seja na capacidade de melhoria de sua interface aérea. Em verdade, os sistemas $2 \mathrm{G}$ foram otimizados para a oferta de serviços de voz e não para serviços de dados [3].

Dentre as quinze propostas de tecnologias submetidas ao IMT-2000 (Internacional Mobile Telecommunication - ano 2000), órgão do ITU-R (Internacional Telecommunication Union - Radiocommunications Sector) responsável por definir os requisitos mínimos para a terceira geração de redes de telefonia móvel, somente dez foram aceitas. Pela semelhança entre os sistemas e, fundamentalmente, por questões de mercado, houve ainda uma fusão entre elas e, assim, restaram apenas cinco opções "vencedoras" de fato [4]. 
Embora a harmonização fosse desejada por todos os colaboradores do IMT-2000, as divergências entre alguns proponentes e os conflitos de direito de propriedade intelectual dificultaram a elaboração de especificações em comum e culminaram com o estabelecimento de dois projetos independentes de parceria global. Esta é a origem do 3GPP e do 3GPP2.

O 3GPP (Third Generation Partnership Project) foi criado em dezembro de 1998 na Europa como fruto da cooperação entre os seguintes órgãos regionais: ETSI (European Telecommunication Standards Institute) da União Europeia, ATIS dos EUA, ARIB\&TTC do Japão, TTA da Coréia do Sul, CCSA da China e de várias outras entidades empresariais. Desde então, o 3GPP ficou responsável em desenvolver especificações, relatórios técnicos e por conduzir a evolução geral do sistema móvel 3G chamado CDMA Direct Spread ou WCDMA que, mais tarde, veio a possuir o nome UMTS conhecido globalmente. A primeira versão da padronização desta tecnologia foi chamada release 99.

Os sistemas 3G UMTS consistem, basicamente, na integração de uma rede de telefonia móvel global com os avançados serviços e vantagens oferecidas pela Internet utilizando uma interface aérea totalmente remodelada, porém sem romper com a infraestrutura do núcleo de rede legada da segunda geração. Ela se constitui como uma evolução natural da linha GSM/GPRS/EDGE cujo núcleo de rede (core) é mantido em suas primeiras versões com pequenas alterações [3, 47].

\section{A.2.2}

\section{A técnica de acesso CDMA (Code Division Multiple Access)}

O CDMA é um sistema de faixa larga no qual todos os usuários podem compartilhar um mesmo canal na frequência e no tempo [4]. Uma sequencia (código) de bits, chamados chips, codifica a informação que se deseja transmitir num processo chamado de espalhamento espectral. Uma vez que o receptor conheça a sequência que originou o espalhamento, ele consegue recuperar o sinal original. Uma ilustração do processo é mostrada a seguir. 


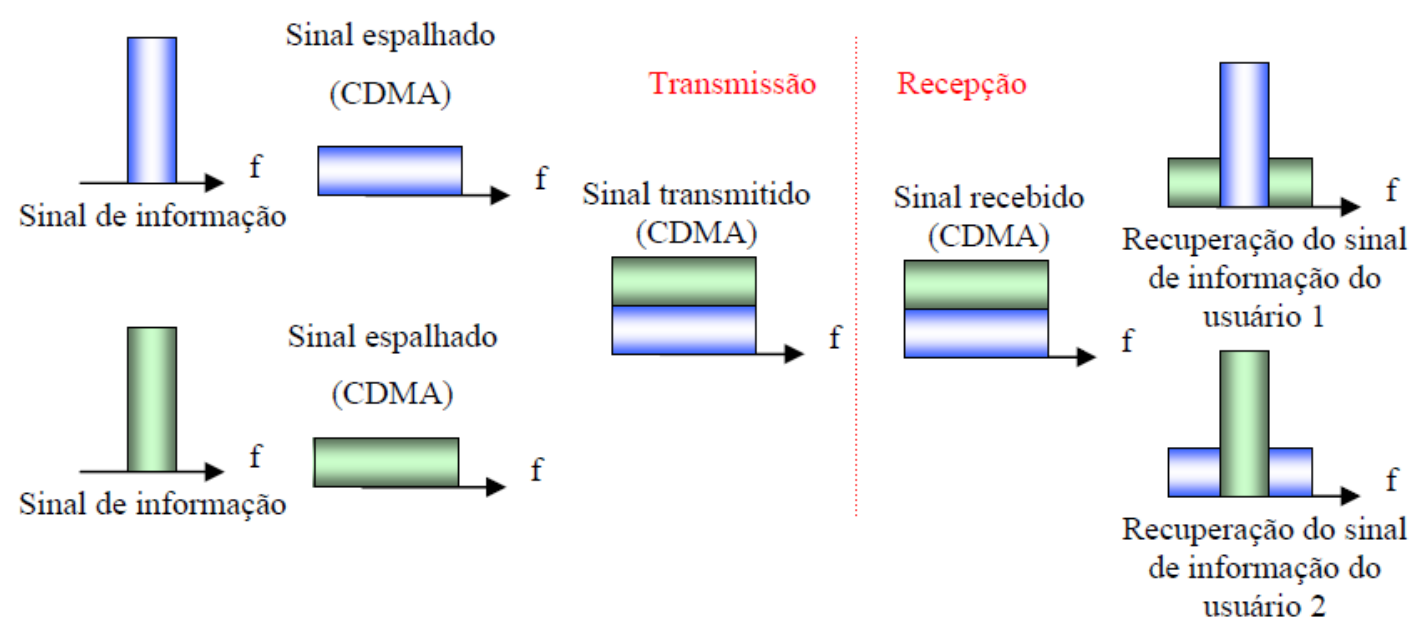

Figura A.1: Espalhamento espectral no DS-CDMA [4]

Uma vez que o código ocupa uma banda maior do que a da informação, o espectro resultante após sua combinação (sinal espalhado na Figura A.1) é maior do que o da informação. Assim se justifica o nome espalhamento espectral para o processo.

Uma condição para a recuperação do sinal no receptor é que o código, tanto o de espalhamento quanto o de desespalhamento, sejam sincronizados e possuam correlação igual a zero.

Um fator limitante nos sistemas CDMA é o número de usuários que utilizam a mesma frequência. No lado direito da Figura A.1, o sinal espalhado recebido pelo usuário 1 possui em si também a informação destinada ao usuário 2 . Do ponto de vista do usuário 1, no processo de desespalhamento do sinal, a informação destinada ao usuário 2 é considerada como interferência para o usuário 1. O mesmo ocorre do ponto de vista do usuário 2. Assim, dependendo do número total de usuários no sistema, a interferência pode chegar a níveis em que inviabilize a recuperação do sinal.

O UMTS não foi o primeiro sistema a utilizar a tecnologia CDMA para o acesso. O sistema de segunda geração IS-95 já a utilizava com um canal de 1,25 MHz. A novidade se deu por conta da nova largura de canal de $5 \mathrm{MHz}$ empregada no UMTS. Por esse motivo, o UMTS também ficou conhecido como WCDMA (Wideband CDMA) fazendo alusão ao canal mais largo. 
O WCDMA suporta variações na taxa de transmissão, o que permitiu a alocação de banda sob demanda. Quadros de 10 ms podem ser alocados para cada usuário nos quais as taxas de transferência são mantidas constantes [4].

\section{A.3}

\section{Classes de QoS definidas para a rede UMTS}

Outra característica importante foi a atenção especial dada à garantia de qualidade de serviço (QoS). Em [5], foram definidas classes de QoS para diferentes tipos de tráfego. A tabela a seguir faz uma breve descrição delas e fornece exemplos de aplicação.

Tabela A.1: Classes de QoS definidas para a rede UMTS [5]

\begin{tabular}{|l|l|l|}
\hline Classe & Uso & Exemplo de aplicação \\
\hline Conversational & $\begin{array}{l}\text { Dedicada às aplicações mais sensíveis ao } \\
\text { atraso e que operem em tempo real }\end{array}$ & $\begin{array}{l}\text { Serviços de voz comutados } \\
\text { a circuitos e VolP }\end{array}$ \\
\hline Streaming & $\begin{array}{l}\text { Transferência de dados em um fluxo contínuo } \\
\text { e fixo }\end{array}$ & $\begin{array}{l}\text { Serviços de vídeo sob } \\
\text { demanda como youtube }\end{array}$ \\
\hline Interactive & $\begin{array}{l}\text { Situações em que o usuário requisita dados } \\
\text { em um equipamento remoto e o atraso é } \\
\text { crítico }\end{array}$ & $\begin{array}{l}\text { Web browsing e consulta à } \\
\text { base de dados }\end{array}$ \\
\hline Background & Serviços em que o atraso não é crítico & $\begin{array}{l}\text { E-mails, SMS, download de } \\
\text { base de dados }\end{array}$ \\
\hline
\end{tabular}

\section{A.4}

\section{Arquitetura da rede UMTS}

A arquitetura de uma rede UMTS é composta de três partes. O UE, o CN e o UTRAN. A Figura a seguir ilustra as três partes constituintes [6, 46, 47,48] 


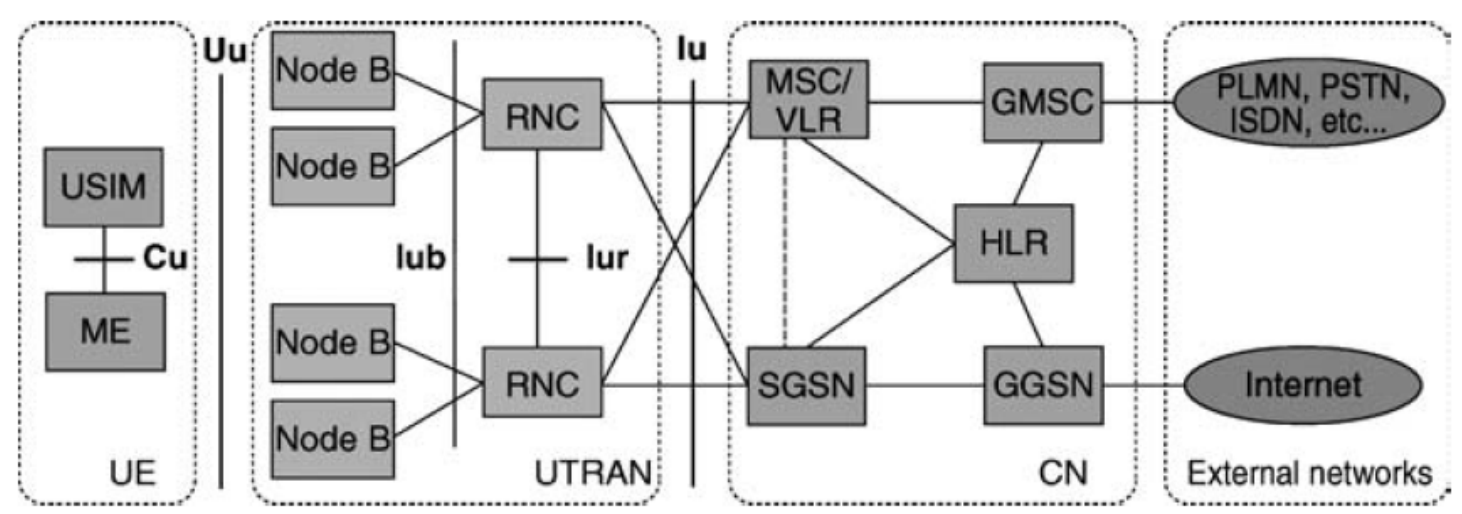

Figura A.2: Principais elementos da arquitetura UMTS [6]

\section{A.4.1}

\section{UE (User Equipment)}

O UE é o nome dado ao terminal móvel da rede UMTS. Ele funciona como interface entre a rede e o usuário e é composto, basicamente, de duas partes:

- ME (Mobile Equipement): é o aparelho eletrônico ou handset utilizado pelo usuário para realizar chamadas e utilizar todos os demais serviços oferecidos.

- USIM (UMTS Subscriber Identity Module): é o cartão inteligente que armazena os dados de cadastro do usuário com a operadora, executa algoritmos de autenticação e armazena chaves de autenticação e cifragem. É popularmente conhecido como o "chip" do aparelho.

\section{A.4.2}

\section{CN (Core Network)}

O CN é responsável por as funções de comutação e encaminhamento das chamadas de voz e de dados trafegados na rede, bem como da interligação dos elementos da própria rede e de sua conexão com redes externas. Seus principais elementos são:

- HLR (Home Location Register): é um banco de dados que armazena informações relativas ao perfil de assinatura do usuário como, por exemplo, informações e serviços cujo acesso seja autorizado ou áreas de roaming não autorizadas. 
- MSC / VLR (Mobile Services Switching Center/ Visit Location Register): O MSC trata de todas as operações de comutação de circuitos da rede. Já o VLR armazena temporariamente muitos dados que estão no HLR enquanto o usuário está no domínio daquele MSC. Este usuário é, portanto, um visitante (roaming) na rede definida pelo MSC. A parte da rede que é acessada através do MSC / VLR é chamada de domínio de comutação de circuitos (CS - Circuit Switching domain).

- GMSC (Gateway MSC): ponto em que a rede é conectada a redes externas de comutação de circuitos. Todas as comunicações, recebidas ou geradas, baseadas em comutação de circuitos, passam através do GMSC.

- SGSN (Serving GPRS Support Node): é a versão do MSC com a diferença de que atua no domínio de comutação de pacotes. Por isso, a parte da rede que é acessada através do SGSN é chamada de domínio de comutação de pacotes (PS - Packet Switching domain).

- GGSN (Gateway GPRS Support Node): é a versão do GMSC com a diferença de que atua no domínio de comutação de pacotes. Ou seja, ele age como um roteador gateway da subrede dos usuários.

\section{A.4.3 \\ UTRAN (UMTS Terrestrial Radio Access Network)}

O UTRAN é o que se chama genericamente de RAN (Radio Access Network). Ela trata de todas as funcionalidades da parte de rádio da interface aérea e é composto de dois elementos básicos: o RNC e o NodeB.

- NodeB: é o nome dado à estação radio base da rede UMTS.

- RNC (Radio Network Controller): realiza a gerência e o controle dos recursos de rádio de todos os NodeBs que fazem parte do seu domínio (RNS). Ele é a interface entre o UTRAN e o CN (núcleo) da rede.

$\mathrm{Na}$ verdade, o UTRAN pode ser formado por um ou mais RNSs (Radio Network Subsystem). Um RNS é uma subrede que consiste de um RNC e uma ou mais estações base (NodeBs) subordinadas as suas respectivas RNCs como mostra a Figura A.3 abaixo. Note-se também que os RNCs são conectados entre si 
através de uma interface chamada Iur, enquanto que NodeBs e RNCs são conectadas via interfaces Iub.

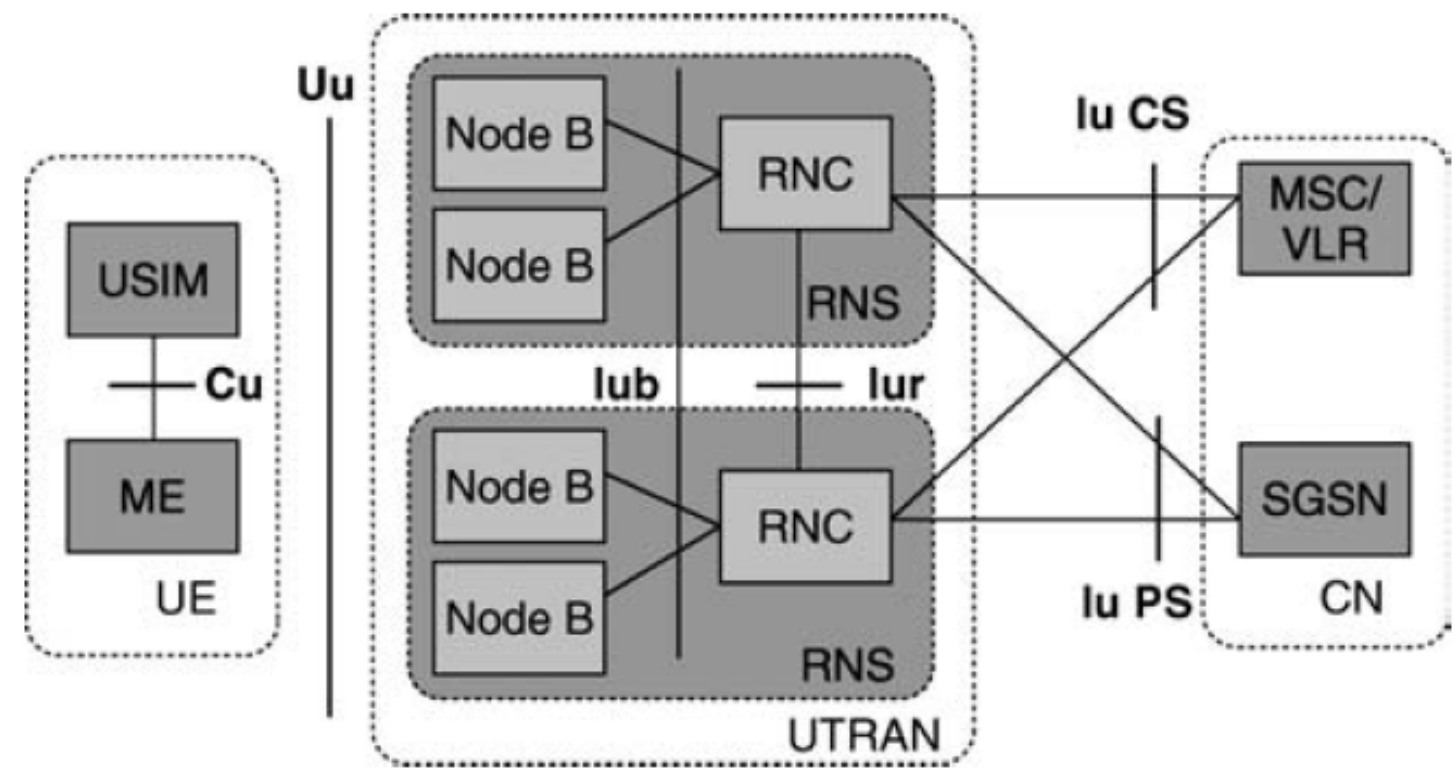

Figura A.3: O UTRAN e o RNS [6]

\section{A.5}

\section{Handover e gerência de mobilidade em nível de camada de enlace}

Devido à característica de sistemas CDMA em que todos os terminais compartilham a mesma faixa de frequências em toda a área de cobertura, podem ocorrer três tipos de handover, a saber [4,7].

- Hard Handover: é o processo de handover que ocorre quando duas estações radio-base ou operam em frequências diferentes, ou não estão sincronizadas. Este processo era comum em sistemas CdmaOne de segunda geração em terminais que operavam em dual mode quando estes realizavam a troca de canais entre sistemas CDMA digitais e o AMPS analógicos.

- Soft Handover: é o processo de handover que ocorre quando uma nova estação radio-base inicia a comunicação com um terminal enquanto este ainda não se desconectou da estação base atual. Isto é possível graças ao receptor RAKE, elemento comum em redes CDMA, que possibilita a combinação de até três componentes de sinal advindas de fontes 
diferentes. A combinação tanto do sinal de voz quanto de sinalização advinda das duas estações radio-base pode ser realizada no RNC ou em outro elemento de hierarquia superior na gerência de mobilidade (ver adiante conceito de mobility anchoring).

- Softer Handover: é o processo de handover que ocorre não entre duas estações radio-base distintas, mas entre dois setores de uma mesma estação radio-base. Neste caso, a própria estação base faz a combinação do sinal de voz e de sinalização.

Observando as definições acima, pode-se notar que o soft e o softer handover tornam o processo global de handover mais suave e confiável e, portanto, preferíveis sob este ponto de vista. Por outro lado, ao realizados em grande número, podem congestionar o sistema de sinalização da rede, implicando numa diminuição significativa na capacidade total do sistema [7].

Como já visto, o RNC realiza o controle dos recursos de rádio de todas ERBs (Estações Radio Base) vinculadas em seu domínio (RNS). Dentre elas, podem ser destacadas as seguintes funções:

- Alocação de Recursos de Radio: é realizada através do RRM (Radio Resource Management). Ele consiste em um sistema de estratégias e algoritmos que tem por finalidade otimizar o uso de toda infraestrutura de radio da rede pelo controle de parâmetros como potência de transmissão, taxa de dados, critérios de handover, controle de admissão de tráfego, agendamento de pacotes (packet scheduling),esquema de modulação, código de erros etc.

- Paging e tracking: são utilizadas para determinar o estado (ligado/desligado) e a posição de um usuário em um determinado grupo de células. O sistema envia mensagens ao terminal móvel através de um canal específico de controle, chamado canal de paging, avisando-o que existe uma chamada para ele.

- Mobilidade com um nó âncora (Mobility Anchoring): é a capacidade de redirecionar o fluxo de informação, de voz ou de dados, quando um terminal executa um soft handover. $\mathrm{O}$ elemento de rede que recebe primeiramente o tráfego e o redireciona para a ERB correta permanece 
imóvel (isto é, ancorado) enquanto o terminal se move em seu entorno (no caso, o RNS comandado pela RNC em questão).

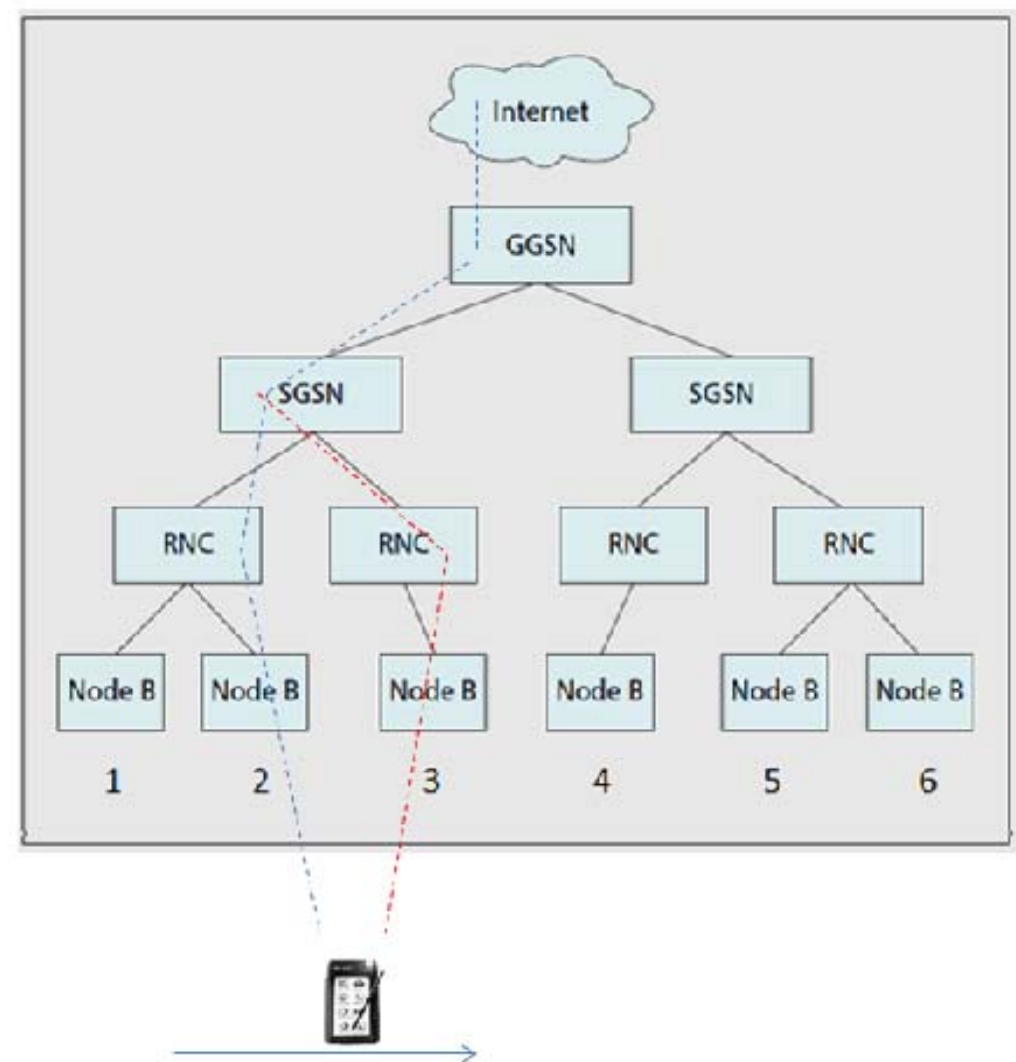

Figura A.4: Hierarquia na gerência de mobilidade com elemento âncora [8]

A Figura A.4 auxilia a compreensão do funcionamento da gerência de mobilidade na situação de um soft handover entre RNSs diferentes, isto é, entre as ERBs 2 e 3 que pertencem a subdomínios de RNCs diferentes. O elemento âncora, nesse caso, é o SGSN e, assim, inaugura-se um nível superior na gerência de mobilidade. Algo idêntico pode ocorrer com o GGSN. Dados oriundos da Internet são roteados para a rede UMTS através dele e, além de aplicar nos dados políticas relacionadas a QoS e accounting, ele também provê mobilidade como nó âncora ao roteá-los, através de um túnel, para o SGSN apropriado.

Portanto, de certa forma, algumas funcionalidades são executadas em múltiplos níveis de hierarquia da gerência de mobilidade além do mobility anchoring como o paging e o tracking [8]. 


\section{A.6}

\section{Principais melhorias: o HSPA e o HSPA+[4,6]}

O HSPA (High Speed Packet Access) é um par de protocolos de alta velocidade, o HSDPA (High Speed Downlink Packet Access) e o HSUPA (High Speed Uplink Packet Access), que ampliam e melhoram o desempenho dos protocolos do UMTS existentes. Um padrão subsequente, o Evolved HSPA, também conhecido como HSPA+, foi lançado no final de 2008 com posterior aprovação em todo o mundo em 2010.

\section{A.6.1}

\section{HSDPA (High Speed Downlink Packet Access)}

O HSDPA, também chamado $3.5 \mathrm{G}$ ou turbo $3 \mathrm{G}$, permite maior velocidade de transferência de dados e maior capacidade a redes baseadas no UMTS. Algumas implantações suportam velocidades de downlink (comunicação da ERB em direção ao MN) de 1,8 ; 3,6 ; 7,2 e 14 Mbps. Na especificação do 3GPP sobre o HSDPA, o release 5, foram incluídos o aumento das taxas de dados acrescentando-se modulação 16QAM, a utilização de modulação adaptativa (Fast Link Adaptation), diminuição no intervalo de transmissão (Short TTI Transmission Time Interval) de $10 \mathrm{~ms}$ para $2 \mathrm{~ms}$, agendamento rápido (Fast Scheduling) e requisição e repetição automática híbrida (HARQ - Hybrid Automatic Repeat reQuest).

\section{A.6.2}

\section{HSUPA (High Speed Uplink Packet Access)}

O HSUPA segue os passos do HSDPA para aperfeiçoamento do enlace de uplink (comunicação do MN em direção à ERB). Dessa forma, ele implanta mecanismos semelhantes aos do HSDPA. O 3GPP não reconhece o acrônimo HSUPA, por isso utiliza o nome Enhanced Uplink em seu release 6. O nome é oriundo do novo canal criado, o E-DCH ou Enhanced Dedicated Channel, o qual é o responsável pela implementação das melhorias. 


\section{A.6.3}

\section{Evolved HSPA ou HSPA+}

O Evolved HSPA, também conhecido como HSPA+, é um padrão de banda larga sem fio definido pelo 3GPP no release 7. Ele oferece taxas de até 56 Mbps no downlink e 22 Mbps no uplink, utilizando tecnologia de antenas MIMO (Multiple Input Multiple Output) e modulação de ordem superior de 64QAM. As antenas MIMO atuam como setores virtuais que proveem capacidade extra. As taxas de 56 Mbps e 22 Mbps representam velocidades de pico teóricas por setor da célula.

O HSPA+ introduz também uma arquitetura totalmente IP (ou all IP) para redes cujas estações base estejam diretamente ligadas a um backhaul baseado em IP e, em seguida, sejam conectadas a roteadores de borda de um ISP (Internet Service Provider). A tecnologia também oferece melhorias significativas na duração da bateria e uma dramática rapidez no tempo de transição entre os estados de operação e não operação (Wake-from-Idle Time), proporcionando um verdadeiro estado de constante conexão (always-on connection).

Um fato importante a ressaltar é que o HSPA+ não deve ser confundido com o LTE. Este último, que será brevemente exposto no próximo tópico, utiliza uma nova interface aérea, ao passo que o HSPA+ não rompe com a interface aérea de origem do UMTS. De fato, o HSPA+ foi desenvolvido em paralelo com a primeira especificação do LTE de modo a ser uma espécie de especificação de transição. Em novembro de 2009, havia vinte redes HSPA+ à taxa de 21 Mbps e duas a $28 \mathrm{Mbps}$ em operação no mundo. O primeiro lançamento foi da Telstra, operadora Australiana, na Austrália no final de 2008, com acesso em toda a Austrália em fevereiro de 2009 e com velocidades de até 21 Mbps.

\section{A.7}

\section{A evolução do UMTS: o LTE (Long Term Evolution) [6]}

Na exposição inicial da evolução das redes 3GPP em direção ao LTE será necessário enxergar a arquitetura de rede de uma maneira ligeiramente diferente da apresentada anteriormente. Desta forma, a atenção será voltada aos principais elementos do UMTS, agora, sob um segundo ponto de vista da arquitetura de 
rede. Esta segunda maneira de se visualizar a rede consiste na separação dela em duas partes lógicas chamadas de Plano de Controle e Plano do Usuário cujos detalhes são tratados no apêndice B onde será feita a análise de uma arquitetura de rede sem fio genérica.

\section{A.7.1}

\section{Considerações sobre evolução para uma arquitetura plana}

Dada a tendência atual das comunicações, as redes 3GPP caminham na direção de oferecer serviços totalmente baseados no protocolo IP. O release 6 do 3GPP define quatro elementos de rede no Plano de Controle e do Usuário que são o NodeB, o RNC, o SGSN e o GGSN. Em contrapartida, o LTE, cuja primeira especificação é o release 8 do $3 \mathrm{GPP}$, terá somente dois elementos principais: a estação radio base, chamada de eNodeB, na interface de aérea e um gateway de acesso, chamado a-GW, no núcleo de rede. Essa mudança é o que configura a planificação da arquitetura de rede. Uma arquitetura plana reduz a latência na rede conseguindo, assim, uma melhoria na eficiência de serviços baseados no IP, bem como nas funcionalidades dos Planos de Controle e do Usuário.

A introdução do HSPA e do HSPA+ já deram um passo na direção da planificação da arquitetura. Algumas funcionalidades foram transferidas do RNC para o NodeB.

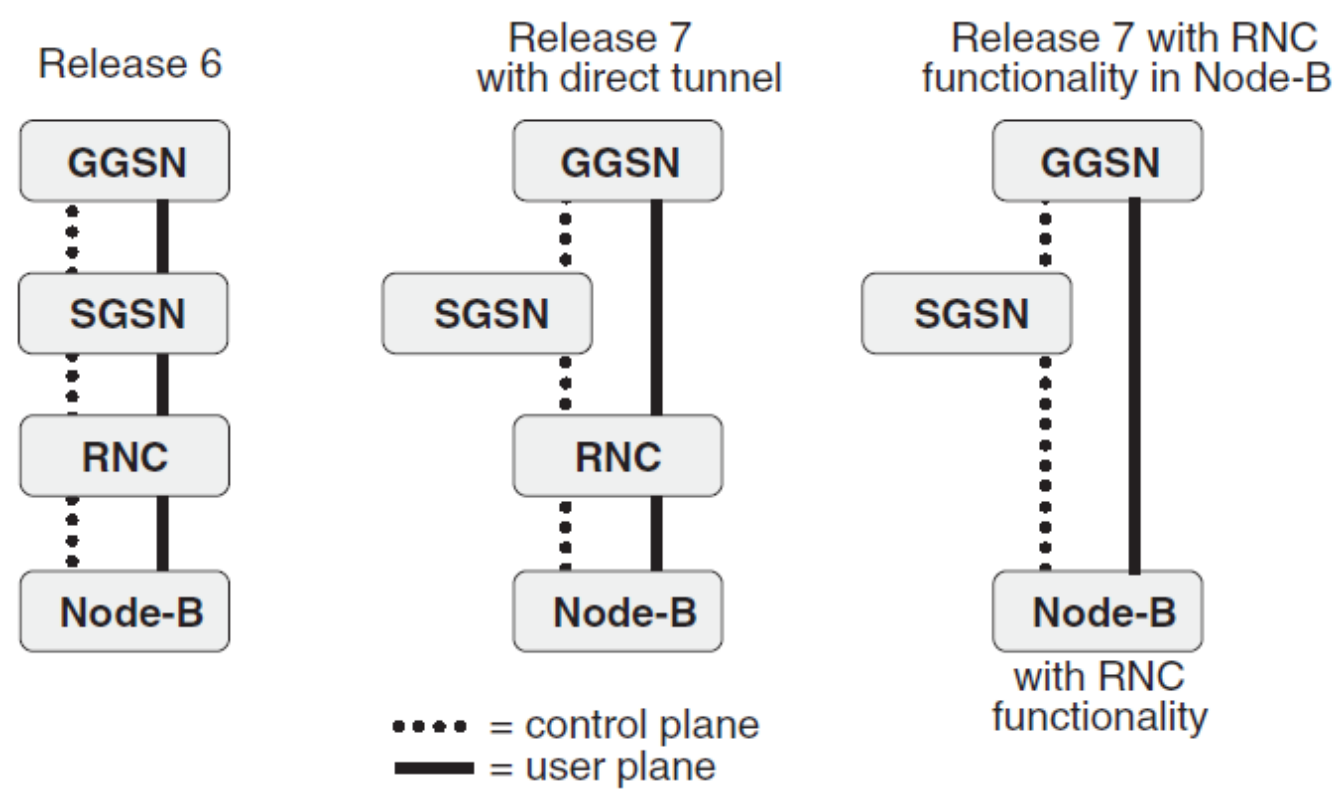

Figura A.5: Processo de planificação da arquitetura [6] 
No release 6, percebe-se a hierarquia na gerência de mobilidade em seu aspecto original do UMTS. Já no release 7, a solução através de um túnel de comunicação com a RNC diretamente permitiu um bypass do SGSN , isto é, uma passagem direta na comunicação entre o GGSN e o NodeB. O passo seguinte se dá na integração das funcionalidades do RNC como parte dos NodeBs.

\section{A.7.2}

\section{Características gerais}

\section{A.7.2.1}

\section{Método de acesso OFDMA}

O método de acesso OFDMA (Ortogonal Frequency Division Multiple Access) apresenta vários benefícios quando comparada a CDMA na medida em que se aumenta a largura de banda disponível para cada usuário: o sinal OFDMA permanece ortogonal enquanto que o CDMA sofre devido a efeitos de multipercurso e possui um processo complexo no que diz respeito à equalização no receptor. O OFDMA tem como base a multiplexação OFDM. Ela será vista com maiores detalhes no tópico A.10.3.

\section{A.7.2.2 \\ Arquitetura plana e agendamento de pacotes no domínio da frequência}

Com a planificação da arquitetura, pode-se alocar as funcionalidades de agendamento de pacotes de maneira muito mais rápida, pois passam a funcionar diretamente nos NodeBs, além de poderem operar no domínio da frequência graças a OFDM. O agendamento no domínio da frequência, que não pode ser feito com o CDMA, tem uma melhoria de cerca de 50\% quando comparado com o agendamento no domínio do tempo. 


\section{A.7.2.3}

\section{Aplicação da tecnologia de antenas múltiplas}

A implantação da tecnologia de antenas MIMO (Multiple Input Multiple Output) é enormemente facilitada quando empregada com o OFDMA ao invés do CDMA. Dessa forma, altas taxas de transmissão podem ser alcançadas através da possibilidade de uma maior largura de banda que as antenas MIMO oferecem.

\section{A.7.2.4}

\section{Mudança de paradigma: comutação de pacotes na interface aérea}

O LTE foi projetado para ser um sistema multiserviço completamente orientado a pacote, não contando com a confiabilidade de circuitos comutados de seus predecessores. Esta filosofia é aplicada através das camadas da própria pilha de protocolos do LTE. Para melhorar a latência do sistema, foi determinado que a duração de um quadro fosse reduzida de $2 \mathrm{~ms}$ (utilizada no HSDPA) para $1 \mathrm{~ms}$. Este pequeno intervalo de transmissão, junto com novas dimensões de frequência e de espaço, estenderá ainda mais a ação conjunta entre as camadas MAC e física. Essa mudança adicionada com as outras características podem ser resumidas da seguinte forma:

- Gerenciamento adaptativo no domínio da frequência e do espaço;

- Adaptação de configuração MIMO, incluindo seleção do número de "camadas" espaciais transmitidas simultaneamente;

\section{A.7.3}

\section{Arquitetura de rede}

\section{A.7.3.1}

\section{SAE (System Architecture Evolution)}

Enquanto o termo Long Term Evolution abrange a evolução da rede de radio acesso UTRAN (UMTS Terrestrial Radio Access Network) para o chamado Evolved-UTRAN, ou simplesmente E-UTRAN, há também uma evolução dos aspectos não ligados a tecnologias de núcleo (core) de rede conhecido por SAE 
(System Architecture Evolution). O SAE inclui o core do LTE chamado de EPC (Evolved Packet Core). O E-UTRAN, juntamente com o SAE, forma o EPS (Evolved Packet System).

O EPS utiliza o conceito de EPS bearers para rotear o tráfego IP de um gateway localizado em uma PDN (Packet Data Network - rede de pacotes qualquer) até um UE (User Equipment). Um bearer é um fluxo de pacotes IP com um nível definido de QoS. O E-UTRAN e o EPC juntos estabelecem e encerram bearers de acordo com as necessidades das aplicações.

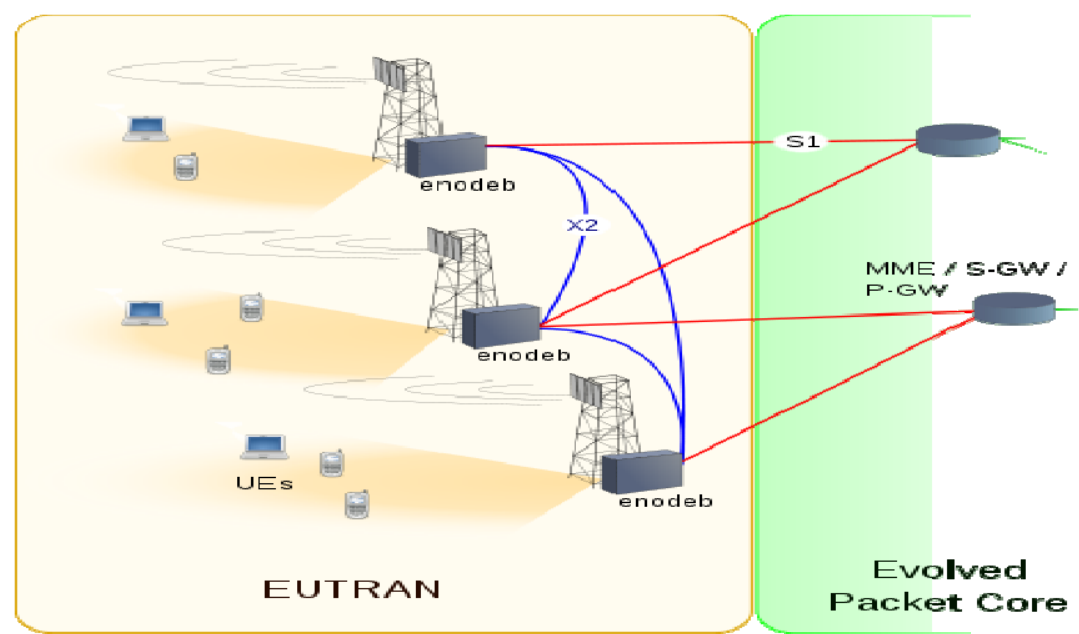

Figura A.6: Visão geral da arquitetura do LTE [55]

\section{A.7.3.2 Interface aérea: a EUTRAN ou Evolved UTRAN}

O E-UTRAN consiste apenas de eNodeBs no lado da rede de acesso. Ele combina as tarefas realizadas pelo RNC (Radio Network Controller) e pelo NodeB na comparação com a rede de rádio acesso do UMTS. Esta simplificação reduz a latência de todas as operações de interface de rádio. Os eNodeBs estão conectados uns aos outros através da interface X2 e se conectam ao EPC através da interface $\mathrm{S} 1$ como mostra a Figura A.6.

Para tráfego normal (isto é, tráfego não broadcast), não há nenhum controle centralizado no E-UTRAN. Por isso, a arquitetura de rede do E-UTRAN é dita plana. Os protocolos utilizados entre o eNodeB e o UE são chamados de protocolos Access Stratum (AS Protocols). 


\section{A.7.3.3}

\section{Núcleo de rede ou EPC (Evolved Packet Core)}

Como o sistema LTE foi projetado para oferecer somente acesso a serviços orientados a pacote, sua concepção foi baseada na ideia de prover conectividade entre usuários de uma PDN (Packet Data Network) qualquer através do protocolo IP sem nenhuma perturbação perceptível aos usuários finais, principalmente durante sua mobilidade.

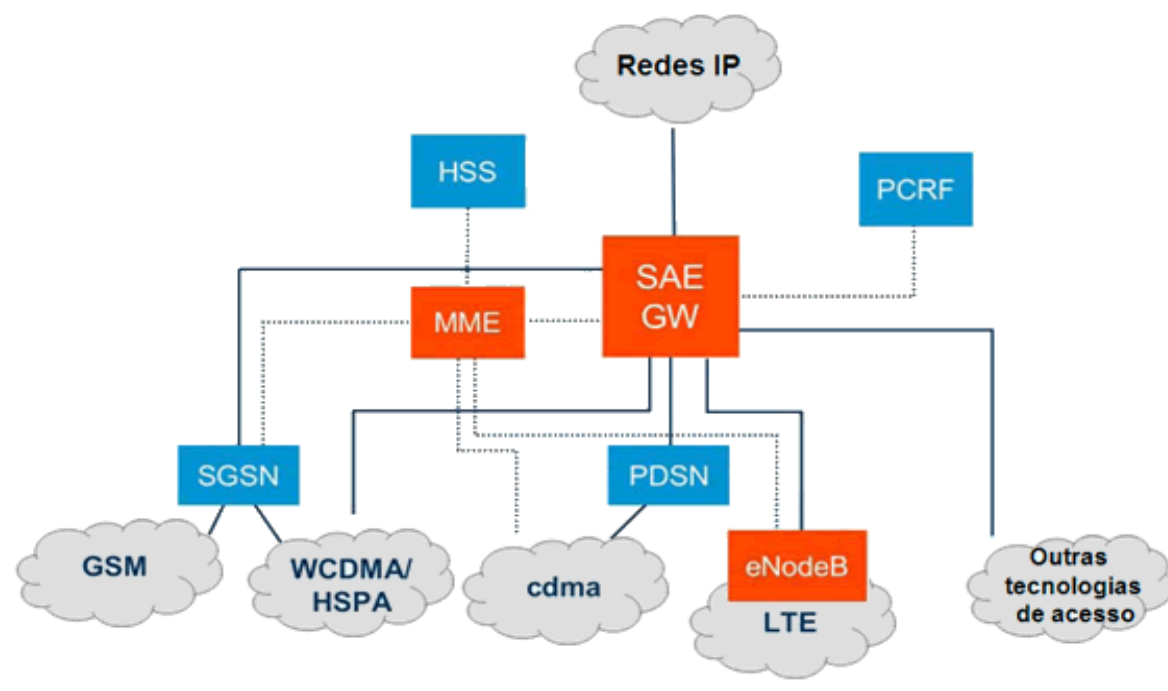

Figura A.7: Principais elementos do EPC [55]

\section{A.8}

\section{Os padrões IEEE 802}

O IEEE (Institute of Electrical Engineers) é a maior associação profissional do mundo. Ele se dedica à inovação tecnológica avançada e excelência em benefício da humanidade [9]. Entre suas atividades está a elaboração de padrões para o setor de telecomunicações.

O IEEE produziu a série de padrões designados como IEEE 802 abrangendo inicialmente LANs (Local Area Networks) e MANs (Metropolitan Area Networks) e, mais recentemente, PANs (Personal Area Networks) [4]. Esta família de padrões limita-se a padronizar processos e procedimentos referentes às duas camadas inferiores do modelo OSI (Open System Interconnetion) de referência. Esta relação é mostrada na Figura A.8 abaixo. 


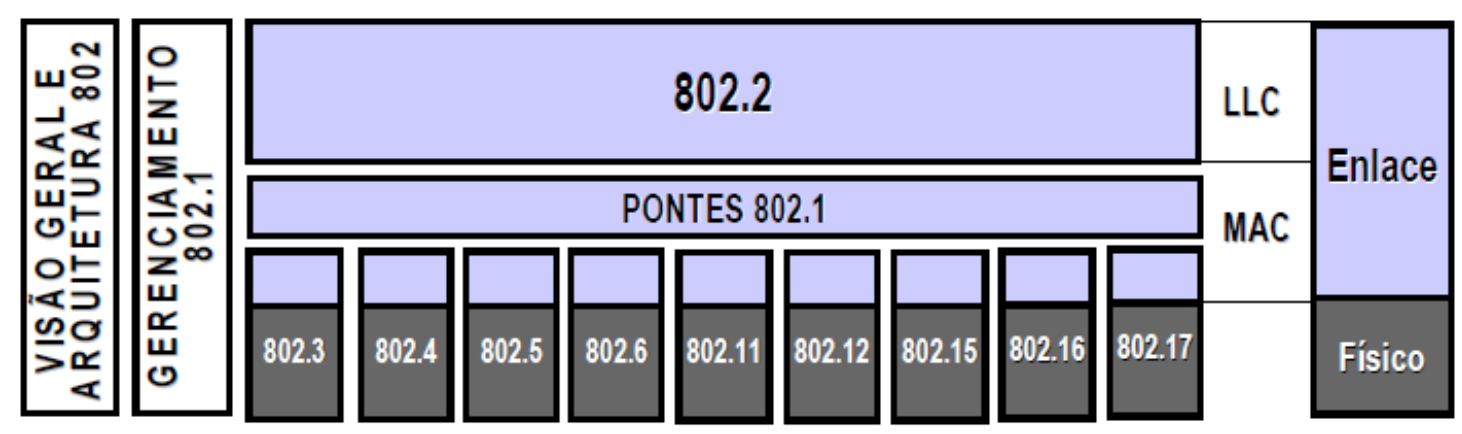

Figura A.8: Escopo dos padrões IEEE 802 comparados ao modelo OSI [4]

No modelo IEEE 802, a camada de enlace é subdividida em duas subcamadas: a LLC (Logic Link Control) e a MAC (Media Access Control).

O comitê encarregado da padronização, denominado IEEE 802 LAN/MAN Standards Commitee, é dividido em grupos de trabalho, chamados WG (Working Groups), cujos temas são altamente específicos. Por exemplo, o WG 802.1 cria padrões relacionados à segurança e o 802.2 referentes à LLC que se aplicam tanto a redes sem fio e cabeadas.

Nesta dissertação, a atenção se volta especialmente para os padrões desenvolvidos pelo WG 802.11, que desenvolve padrões para redes locais sem fio ou WLANs (Wireless Local Area Network) e para o WG 802.16 voltado para as redes sem fio metropolitanas ou WMANs (Wireless Metropolitan Area Network).

\section{A.9 \\ O padrão 802.11}

\section{A.9.1}

\section{Histórico e características gerais}

Presentes nos locais de trabalho, em casa, em instituições educacionais, cafés etc., as WLANs são uma das mais importantes tecnologias de acesso à Internet hoje em dia. Embora muitas tecnologias de rede sem fio tenham aparecido na década de 1990, o padrão 802.11, mesmo sendo inicialmente desenvolvido para o mercado corporativo, teve uma penetração impressionante. A redução nos custos de equipamentos associada às maiores taxas de transmissão conseguidas, fizeram com que sua aplicação se estendesse também às redes 
domésticas. Assim, o padrão 802.11 tornou-se uma solução de baixo custo e elevada eficiência [4].

Existem, basicamente, quatro padrões dominantes das redes 802.11. A tabela a seguir apresenta um resumo de suas principais características.

Tabela A.2: Padrões IEEE 802.11

\begin{tabular}{|l|l|l|l|l|}
\hline Padrão & Faixa de frequência & Taxa de transmissão & Modulação & Largura de banda \\
\hline $802.11 \mathrm{~b}$ & $2,4-2,485 \mathrm{GHz}$ & até $11 \mathrm{Mbps}$ & QPSK & $20 \mathrm{MHz}$ \\
\hline $802.11 \mathrm{a}$ & $5,1-5,8 \mathrm{GHz}$ & até $54 \mathrm{Mbps}$ & FSK (OFDM) & $20 \mathrm{MHz}$ \\
\hline $802.11 \mathrm{~g}$ & $2,4-2,485 \mathrm{GHz}$ & até $54 \mathrm{Mbps}$ & QPSK e FSK (OFDM) & $20 \mathrm{MHz}$ \\
\hline $802.11 \mathrm{n}$ & 2,4 ou $5 \mathrm{GHz}$ & até $150 \mathrm{Mbps}$ & QAM-64(OFDM) & de 20 a $40 \mathrm{MHz}$ \\
\hline
\end{tabular}

\section{A.9.2}

\section{Arquitetura de rede e modos de operação da camada MAC [4, 49]}

O padrão 802.11 define apenas a subcamada MAC referente à camada de enlace. Foram definidos dois tipos de controle de acesso, um síncrono e outro assíncrono. A topologia da rede depende do controle de acesso escolhido assim como o modo de operação da camada MAC [4].

O controle é dito assíncrono quando as estações móveis se comunicam diretamente uma com as outras sem necessidade de uma entidade central de coordenação de tráfego, isto é, sem a presença de uma estação radio base. Esse modo de operação é chamado de modo ad-hoc e o controle de acesso assíncrono é realizado por uma função de coordenação distribuída, a DCF (Distribute Coordination Function), que, como o próprio nome sugere, funciona de forma distribuída, ou seja, em cada uma das estações móveis.

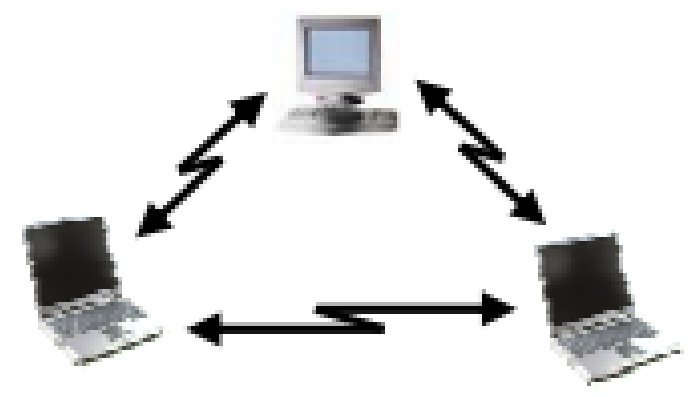

Figura A.9: Topologia de rede em modo ad-hoc [4] 
Nesta topologia, a área de cobertura da rede é chamada de IBSS (Independent Basic Service Set) como mostra a Figura A.9.

Já o controle síncrono acontece quando as estações móveis só se comunicam através de uma estação radio base que, na terminologia 802.11, é chamado de AP (Access Point). Esse modo de operação é chamado de modo Infraestrutura e o controle é realizado a partir de uma função chamada PCF (Point Coordination Function) que, basicamente, implementa um polling como método de acesso.

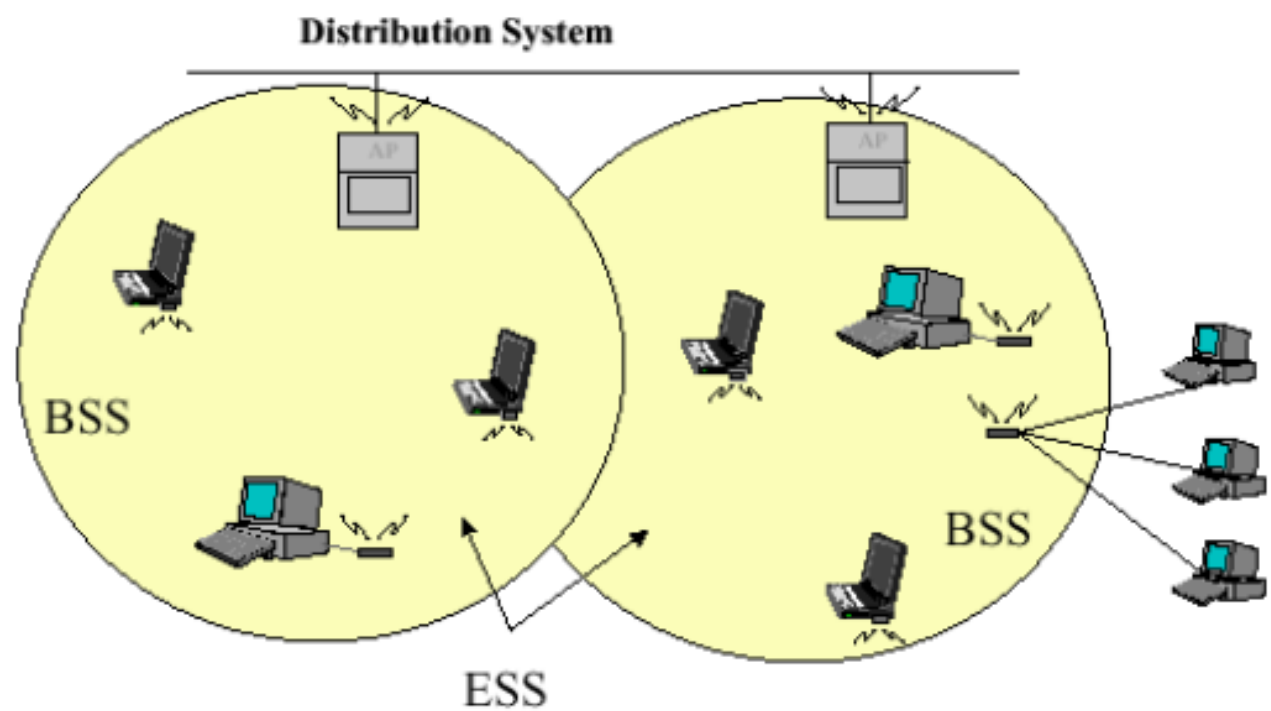

Figura A.10: Topologia de rede em modo infraestrutura [7]

A área de cobertura na topologia infraestrutura é chamada de BSS (Basic Service Set) como se vê na Figura A.10. Um conjunto de duas ou mais BSSs é chamado de ESS (Extended Service System) e é obtido através da interligação de vários APs em cadeia. Em termos práticos, uma ESS compreende toda a extensão física onde a WLAN funciona. A comunicação entre os APs é feita, geralmente, por uma rede Ethernet, porém pode ser utilizada outra rede qualquer, inclusive uma sem fio como a WiMax. A rede de comunicação entre os APs é designada genericamente de DS (Distribution System). 


\section{A.9.2.1 \\ DCF (Distribute Coordination Function)}

A DCF utiliza a técnica de acesso CSMA/CA (Carrier Sense Multiple Access with Collision Avoidance). É um meio de acesso sem prioridade em que uma estação que deseja transmitir "escuta" o meio, isto é, tenta detectar a presença de alguma portadora nele antes de iniciar sua transmissão evitando, assim, colidir com uma alguma transmissão que já esteja em curso. A diferença para o CSMA/CD das redes cabeadas é que, no CSMA/CA a colisão é evitada, ao passo que no CSMA/CD ela só pode ser detectada [49].

A detecção de portadora, na verdade, é realizada de forma integrada gerando uma dependência cross-layer [14]. O CCA (Clear Channel Assessment) checa a atividade do canal em nível físico. O padrão 802.11 tem como obrigatória a implementação do CCA.

Na camada de enlace, realizada pelo CSMA/CA, a detecção de portadora utiliza um mecanismo chamado NAV (Network Allocation Vector). O NAV é um contador decrescente que, enquanto não for igual a zero, indica que o meio está ocupado. Todas as estações móveis configuram, em microssegundos, seu NAV a partir do valor do campo duração do quadro 802.11 que será visto posteriormente. Por esse motivo, o NAV é chamado de mecanismo de detecção virtual de portadora ou Virtual Carrier Sensing.

Caso uma estação tenha um quadro para transmitir e ela perceba que o meio está livre (isto é, o NAV é igual a zero), ela transmitirá seu quadro após um intervalo de tempo aleatório conhecido como backoff time. A probabilidade de duas estações móveis transmitirem simultaneamente após os seus respectivos NAVs zerarem é bastante considerável e o backoff time evita colisões de tal natureza. A probabilidade de colisão com sua utilização é reduzida a valores bem próximos de zero.

Além do backoff time, uma estação ainda espera um intervalo de tempo não aleatório chamado DIFS (Distributed Interframe Spacing) para transmitir. Caso o meio esteja ocupado, a estação adiará a transmissão novamente por um backoff time. 
Uma vez que a estação recebe um quadro, ela espera um curto intervalo de tempo, chamado SIFS (Short Interframe Spacing), para enviar um quadro de reconhecimento (quadro ACK).

Uma implementação opcional do padrão utiliza um esquema de quadros especiais chamados de RTS/CTS (Request to Send/Clear to Send). Este esquema foi criado para resolver problemas típicos de redes em modo ad-hoc como o problema da estação exposta (Exposed Station Problem) e da estação escondida (Hidden Station Problem). Entretanto, em [11] vê-se que, além de não resolver estes problemas totalmente, este esquema ainda cria outros problemas, como o da estação sufocada (Gagged Station Problem), que consiste em impedir transmissões que, em princípio, seriam bem sucedidas.

\section{A.9.2.2 \\ PCF (Point Coordination Function)}

O PCF é uma função opcional construída sobre o DCF e implementada através de um mecanismo de acesso ordenado ao meio que proporciona a oportunidade de transmitir sem contenção, ou seja, há prioridade no acesso ao meio. Ele utiliza o AP como um coordenador central cuja função é acessar as estações ciclicamente, como um polling, dando-lhes a oportunidade de transmitir através da divisão do tempo de acesso em períodos de superquadros. Cada superquadro corresponde a um período livre de contenção, chamado CFP (Contention Free Period) em que a função operante é a PCF e um período com contenção, chamado CP (Contention Period) em que a função operante passa a ser a DCF [12].

Quando o AP ganha o controle do CFP, ele tenta manter este controle pelo período inteiro, pois uma estação no modo PCF, aguarda um tempo menor para transmitir do que estações utilizando o modo DCF. Este intervalo, pouco menor que um DIFS e maior que um SIFS, é chamado PIFS (PCF Interframe Spacing). 


\section{A.9.3}

\section{Formato dos Quadros da camada MAC 802.11}

A Figura A.11 mostra o quadro utilizado na 802.11. Na parte inferior, há um detalhamento do campo de Controle do quadro. Os números acima dos campos representam o seu comprimento em bytes $[10,13,50]$.

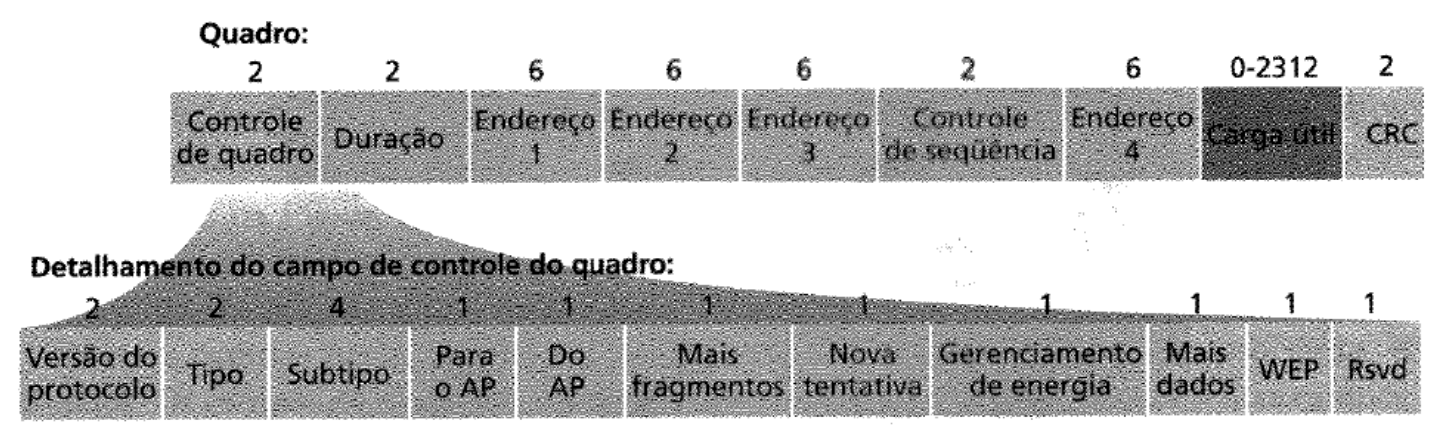

Figura A.11: Quadro 802.11 e seu campo de controle [10]

- CRC (Cyclic Redundant Check): A verificação de redundância cíclica existe para que o receptor possa detectar erros de bits no quadro recebido.

- Carga útil: é onde fica o pacote IP oriundo da camada de rede. Normalmente, tem o tamanho de 1500 Bytes mesmo tendo capacidade superior.

- Duração: corresponde ao tempo necessário de transmissão do quadro. As estações móveis atualizam seu NAV com este valor para saber quanto tempo o meio estará ocupado transmitindo este quadro.

- Controle de sequencia: número de sequencia do quadro (ou do fragmento: ver campo de controle) para fins de reconhecimento de duplicação.

- Endereço 1: endereço MAC da estação de destino do quadro.

- Endereço 2: endereço MAC da estação de origem do quadro.

- Endereço 3: endereço MAC do próximo elemento de rede que receberá o quadro. Utilizado para a interconexão de um BSS com um LAN cabeada. 
- Endereço 4: endereço MAC do último elemento que transmitiu o quadro. Utilizado em modo ad-hoc.

Sub campos do campo do controle:

- Tipo: define se o quadro é de gerência, de controle ou de dados.

- Subtipo: existem vários subtipos dependendo do tipo do quadro. Exemplos: associação, RTS, CTS ou ACK.

- Mais fragmentos: indica se há mais fragmentos do quadro.

- Nova tentativa: indicas se quadro é ou não uma retransmissão.

- Gerenciamento de energia: indica se estação está em modo ativo ou em modo de economia de energia.

- Mais dados: indica se uma estação em modo de economia de energia tem mais quadros para enviar.

- WEP: indica se a criptografia WEP está sendo utilizada.

- Rsvd: indica se todos os quadros de dados recebidos devem ser processados em ordem.

\section{A.9.4}

\section{Tipos de quadro e aspectos da gerência de mobilidade}

O padrão IEEE 802.11 apresenta três tipos básicos de quadros [7]:

- Quadros de dados: são quadros que transportam efetivamente os dados sem a existência de informações de sinalização ou controle da rede.

- Quadros de controle: são os quadros que atuam realizando algum tipo de controle ou ordenação do envio dos quadros entre os nós. Constituem exemplos os quadros RTS, CTS, ACK (confirmação).

- Quadros de gerência: são quadros que desempenham funções bem específicas dependendo do elemento de rede em questão.

No que tange à gerencia de mobilidade, os quadros de gerência desempenham um papel de suma importância. Isso se deve ao fato de que, devido a concepção original do padrão ser de amplitude local, o IEEE 802.11 não apresenta uma gerência de mobilidade tão sofisticada e complexa como a das 
redes UMTS. A seguir, são vistos alguns tipos de quadros de gerência em que alguns aspectos da gerência de mobilidade podem ser observados:

- Quadro de Beacon: é um quadro de anúncio de características importantes da rede sem fio. O AP envia este quadro periodicamente de forma a orientar os terminais em seu entorno sobre, por exemplo, sincronização do tempo (importante em redes que operam em FHSS), taxas de transferência suportadas e o SSID (Service Set Identifier). O SSID é um identificador da rede. Seu valor é único e pode conter até 32 caracteres alfanuméricos [22].

- Quadro de associação: enviado quando a WNIC (Wireless Interface Network Card) de uma estação deseja se conectar a um AP. Isso pressupõe que a estação tenha identificado o SSID da rede ou já o conheça de antemão. Após verificações de identidade, trocas de chaves précompartilhadas e de autenticação, o AP pode aceitar ou negar a solicitação. Ao aceitar a solicitação, o AP já inicia o processo de sincronização e de alocação de recursos para a nova estação. Cada estação só pode se associar a um único AP por vez.

- Quadro de desassociação: enviado por uma estação ou por um AP para terminar uma associação, ou seja, terminar sua conexão. Como se trata de uma notificação, não pode ser recusada. As estações devem se desassociar quando saírem da rede. Por exemplo, um AP pode desassociar todas as suas estações por necessidade de manutenção.

- Quadro de requisição de reassociação: uma estação envia este quadro quando percebe que está saindo do seu BSS atual e encontra outro AP com um sinal mais forte.

- Quadro de resposta de reassociação: enviado por um AP que recebeu um quadro de requisição de reassociação contendo a recusa ou a aceitação do pedido. Neste quadro, caso a solicitação seja aceita, também são informados o ID de associação e as taxas suportadas pelo AP. 
Em [15], vê-se que o controle geral dos quadros de gerência é realizado por dois protocolos chamados de Rápida Transição (FT - Fast Transition Protocols). Eles são responsáveis por gerenciar e reduzir a latência de desconexão que ocorre quando uma estação muda de um BSS para outro e só se aplicam a transições entre APs que pertençam a um mesmo domínio ESS.

O FT Protocol é executado quando não se faz necessária uma alocação prévia de recursos no AP alvo. Já o FT Resource Request protocol é executado quando uma alocação prévia se faz necessária [51].

Existem duas maneiras nas quais os protocolos de rápida transição efetuam a sinalização entre os APs envolvidos, isto é, a troca de quadros de gerência. Ela pode ser feita via interface aérea ou através do DS. Nesta segunda forma, os quadros são chamados de quadros de ação e possuem um tipo específico de encapsulamento em nível de enlace.

\section{A.9.5}

\section{Classes de QoS e o padrão 802.11e}

Além dos padrões IEEE 802.11 já mencionados, existem outras especificações que constituem um conjunto de extensões e suplementos não obrigatórios mas que podem ser adotados pelo fabricante dos elementos de rede. Tudo depende do destino, uso e qualidade desejados para o equipamento [4]. Algumas delas estão presentes na Figura A.12: 


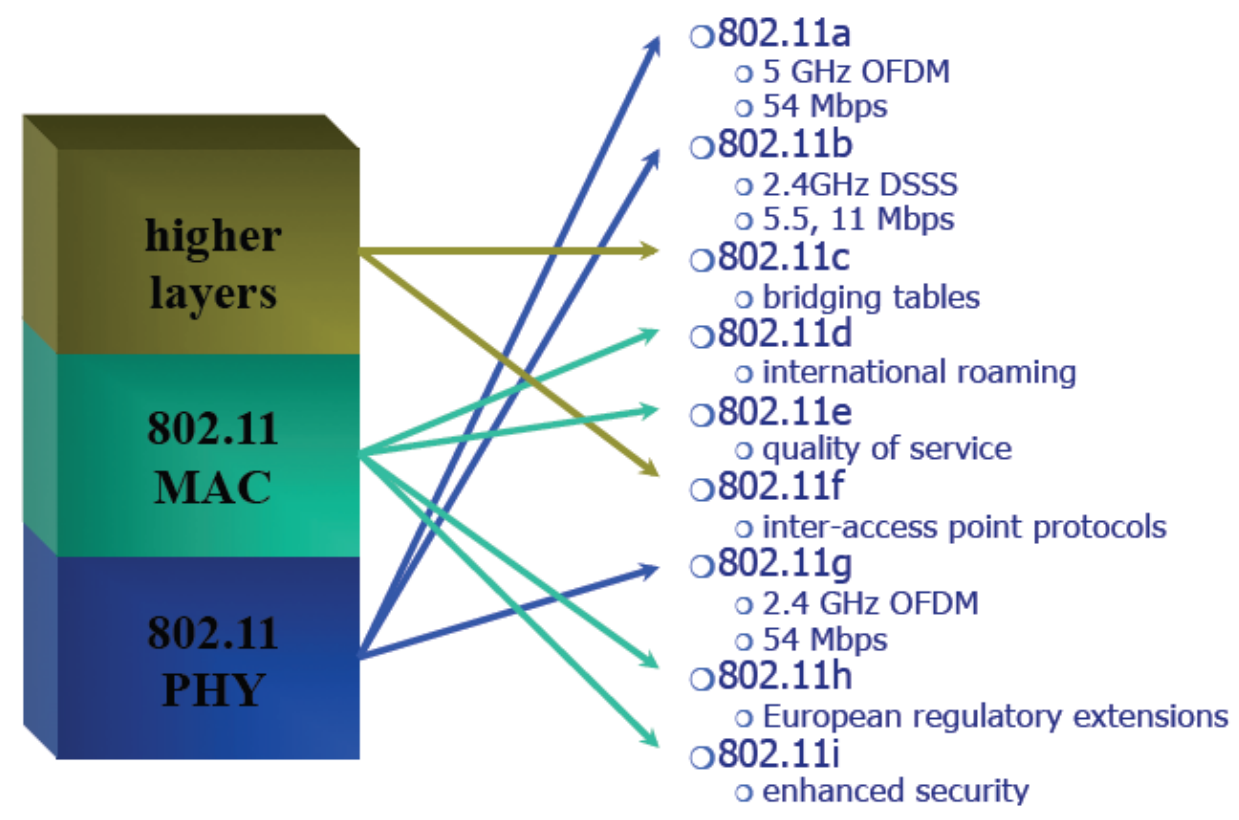

Figura A.12: Outras especificações IEEE 802.11 [7]

Dentre eles, destaca-se o padrão 802.11e que agrega QoS às redes IEEE 802.11. Ele permite a transmissão de diferentes classes de tráfego ao implementar uma nova função chamada HCF (Hybrid Coordination Function) [12]. O HCF cria dois novos mecanismos de suporte de QoS chamados EDCA (Enhanced Distributed Channel Access) e o HCCA (HCF Controlled Channel Access) $[12,13]$.

\section{A.9.5.1}

\section{EDCA (Enhanced Distributed Channel Access)}

O EDCA trata o tráfego baseando-se em diferentes prioridades de usuário. Os níveis de prioridade são chamados de AC (Access Categories). As ACs podem ser construídas levando-se em conta os seguintes aspectos:

- O intervalo de tempo em que uma estação identifica o canal como ocioso antes de um backoff time ou transmissão ou;

- O tamanho da janela de contenção a ser usada no backoff time ou;

- A duração de tempo concedido a uma estação para transmissão.

O EDCA provê um acesso livre de contenção ao canal por um período chamado TXOP (Transmission Oportunity). Ele corresponde a um intervalo limitado de tempo no qual uma estação pode enviar o máximo de quadros que 
puder contanto que a duração total dos quadros não exceda o tempo TXOP. Se o quadro é longo demais para ser transmitido em um único TXOP, executa-se sua fragmentação em quadros menores. O TXOP procura minimizar o desperdício que ocorre com a DCF que permite que estações cuja taxa de transferência são baixas ocupem o canal por muito tempo.

\section{A.9.5.2}

\section{CCA (HCF Controlled Channel Access)}

O HCCA tem seu funcionamento parecido com o da PCF, porém distingue-se no fato de que permite que um CFP seja iniciado a qualquer momento, inclusive durante um CP. Esse CFP recebe o nome de fase de acesso controlado ou PAC (Phase Controlled Access) e é utilizado para quando o AP deseja enviar ou receber um quadro de uma maneira livre de disputa com outro terminal. Durante um PAC, o AP possui controle total sobre o meio. Fora dele (em um CP), todas as estações funcionam na função EDCA.

Outra particularidade é que as classes de tráfego e seus fluxos são bem definidos. Isto é, o AP pode coordenar esses fluxos e sessões da forma que desejar. Além disso, as estações informam ao AP sobre a condição de suas filas para cada classe de tráfego e essa informação é utilizada para dar prioridade a uma estação sobre outras.

A HCCA é considerada a mais avançada e complexa função de coordenação, porém consegue configurar o QoS com grande precisão.

\section{A.9.6}

\section{Cálculo de banda residual com o auxílio da especificação $802.11 e$}

Uma estimativa importante que se pode realizar com o auxílio da especificação 802.11e é a de banda residual ou RB (Residual Bandwidth) em uma WLAN IEEE 802.11. O valor de RB é calculado através da seguinte expressão aproximada retirada de [21]:

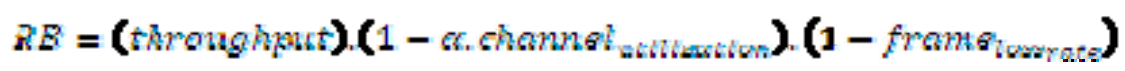


O valor throughput na fórmula acima é definido como o valor real da vazão que compõe o padrão da WLAN. Por exemplo, este valor seria 6 Mbps em uma $802.11 b$.

Os dois próximos valores da expressão, frame_loss_rate e channel_utilization, são obtidos do campo QBSS (QoS Basic Service Set) inserido no quadro de beacon pelo padrão 802.11e.

- frame_loss_rate: este valor representa a parte dos MPDUs (MAC PDUs) que precisaram ser retransmitidos ou foram considerados como mal sucedidos em sua entrega. Ou seja, na prática, representam um percentual da banda que foi desperdiçado (a banda foi utilizada, mas perdida).

Portanto, o fator (1 - frame_loss_rate) representa a fração ainda disponível da banda.

- channel_utilization: representa a fração do tempo em que cada estação "escuta" o meio sendo utilizado uma através do NAV.

O valor representado por $\alpha$ reflete o "overhead" inserido, medido em períodos de tempo, que o método de acesso utiliza para prevenção de colisões (backoff time, DIFS, SIFS, PICS etc.). Em outras palavras, representa o valor que reflete a sinalização (MAC signaling overhead) do 802.11.

A partir de resultados empíricos, o limite superior de utilização do canal é cerca de $80 \%$ no padrão IEEE 802.11 quando a WLAN está sobrecarregada. Por isso, $\alpha$ é fixado em 1,25 de forma a refletir a proporção real de tempo efetivamente utilizado para a transmissão (acréscimo de $25 \%$ ao tempo de transmissão dos dados (channel_utilization). Portanto, o fator (1 a.channel_utilization) representa a fração do tempo livre para transmissão.

Uma última observação a se fazer sobre o valor channel_utilization é que ele é calculado pelo 802.11e por uma média de utilização dentro do QBSS (nome dado a um BSS que utiliza a especificação de QoS 802.11e) em questão. Portanto, a expressão para RB é, na verdade, uma aproximação, uma predição do desempenho ao invés de seus valores instantâneos. 


\section{A.10}

\section{O padrão IEEE 802.16}

\section{A.10.1}

\section{Histórico e Características Gerais}

O WiMax (Worldwide Interoperability for Microwave Access) foi proposto inicialmente como uma tecnologia de acesso para última milha constituindo, assim, uma tecnologia WMAN com desempenho igual ou superior às linhas T1/E1 do antigo sistema PDH (Plesiochronous Digital Hierarchy) e da tecnologia ADSL (Assymetric Digital Subscribe Line) que eram tecnologias tradicionais existentes à época.

Desta forma, ele procurava preencher a lacuna existente entre a rede de o UMTS, que fornece uma ampla cobertura, porém de taxa reduzida, e da rede 802.11 que tem características opostas, isto é, cobertura reduzida e taxas de transmissão altas.

Nesse contexto, surgiu em 2001 o primeiro padrão para banda larga sem fio, o padrão 802.16 cuja proposta inicial era prover acesso banda larga sem fio fixa na faixa de frequências entre $10 \mathrm{GHz}$ e $66 \mathrm{GHz}$.

Paralelamente a tudo isso, surge o projeto IMT-A (Internacional Mobile Telecommunication Advanced) cuja meta era a de iniciar as especificações para a quarta geração de sistemas de telefonia móvel conforme definido pelo ITU-R. Alguns pré-requisitos estipulados para a 4G pelo IMT- A são:

- Taxas de dados de 100 Mbps para usuários em alta mobilidade e de 1 Gbps para usuários com mobilidade reduzida;

- Núcleo de rede uma totalmente baseado em IP (all IP Architecture);

- Alta qualidade de serviço para tráfegos multimídia;

- Suporte a endereçamento IPv6.

Devido aos requisitos estipulados, a tecnologia CDMA é deixada de lado e substituída por métodos que realizam equalização no domínio da frequência como o OFDMA (Ortogonal Frequency Division Multiple Access). A OFDMA combinada com a tecnologia MIMO de múltiplas antenas e de alocação dinâmica 
de canais são algumas das grandes diferenças com relação aos sistemas de terceira geração.

Em setembro de 2009, algumas propostas foram apresentadas ao IMT-A como candidatas. Basicamente, todas as propostas foram baseadas em duas tecnologias:

- LTE-A (Long Term Evolution - Advanced): proposta desenvolvida pelo 3GPP que corresponde à evolução "natural" do UMTS já comentada brevemente.

- 802.16m: proposta desenvolvida pelo IEEE que eleva as características das redes 802.16 para enquadrarem-se como uma tecnologia de quarta geração de telefonia móvel.

A tabela A.3 seguir apresenta um resumo das principais características das principais especificações.

Tabela A.3: Características das principais especificações 802.16

\begin{tabular}{|c|c|c|c|c|}
\hline & 802.16 & $802.16 a$ & $802.16 \mathrm{e}$ & $802.16 \mathrm{~m}$ \\
\hline Espectro & $10-66 \mathrm{GHz}$ & $2-11 \mathrm{GHz}$ & $2-6 \mathrm{GHz}$ & \\
\hline $\begin{array}{c}\text { Canal de } \\
\text { Propagação }\end{array}$ & LOS & LOS e NLOS & LOS e NLOS & LOS e NLOS \\
\hline $\begin{array}{c}\text { Taxa de } \\
\text { transmissão }\end{array}$ & 32-134 Mbps & até $75 \mathrm{Mbps}$ & até $15 \mathrm{Mbps}$ & até 300 Mbps* \\
\hline Modulação & $\begin{array}{c}\text { QPSK, 16QAM e } \\
\text { 64QAM }\end{array}$ & $\begin{array}{l}\text { QPSK, 16QAM e } \\
\text { 64QAM(OFDM) }\end{array}$ & $\begin{array}{l}\text { QPSK, 16QAM e } \\
\text { 64QAM(OFDM) }\end{array}$ & $\begin{array}{l}\text { QPSK, 16QAM e } \\
\text { 64QAM(OFDM) }\end{array}$ \\
\hline Mobilidade & fixo & fixo & restrita & total \\
\hline $\begin{array}{l}\text { Larguras de } \\
\text { canal }\end{array}$ & 20,25 e $28 \mathrm{MHz}$ & $\begin{array}{c}\text { selecionável entre } \\
1,25 \text { e } 20 \mathrm{MHz}\end{array}$ & $\begin{array}{c}\text { selecionável entre } \\
1,25 \text { e } 20 \mathrm{MHz}\end{array}$ & até $100 \mathrm{MHz}$ \\
\hline Raio de célula & $1,5-5 \mathrm{Km}$ & até $50 \mathrm{Km}$ & $1,5-5 \mathrm{Km}$ & até $100 \mathrm{Km}$ \\
\hline
\end{tabular}

Observações:

- $\operatorname{LOS}=$ Line of Sight (Linha de visada)

- $\quad$ NLOS $=$ Non Line of Sight (Sem Linha de visada)

- * utilizando-se canal de $20 \mathrm{MHz}$ sem agregação de portadoras [16] 


\section{A.10.2}

\section{Arquitetura de rede do padrão IEEE 802.16}

A arquitetura de rede do padrão 802.16 foi projetada para atingir os requisitos do IMT-A, bem como maximizar o uso dos padrões abertos da IETF (Internet Engineering Task Force) através de uma arquitetura totalmente baseada em IP (all IP Architecture).

O NRM (Network Reference Model) do 802.16, ilustrado na Figura 2.13 a seguir, consiste em várias entidades lógicas. Basicamente, ele é dividido em um ASN (Access Service Network) e um CSN (Connectivity Network), que correspondem, respectivamente, a interface aérea e ao núcleo da rede [18].

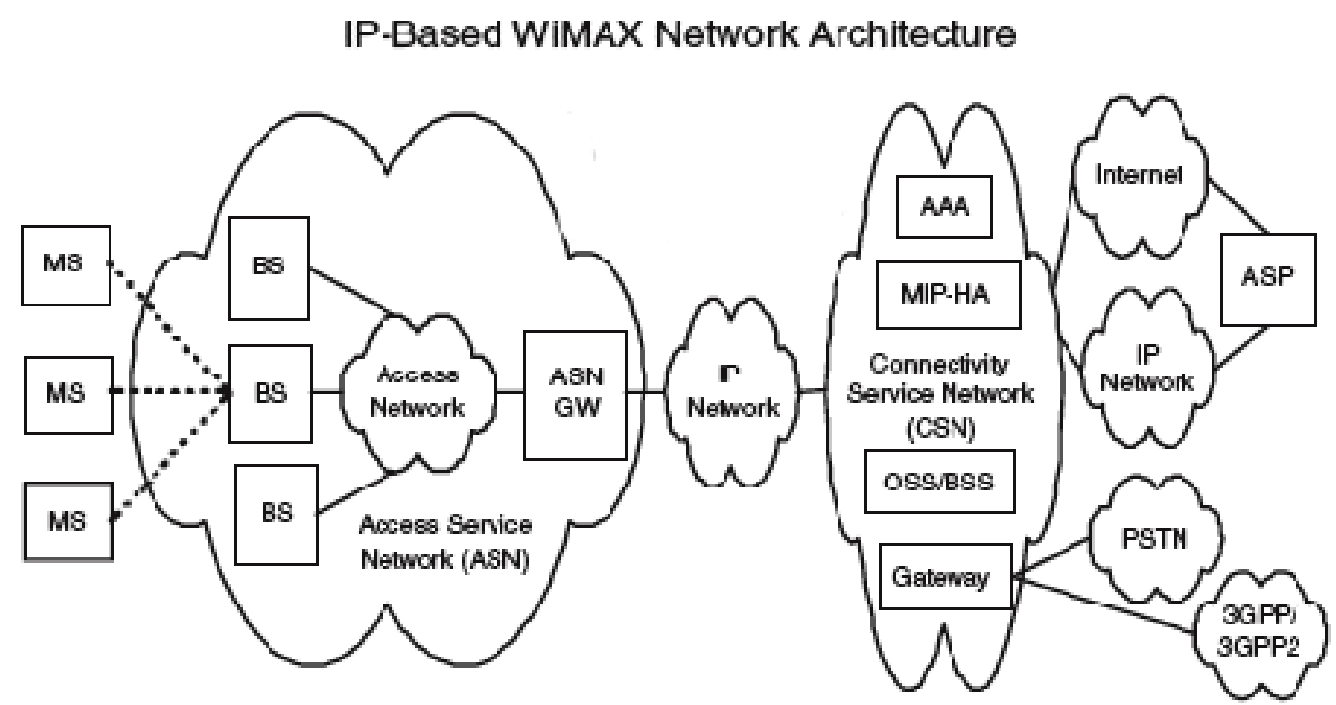

Figura A.13: Arquitetura de rede IEEE 802.16 [13]

\section{A.10.2.1}

\section{MS (Mobile Station)}

É o aparelho ao qual um usuário utiliza os serviços da rede. Ele tem acesso à rede por meio de sua conexão com a estação radio base. O MS pode representar tanto um nó fixo quanto um nó móvel dependendo da especificação IEEE 802.16 utilizada. 


\section{A.10.2.2}

\section{ASN (Access Service Network)}

O ASN representa o conjunto completo de funcionalidades de radio acesso da rede. Ele pode ser visto como uma entidade lógica central, onde todas as funções são concentradas, ou de forma distribuída, ou seja, com suas funções alocadas em subgrupos ASN. Um subgrupo ASN é formado por um gateway, o ASN-GW, e uma estação radio base que, na nomenclatura 802.16, recebe o nome simples de BS (Base Station). É dessa segunda forma que a Figura A.13 representa o ASN. Um ASN decomposto é formado por, no mínimo, um ASNGW e, vinculada a ele, uma ou mais BSs.

- ASN-GW: o gateway ASN age como um ponto de agregação de tráfego de camada dois, de gerências de mobilidade e de segurança dentro de um ASN. Suas funções incluem, aplicação de políticas de QoS, controle de admissão de tráfego e encaminhamento para a CSN correta, armazenamento das informações sobre os perfis de assinantes e criação e alocação de chaves de criptografia. E, pelo lado da gerência de mobilidade, incluem criação e gestão de túnel para mobilidade entre estações de base, gerência de localização (tracking) e de paging intraASN, gestão de recursos de rádio e funcionalidades de FA (Foreign Agent) no caso do uso de IP móvel em rede visitante.

- BS (Base Station): é o elemento de rede que faz a interface entre o usuário no MS e a rede (ASN-GW). Ela executa as funções de radio acesso através da interface aérea segundo as especificações das camadas física e de enlace. Algumas funções adicionais que podem fazer parte da BS incluem gestão de mobilidade restrita, como acionamento de handover e estabelecimento de túneis, gestão de recursos rádio, aplicação de políticas de QoS, classificação de tráfego, serviço DHCP (Dynamic Host Control Protocol), gerenciamento de chaves para autenticação, gerenciamento de sessão e gerência de grupos de transmissão multicast. Tipicamente, várias BSs podem estar associadas a mais de um ASN-GW, permitindo, assim, ações de balanceamento de rede e opções de redundância. 


\section{A.10.2.3 \\ CSN (Connectivity Service Network)}

O CSN corresponde a uma série de funções de rede que proveem serviços IP aos seus usuários. Ele é composto de elementos como roteadores, servidores proxy de AAA (Authentication, Authorization \& Accounting) e banco de dados que contenham o perfil de cada usuário, bem como o controle dos serviços a que ele pode ter acesso. Suas funções incluem gerência de endereçamento IP, controle de admissão de tráfego baseado na política de QoS e no perfil do usuário, conectividade entre ASNs distintas e entre CSNs distintos em caso de roaming através de tunelamento e cobrança (billing) de usuários.

\section{A.10.2.4}

\section{Gerência de Mobilidade [44]}

A rede dá suporte a dois níveis de mobilidade. No primeiro, a mobilidade entre ASNs (ASN anchored handover) ocorre em cada mudança de BS executada pelo MS. Este handover é transparente para o CSN, pois as próprias funções da ASN fazem o novo encaminhamento do fluxo de dados para a BS correta. No segundo nível, a mobilidade ocorre entre CSNs e, desta forma, existe a necessidade de gerência de mobilidade em nível de camada de rede. Essa segunda modalidade é chamada de (CSN anchored handover) e é conseguida com a utilização do IP móvel que é o protocolo especificado pelo padrão para tal situação.

As funcionalidades que dão suporte à gerência de handover são distribuídas entre o ASN e o CSN. Para que a mobilidade ocorra tanto entre as BSs/ASNs, o CSN dá o suporte necessário realizando as funcionalidades de tracking e de paging fora do ASN e, como já dito, também realiza de túneis entre ASNs e CSNs distintos. 


\section{A.10.3}

A camada física do IEEE 802.16

\section{A.10.3.1}

\section{A técnica de acesso OFDMA [17]}

Uma característica comum a todas as especificações IEEE 802.16 é a utilização do método de acesso chamado OFDMA que utiliza os princípios da OFDM.

A OFDM é um caso particular de transmissão do tipo multicarrier. Este esquema divide o canal utilizado em vários subcanais estreitos ou, de forma equivalente, divide uma portadora em várias subportadoras com um mesmo espaçamento entre elas. Os subcanais (ou subportadoras) não são préselecionáveis individualmente. Somente o canal principal é selecionável.

O que torna a OFDM um caso particular de modulação multicarrier é o fato de que os subcanais são sobrepostos uns aos outros. Não há uma Banda de Guarda (Guard Band), recurso geralmente usado como prevenção para que não haja interferência entre subportadoras em multiplexação FDM comum. Na OFDM, o espaçamento é feito de modo que as subportadoras sejam facilmente detectáveis no receptor e que se consiga, também, ortogonalidade entre os sinais mesmo com a sobreposição das subportadoras.

A ortogonalidade entre as subportadoras é uma propriedade importante no que se refere a tornar baixa a complexidade do receptor. Observa-se também, na Figura A.14, a eficiência espectral que este esquema apresenta.

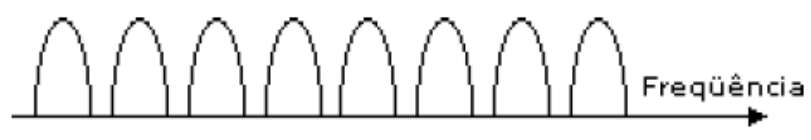

\section{Espectro de oito subportadoras associadas em FDM}

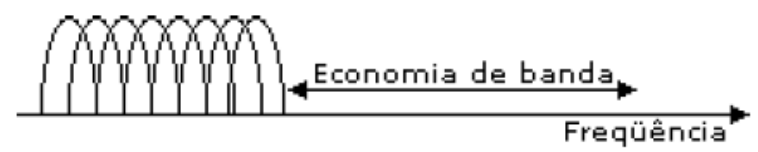

Espectro de oito subportadoras associadas em OFDM

Figura A.14: Eficiência espectral na OFDM [13] 
Cada uma das subportadoras pode transportar fluxos de informação de maneira independente e com diferentes esquemas de modulações como, por exemplo, BPSK, QPSK, QAM-16 ou QAM-64.

O período de um símbolo de um fluxo de dados de alta velocidade tem uma duração extremamente pequena quando comparado com o tempo de atraso natural causado pela propagação do sinal no canal quando se utiliza transmissão serial. Isso acaba causando um fenômeno chamado Interferência entre símbolos ou ISI (Inter-Symbol Interference).

Para minimizar a ISI, faz-se, primeiramente, uma conversão série-paralela dos símbolos a serem transmitidos. Obtêm-se, assim, M transmissões em paralelo. Este fato aumenta a duração dos símbolos de um fator $\mathrm{M}$ aproximadamente. As $\mathrm{M}$ transmissões em paralelo são mapeadas nas $\mathrm{M}$ subportadoras do esquema OFDM. Estas M subportadoras (ou M subcanais) podem utilizar qualquer tipo de modulação independentemente.

Devido à sensibilidade à seleção de frequência que um canal pode apresentar (efeito de multipercurso), diferentes atenuações ocorrem nos diferentes subcanais. Por esse motivo, mesmo com a diminuição da ISI que o esquema OFDM consegue, alguns canais podem apresentam taxas maiores de transmissão do que outros quando se utiliza a mesma modulação neles.

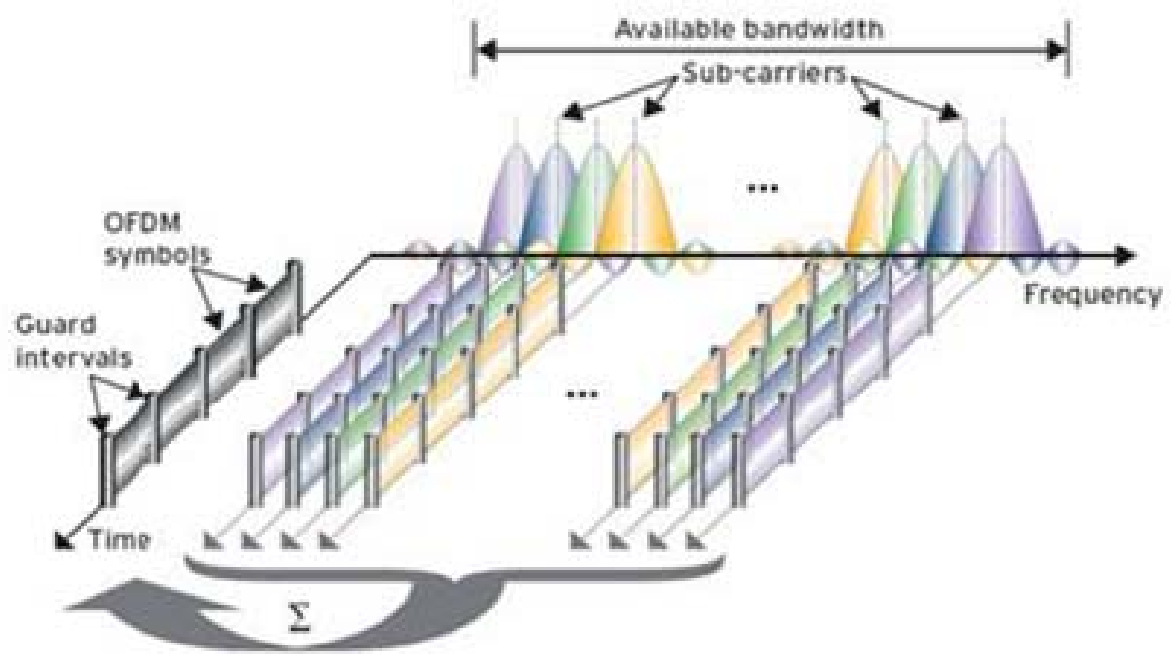

Figura A.15: Divisão em M portadoras e minimização da ISI [55] 
Alguns outros pontos relevantes da OFDM são destacados a seguir:

- Apresenta flexibilidade em diferentes contextos:

o Diferentes bandas podem ser utilizadas sem mudança nos parâmetros fundamentais do sistema ou em equipamentos;

o Recursos de transmissão podem ser alocados a diferentes usuários e agendados livremente no domínio da frequência;

o A reutilização de frequências e a coordenação de interferência entre células são facilitadas.

- Robustez à dispersão temporal (desvanecimento seletivo) que ocorre em canais de rádio, graças à subdivisão das portadoras que, ao invés de transmitir uma banda "larga", transmite subportadoras "estreitas" e com a duração do pulso de transmissão sendo maior em cada uma das portadoras. A baixa interferência entre símbolos é garantida através de um intervalo de guarda (Guard Interval) inserido no início de cada símbolo OFDM (vide Figura A.15 acima).

- Baixa complexidade nos receptores, explorando os benefícios de um processo simples de equalização no domínio da frequência.

\section{A.10.3.2}

\section{Tecnologias de antenas múltiplas}

Esta tecnologia visa explorar uma nova "dimensão" no que se refere a técnicas de multiplexação: a multiplexação espacial. É uma técnica essencial para atingir altas taxas de transmissão. Basicamente, é aplicada em três princípios:

- Ganho de Diversidade (Diversity Gain): Utilização da diversidade do espaço das múltiplas antenas para aumentar a robustez de transmissão contra o desvanecimento causado por multipercurso.

- Ganho de Conjunto (Array Gain): Concentração da energia em uma ou mais direções através de beamforming ou precoding. Isto também permite a múltiplos usuários em diferentes direções serem atendidos simultaneamente (tecnologia MIMO multiusuário).

- Ganho de Multiplexação Espacial (Spacial Multiplexing Gain): Transmissões de múltiplos fluxos (streams) para um único usuário através 
de múltiplas "camadas" espaciais criadas pela combinação das antenas disponíveis.

\section{A.10.3.3}

\section{Modulação Adaptativa}

Esta tecnologia consiste em alterar o esquema de modulação utilizado dependendo das condições do canal com o objetivo de melhorar o desempenho e a qualidade do enlace.

Se uma Estação Base (BS) não consegue estabelecer uma conexão robusta com um assinante usando certo esquema de modulação, ela pode alterá-lo reduzindo a taxa de dados. A potência do sinal recebido varia com a distância e, por isso, a relação sinal-ruído será reduzida quando a distância entre receptor e transmissor também diminuir. A Figura abaixo mostra um exemplo de como se pode utilizar o melhor tipo de modulação no canal variando a distância do receptor móvel para a BS [19].

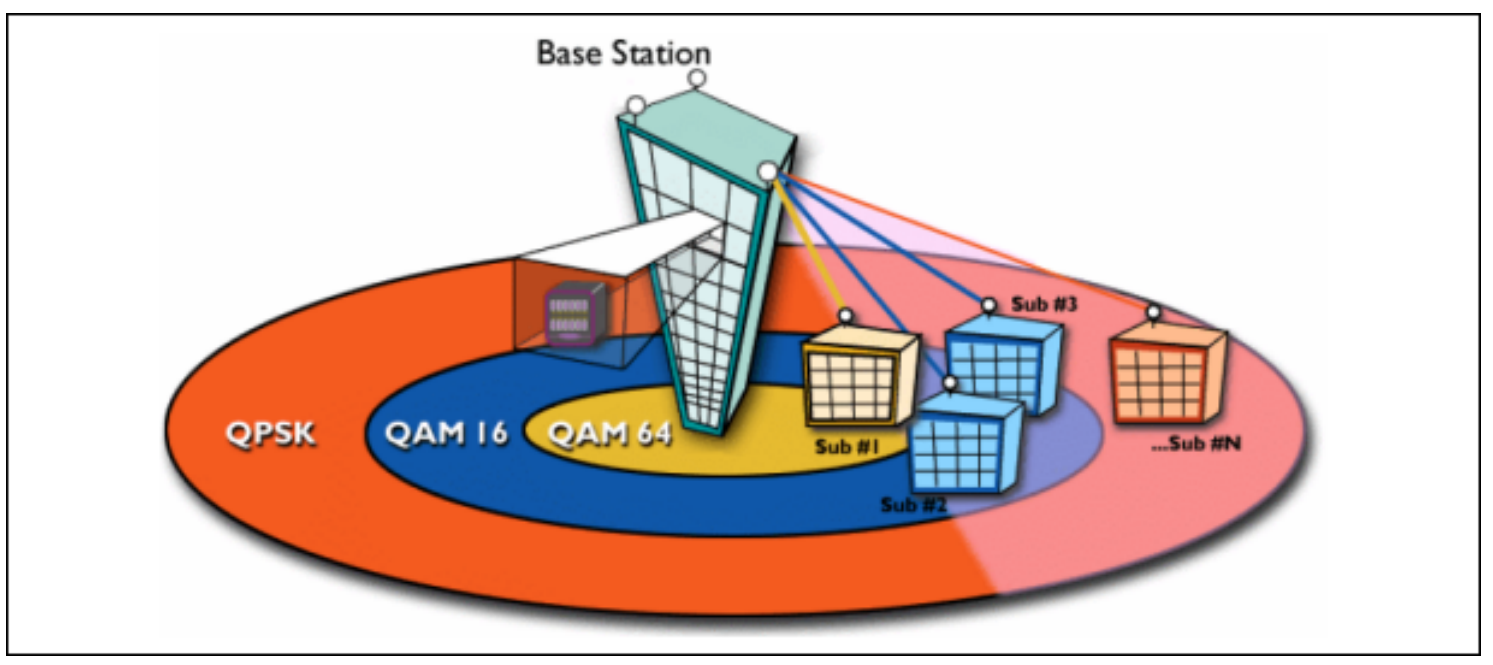

Figura A.16: Ilustração do uso da modulação adaptativa [19]

Para distâncias pequenas entre transmissor e receptor, a modulação mais adequada será a QAM-64. Ela também será de utilizada caso o canal apresente qualidade elevada. Já para grandes distâncias ou onde a estabilidade seja escolhida em detrimento da qualidade, a modulação QPSK se torna mais adequada. 


\section{A.10.4}

\section{A camada MAC do IEEE 802.16}

A camada MAC do IEEE 802.16 está estruturada para trabalhar com múltiplas especificações de camada PHY otimizadas de acordo com a faixa de frequências e com a aplicação ou serviço. Ela está dividida em três subcamadas: subcamada de convergência de serviços específicos, subcamada parte comum de controle de acesso ao meio e subcamada de segurança $[18,20,45]$.

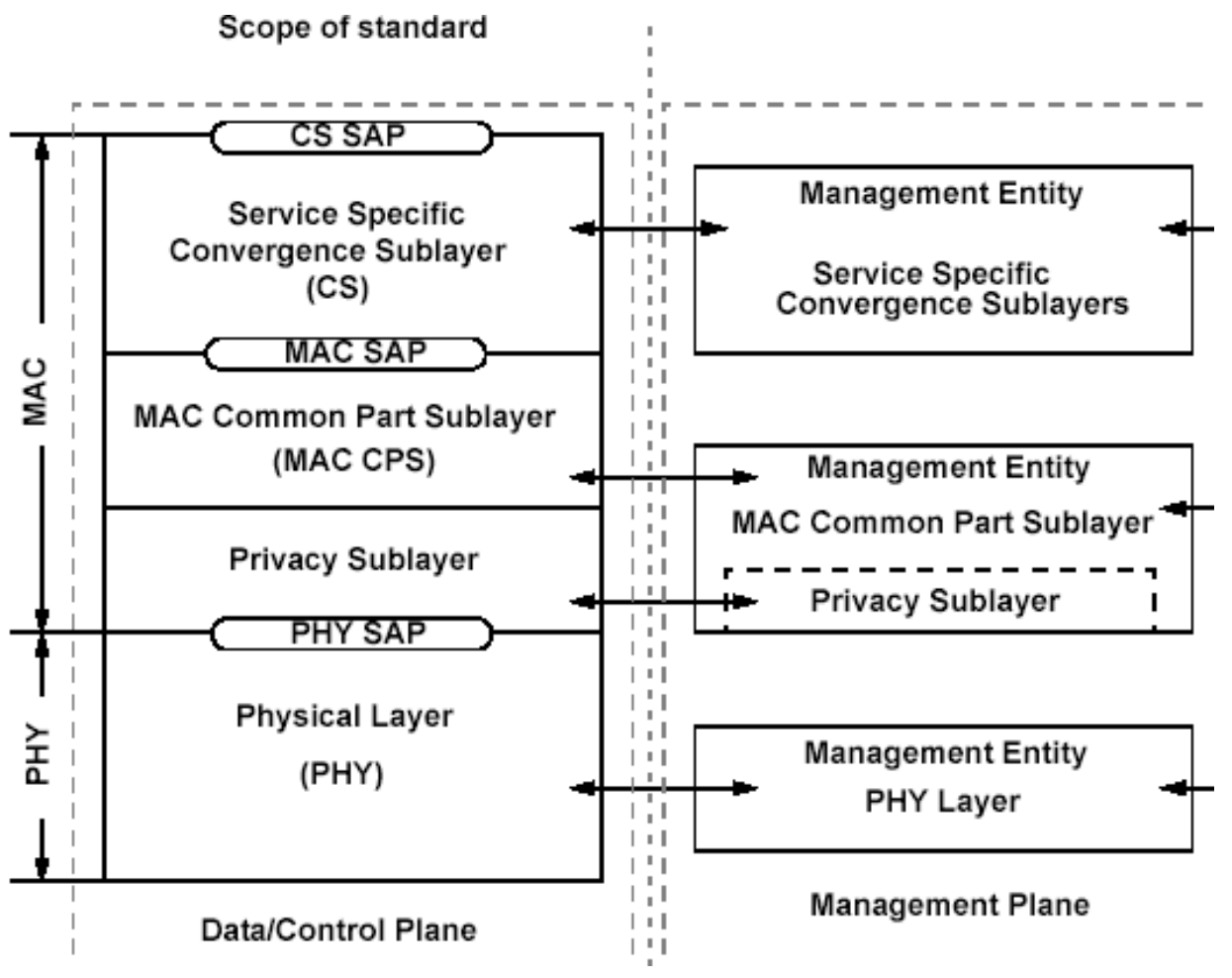

Figura A.17: Camada MAC do IEEE 802.16 [56]

- Subcamada de convergência de serviços específicos ou CS (Service Specific Convergence Sublayer): esta subcamada substitui a subcamada LLC do padrão 802.2, tendo como sua principal função realizar a interface com a camada de rede. Ela classifica os SDUs (Service Data Units) de cada conexão procurando compatibilizar PDUs (Packet Data Units) oriundos de redes ATM (Assinchronous Transfer Mode) ou de pacotes TCP/IP. 
- Subcamada Parte Comum de Controle de Acesso ao Meio ou MAC CPS (MAC Common Part Sublayer): nela estão presentes os principais protocolos da camada MAC. Suas funções mais importantes são o estabelecimento e manutenção das conexões com suporte de QoS e gerenciamento de largura de banda. A subcamada de convergência comum é orientada a conexão com o propósito de mapear os serviços e, posteriormente, associá-los a níveis de QoS (próximo tópico). Pode ser necessária alguma garantia de banda para o estabelecimento da conexão. Dependendo do serviço, a alocação de banda pode ser feita sob demanda ao longo de seu estabelecimento. Uma vez estabelecida uma conexão é necessária uma manutenção contínua dependendo do tipo de serviço conectado. Cada conexão possui um CID (Conection Identificator) composto por um conjunto de 16 bits.

- Subcamada de privacidade (Privacy Sublayer): a subcamada de privacidade ou de segurança possui a função de estabelecer segurança através de criptografia e de autenticação nas conexões entre MSs e BSs utilizando um sistema híbrido de criptografia: a criptografia assimétrica para autenticação e transporte de chaves e criptografia simétrica para cifragem e decifragem de dados.

\section{A.10.5}

\section{Classes de QoS do padrão 802.16}

Existem quatro classes de serviços definidas para redes 802.16. A seguir, uma descrição de cada uma delas [20].

- UGS (Unsolicited Grant Service UGS): voltada para serviços que necessitam de tráfego em tempo real e que possuam tamanho de pacotes fixo, gerando assim, um fluxo de dados contínuo. Neste caso, ao estabelecer uma conexão utilizando essa classe é fornecida uma taxa fixa de largura de banda determinada pela BS sem que o MS a solicite. Com isso, as conexões de classe UGS não podem disputar oportunidades de acesso aleatório de transmissão. 
- rtPS (real time Polling Service): projetada para suportar serviços que necessitem de tráfego em tempo real, mas com fluxo de dados variável, ou seja, pacotes de dados de tamanho variável. Aqui, um MS pode solicitar uma determinada largura de banda. Este tipo de classe também não pode disputar acesso aleatório de transmissão.

- nrtPS (non-real-time Polling Service): desenvolvida para serviços que não necessitam de tráfego em tempo real e, portanto, é voltada para tráfego tolerante a atrasos e com fluxo variável. Trabalha com o sistema de polls de transmissão, pois isso garantirá que haja oportunidade de transmissão mesmo que haja congestionamento. Podem disputar acesso aleatório de transmissão para a requisição de banda.

- BE (Best Effort): projetada para fornecer serviços baseados em tráfego de melhor esforço. É utilizado para transmissão de fluxo variável de dados. Sendo assim, os pacotes de dados nessa classe possuem tamanho variável. Não há garantia de atraso ou de vazão. Um MS terá a oportunidade de disputa para envio de um pedido de requisição de largura de banda através de duas formas: em slots de tempo aleatório ou em oportunidades de transmissão dedicada. 


\section{Apêndice B: Aspectos genéricos da teoria de redes sem fio}

\section{B.1 \\ Introdução}

Este apêndice é composto de três partes. Na primeira parte, são introduzidas análises da arquitetura e definições gerais aplicáveis no contexto de uma rede sem fio genérica. Uma sistematização sobre arquitetura é feita com o objetivo de estabelecer um melhor entendimento do gigantesco número de funcionalidades e do complexo entrelaçamento entre os elementos das redes em fio e também melhorar o entendimento da discussão no que diz respeito à planificação de arquitetura. Assim, ao longo do texto são feitos comentários a respeito dos elementos e funcionalidades das redes UMTS, 802.11 e 802.16 aplicados neste contexto.

$\mathrm{Na}$ segunda parte, entra-se mais profundamente em todas as implicações do processo de handover sendo nela expostas sua definição e suas fases. Após isso, de forma a complementar as considerações do handover em nível de camada de enlace, são consideradas as implicações do handover em nível de camada de rede, situação em que o protocolo IP móvel possui singular importância.

Por fim, na terceira parte são apresentadas as principais propostas de interoperação de redes hoje existentes tendo como destaque o protocolo IEEE 802.21.

\section{B.2}

\section{Arquitetura genérica de uma rede sem fio}

De uma maneira global, a arquitetura de uma rede sem fio pode ser dividida em duas partes: o núcleo da rede ou, do inglês, o CN (Core Network) e a sua interface aérea, também chamada de rede de acesso ou de radio acesso como o nome em inglês sugere: RAT (Radio Acesss Technology).

De fato, cada tecnologia possui um tipo de RAT otimizada para uma situação específica, ou seja, não existe uma tecnologia cuja RAT seja ótima em 
todas as situações [23]. Por exemplo, uma RAT que cobre uma grande extensão territorial, possuindo, assim, grande capacidade de mobilidade, tem, por outro lado, certa ineficiência no que diz respeito à taxa de transferência e em sua escalabilidade (aumento de demanda). O oposto também ocorre, ou seja, uma RAT que permita taxas de transferências altas só o consegue com um alcance bastante limitado. Como um exemplo da primeira situação pode-se enquadrar as redes de telefonia móvel e, na segunda, as redes WLANs.

Dessa maneira, tem-se na interoperabilidade entre tecnologias distintas uma grande possibilidade no aumento e na melhoria dos serviços. Entretanto, para sua realização, [23] enumeram-se como desafios técnicos principais os seguintes aspectos:

- Melhorias no projeto das arquiteturas de rede existentes;

- Mecanismos e protocolos novos para a gerência de handover;

- Gerência de funcionalidades avançada onde as redes heterogêneas possam trocar informações e gerenciar eventos de forma integrada.

A subdivisão da arquitetura de rede acima exposta foi exatamente a utilizada no capítulo precedente para as redes UMTS, 802.11 e 802.16. Agora, será trabalhada uma segunda maneira de enxergar os diferentes componentes de uma rede sem fio.

A Figura B.1 mostra uma arquitetura genérica de rede sem fio em termos de seus principais elementos e de sua pilha de protocolos. Nela, percebe-se outra maneira de se pensar a arquitetura dividindo-a em dois blocos de maneira parecida com o que se faz em um roteador. São eles o Plano de Dados (Data Plane) e o Plano de Controle (Control Plane). Algumas vezes, o Plano de Dados é também chamado de Bearer Plane ou User Plane.

A diferença entre eles é sutil e importante. O Plano de Dados trata das funcionalidades que agem diretamente no fluxo de dados e das informações que passam pela rede. Já o Plano de Controle trata das funcionalidades que decidem o que fazer com esses fluxos e como executar a decisão tomada e, por isso, não atua diretamente no fluxo de dados e de informações. 
A rede de transporte, simbolizada pela nuvem na Figura, é a responsável pela interconexão de todo os elementos (núcleo) da rede sem fio. Ela pode ser uma rede qualquer de pacotes de propósito geral. Há algum tempo, a preferência era por redes ATM (Asynchronous Transfer Mode), mas, hoje em dia, grande parte delas utiliza anéis SDH (Synchronous Digital Hierarchy) conjugadas com redes Metroethernet.

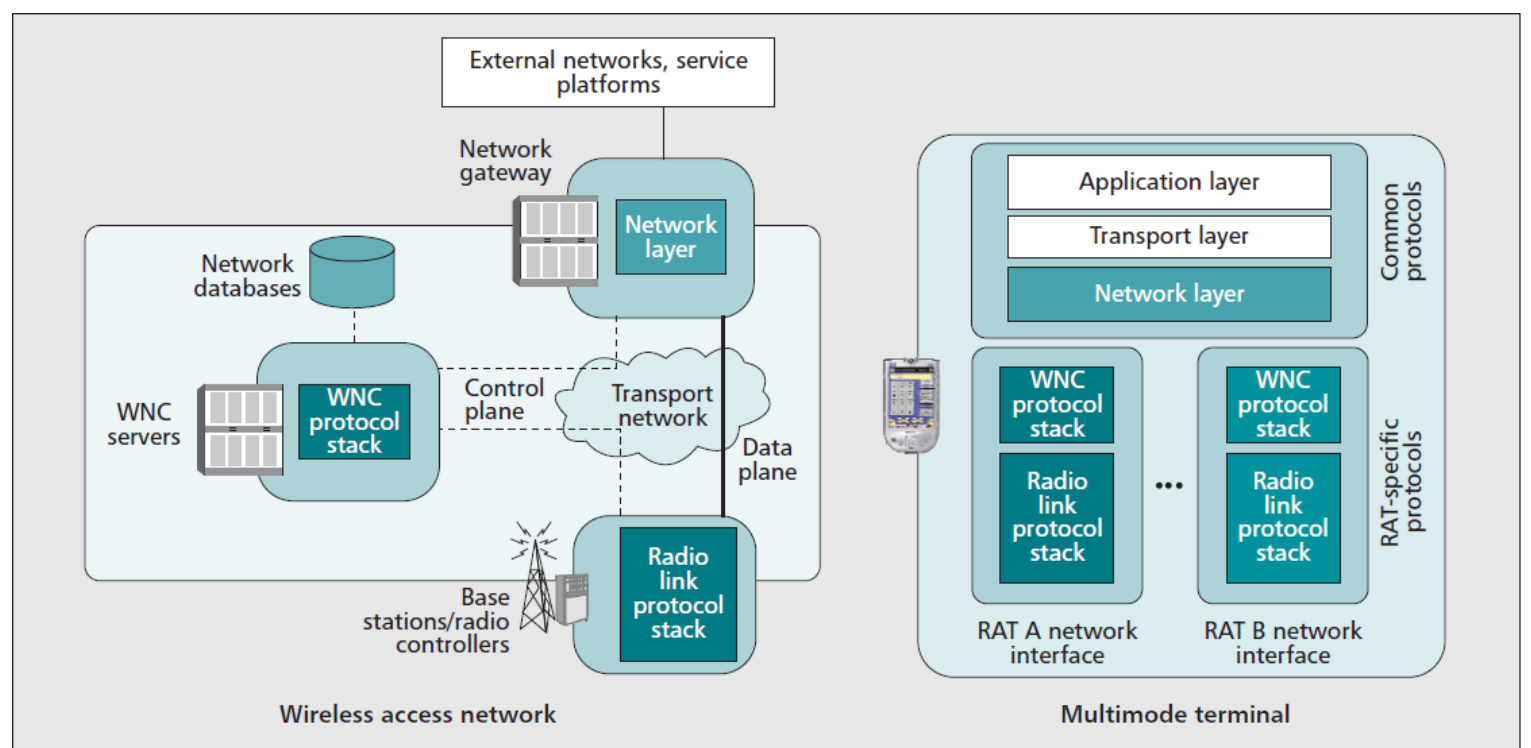

Figura B.1: Plano de Dados e Plano de Controle [23]

\section{B.2.1}

\section{Plano de Dados}

Observam-se, na Figura B.1, os principais elementos pertencentes ao Plano de Dados. O NG (Network Gateway) é o elemento que provê conectividade com a camada de rede além de prover mecanismos onde são executadas, de forma dinâmica, as políticas de QoS e de cobrança (billing) dos serviços oferecido aos usuários móveis da rede. Em redes cuja camada de enlace seja de complexidade elevada, várias entidades, físicas ou lógicas, desempenham o papel do NG. Enquadram-se nesse perfil o GGSN, SGSN, MSC/VLR e HLR para a rede UMTS e elementos diversos do CSN para as redes 802.16.

Outro elemento é a pilha de Protocolos de Enlace de Rádio (Radio Link Protocol Stack, na Figura). Nela é executada a gerência de todos os recursos de rádio (chamados de $R R M$ - Radio Resource Manegement) como, por exemplo, o controle de acesso ao meio e alocação de canais. 
Esta pilha de protocolos pode ser executada inteiramente nas estações radio base, de forma que todas as funções de rádio estejam centralizadas, ou executadas hierarquicamente entre as estações radio base e alguma outra entidade que centralize em si o controle das funções de rádio.

Ainda que algumas funções de rádio sejam executadas no NodeB, a rede UMTS tem em seus RNCs a sua RRM. As redes IEEE 802 trabalham de forma distribuída tendo a sua RRM nas suas estações radio base (AP na 802.11 e BS na 802.16).

\section{B.2.2}

\section{Plano de Controle}

O Plano de Controle realiza a gerência geral de interconectividade dos elementos da rede não operando diretamente, portanto, no fluxo de dados e de informações que trafegam pela rede. Suas funcionalidades são designadas de forma geral como sinalização da rede. Os servidores WNC (Wireless Network Control) representam os elementos de rede em que as seguintes funcionalidades são implementadas:

- Gerência de segurança de sessão;

- Controle de acesso à rede;

- Funções de contabilidade e de cobrança;

- Gerência de mobilidade (em nível de camada de enlace e de rede).

Ao comparar as características do Plano de Dados e de Controle percebese que existem algumas funcionalidades em comum. Isto é uma consequência natural da divisão da arquitetura em que o Plano de Controle dá a ordem para a execução de uma dada funcionalidade e o Plano de Dados a executa. Por isso, os mesmos elementos de rede citados no Plano de Dados podem atuar na aplicação das funcionalidades dos WNCs. 


\section{B.2.3}

\section{Terminal móvel (ou Multimode Terminal)}

No lado direito da Figura B.1, encontra-se outra parte fundamental na arquitetura de rede: o terminal móvel. A divisão que aparece dentro do terminal móvel é baseada na pilha de protocolos TCP/IP e é comentada a seguir.

Na parte de baixo, estão os protocolos relacionados à RAT da rede. Por isso, eles são altamente específicos e, no caso de interoperação com tecnologias de rede diferentes, faz-se necessária uma interface de rede específica para cada tecnologia. Cada interface possuirá os protocolos correspondentes às camadas física e de enlace referentes a sua tecnologia de rede que, por sua vez, irão lidar com a transferência de dados pela interface aérea e com os protocolos relacionados à sinalização de seus respectivos WNCs.

Aqui pode-se inserir um comentário sobre o desafio técnico de se gerir eventos de forma integrada em um ambiente de redes heterogêneo. Hoje em dia, as interfaces de rede nos dispositivos móveis não podem trabalhar de forma integrada, isto é, em uma única WNIC (Wireless Network Interface Card). De fato, dificuldades nos dispositivos de DSPs (Digital Signal Processors) impedem essa integração [25].

Na parte de cima da Figura B.1, estão os protocolos ditos comuns, pois realizam suas funções independentemente da tecnologia utilizada no radio acesso. Ou seja, nada "enxergam" do que ocorre em nível das camadas física e de enlace, mas sofrem, obviamente, consequências do que ocorre nessas duas camadas.

\section{B.3}

\section{O processo de handover}

\section{B.3.1}

\section{Definições e tipos de handover}

No Apêndice A, foram vistos alguns aspectos da gerência de mobilidade das redes UMTS, 802.11 e 802.16. Os comentários até então se voltaram para o aspecto da mobilidade em nível de camada de enlace. De fato, cada tecnologia 
tem especificado o tratamento adequado para o handover horizontal, isto é, para o handover que ocorre entre estações radio base de mesma tecnologia.

Quando se trata de interoperabilidade entre redes de diferentes tecnologias, surge outra categoria de handover. Nessa situação, a transição da conexão de um terminal móvel de uma estação radio base de uma tecnologia A para uma estação radio base de tecnologia $\mathrm{B}$ diferente recebe o nome de handover vertical. O termo vertical surge do fato de que o handover pode ocorrer de uma rede de menor capacidade de transmissão para uma de maior capacidade, dando um "salto para cima" (upward vertical handover) ou, de maneira similar, de uma rede de maior capacidade de transmissão para uma de menor capacidade, dando um "salto para baixo" (downward vertical handover).

\section{B.3.2}

\section{Modalidades e políticas de handover}

Há várias razões para a ocorrência de um handover. Pode-se dividir em dois grupos as razões para sua ocorrência, seja ele vertical ou horizontal. O primeiro grupo é relacionado às preferências do usuário como custo do serviço da operadora, economia com bateria do aparelho, QoS esperada para a aplicação e, last not least, a continuidade do serviço ao movimentar-se para qualquer local. No segundo grupo, entram às preferências da operadora da rede que incluem, entre outras, balanço de carga, seja na estação radio base, seja em outros nós da rede, capacidade de comprometimento de QoS com seus usuários e aumento de receita (isto é, em verdade, uma razão para não realizar o handover).

Na prática, designa-se como políticas de handover de uma rede a tentativa de equalização das preferências dos usuários e das preferências do operador da rede. Assim, quanto às políticas de handover, há três modalidades no que diz respeito à participação da rede $[23,24]$ :

- Handover controlado pela rede ou NCHO (Network Controlled Handover): essa é uma solução totalmente centralizada em que a rede controla a decisão de handover através de medidas realizadas pelo terminal móvel com relação a um determinado número de estações radio base. Os principais problemas deste modo são a grande necessidade de 
processamento em um único ponto e o desconhecimento da situação atual de cada terminal móvel no sistema.

- Handover controlado pelo móvel ou MCHO (Mobile Controlled Handover): nessa modalidade, o terminal móvel tem toda a autoridade e inteligência para executar o handover e selecionar a estação radio base a se reconectar. Entretanto, tais decisões podem impactar na estabilidade e na segurança da rede, uma vez que uma política global não pode ser aplicada.

- Handover assistido pelo móvel ou MAHO (Mobile Assisted Handover): essa é uma modalidade de meio termo com relação às anteriores. Nela, o terminal móvel realiza várias medidas, porém a rede é que toma a decisão final. Aqui se leva em conta a situação atual do terminal móvel, mas ainda se faz necessário grande poder computacional concentrado.

\section{B.3.3}

\section{Fases do processo de Handover}

A gerência de handover é o conjunto de funções que permitem a um terminal móvel permanecer utilizando os serviços de rede enquanto se move entre diferentes áreas. Por isso, ela é uma entidade fundamental em qualquer rede sem fio. Mesmo que sua implementação seja diferente em tecnologias de rede distintas, existem funções básicas que são comuns a todas elas, como por exemplo, as fases do processo de operação de um handover. O handover pode ser dividido nas fases de iniciação, decisão e execução [24,27].

- Iniciação, Preparação ou System Discovery: é a fase na qual o processo de handover se inicia a partir de alguma necessidade (por exemplo, nível baixo de sinal oriundo da estação radio base) e de acordo com as políticas de handover da rede. Ela recebe várias denominações porque também realiza uma coleta de informações sobre a topologia e os recursos disponíveis das redes candidatas à migração. 
- Decisão: essa é a fase na qual são escolhidos tanto a nova rede na qual se vai migrar quanto a melhor estação radio base para se reconectar. Aqui entram em cena os algoritmos de decisão de handover que, munidos das informações coletadas na fase anterior juntamente com as políticas de handover da rede, procuram fornecer a decisão ótima. Esta fase também é responsável por alocar recursos na rede escolhida. Nesse caso, um algoritmo de controle de admissão de conexão deverá ser executado na rede escolhida para o handover.

- Execução: nesta fase ocorrem a sinalização e a troca de informações necessárias ao restabelecimento e redirecionamento do tráfego através do novo enlace. A troca de conexão ou trigger é realizada em nível de camada de enlace embora, em alguns casos, particularmente os que envolvem conexões TCP/IP, o término do processo global do handover não ocorra no instante em que o trigger é feito. Este caso será visto com detalhes quando se comentar a mobilidade em nível de camada de rede.

Alguns ainda acrescentam uma quarta fase ao processo de handover cuja função é desalocar os recursos na rede antiga (release) tornando-os disponíveis a outros usuários [27].

\section{B.3.4}

\section{Gerência de mobilidade e problemas associados ao handover}

O handover é um processo crítico de uma rede sem fio. Ele é ainda mais desafiador quando se trata de um handover vertical. O problema fundamental da gerência de mobilidade consiste na identificação e na localização do terminal móvel que executa o handover. A identificação trata do redirecionamento do fluxo para o terminal móvel correto enquanto a localização corresponde ao local onde o terminal correto se encontra fisicamente.

A identificação e a localização são tratadas nas redes de telefonia móvel pelas funcionalidades chamadas paging e tracking respectivamente. Funções semelhantes ocorrem nas redes 802.11 através dos quadros de controle e de 
gerência (especialmente o Quadro de Beacon) enviados pelo APs periodicamente e que executam as associações e desassociações dos terminais móveis nos APs.

Estes comentários foram realizados no Apêndice A enquanto se falava sobre a gerência de mobilidade nas tecnologias de rede UMTS, 802.11 e 802.16. Ou seja, só foram comentados até agora alguns detalhes do tratamento em nível de camada de enlace. No próximo tópico, será visto o que ocorre em nível de camada de rede.

\section{B.3.4.1}

\section{O protocolo IP Móvel ou MIP (Mobile IP)}

Toda conexão TCP (ou UDP), em curso ou já estabelecida, necessita de um endereço de porta da camada de transporte e de um endereço IP vinculados entre si [10]. Este endereço IP faz parte do conjunto (range) dos endereços IP da rede (ou subrede) a qual o terminal móvel está conectado antes do handover, ou seja, de sua rede de origem.

No momento em que o terminal móvel entra na área de cobertura de outra rede e inicia o processo de handover, horizontal ou vertical, para essa rede, uma série de informações de sinalização entre as redes deve ocorrer para que, antes que se realize o trigger na camada de enlace, o terminal móvel venha a receber um novo IP que, obviamente, pertencerá ao conjunto da nova rede. Caso contrário, a conexão TCP/UDP se perderá logo após a conclusão do trigger. $\mathrm{O}$ endereço IP recebido pelo terminal móvel pertencente à rede de destino recebe o nome especial de CoA (Care of Address).

Conclui-se então que, da mesma forma que se deve saber a identificação correta e a localização do nó móvel na camada de enlace, algo semelhante deve ocorrer também em nível de camada de rede, seja em um handover horizontal, seja em um handover vertical. O protocolo que faz esta gerência de mobilidade na camada de rede é o protocolo IP Móvel. Serão vistos agora alguns aspectos da arquitetura e da operação do MIP. A Figura B.2 abaixo mostra um cenário típico de ação dele. 


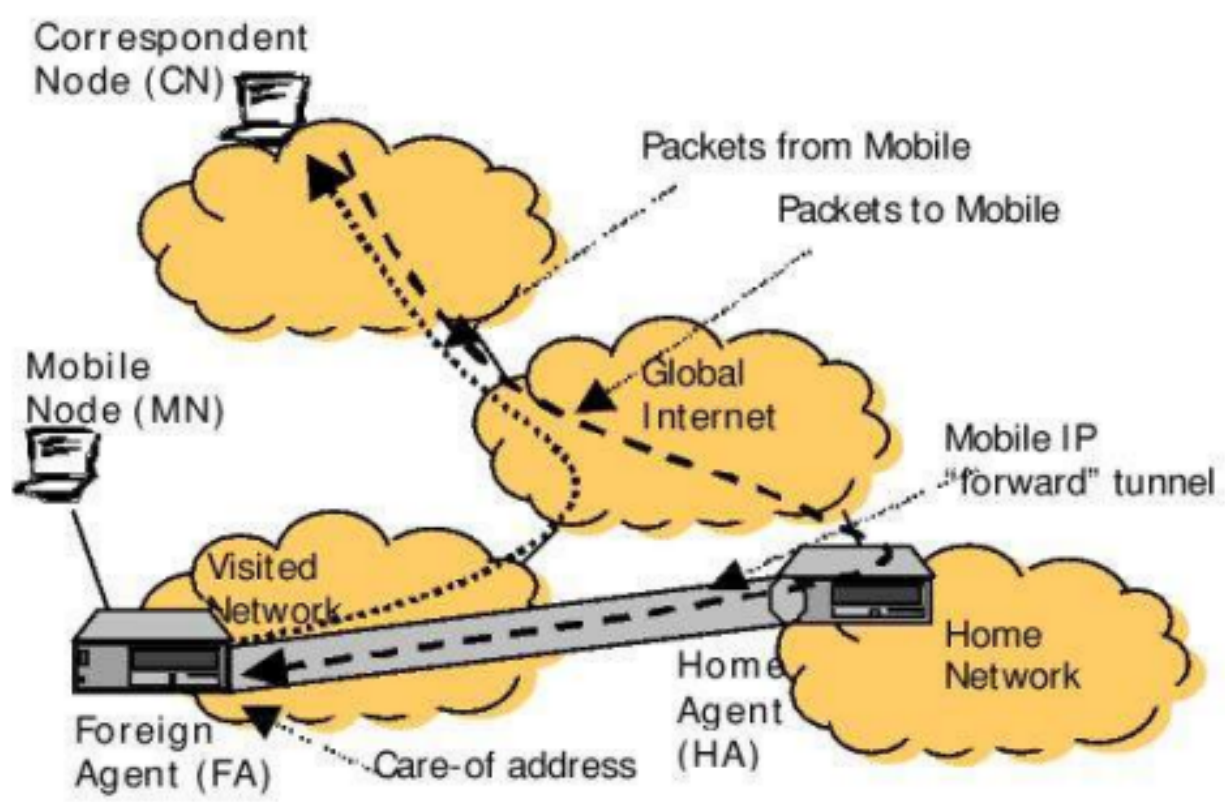

Figura B.2: Móvel em uma rede estrangeira utilizando o MIP [56]

Os elementos principais da arquitetura do MIP são:

- MN (Mobile Node): representa o nó móvel que realiza o handover.

- Rede de origem ou Home Network: é a rede de origem do MN.

- Rede de destino, rede estrangeira ou Foreign Network: é a rede para a qual o MN migra.

- HA (Home Agent): representa um roteador na rede de origem que deve ter instalado o protocolo MIP É ele quem mantém a identificação e a localização corrente do $\mathrm{MN}$ em nível de camada de rede.

- FA (Foreign Agent): representa um roteador na rede de destino que também deve ter instalado o protocolo MIP e que provê o serviço de roteamento ao $\mathrm{MN}$ enquanto estiver conectado na rede de destino.

- CN (Correspondent Node): é qualquer nó, fixo ou móvel, que tem uma conexão TCP/IP ativa com o MN.

Descrição de operação do MIP:

- Anúncio de Presença: os agentes de mobilidade (HA e FA) anunciam suas presenças enviando periodicamente mensagens de Agent Advertisement (também chamadas de RA - Router Advertisement). No entanto, o MN 
pode, opcionalmente, solicitar uma mensagem de Agent Advertisement a qualquer FA acessível através da mensagem Agent Solicitation. Todas estas mensagens são relativas à camada de rede. Logo, já se pressupõe uma conexão em curso com a rede de destino nos níveis de camada física e de enlace.

Um fato importante a se destacar é que, neste ponto, embora já exista conexão em nível de camada de enlace, o processo global do handover ainda não terminou. Ele só irá terminar no recebimento do primeiro pacote de dados por $\mathrm{MN}$, oriundo do $\mathrm{CN}$, que tenha como endereço IP de destino o CoA. As linhas da Figura B.2 com pontilhado mais espesso exemplificam o sentido desses pacotes.

- Registro do MN na rede de destino: quando o MN detecta que se moveu para uma rede estrangeira, um endereço CoA deve ser obtido nesta nova rede. Esse endereço pode ser obtido a partir do conteúdo da mensagem Agent Advertisement ou por algum mecanismo de atribuição externo como, por exemplo, um servidor DHCP (Dynamic Host Configuration Protocol). Em seguida, o MN deve registrar seu novo IP, o CoA, em seu HA. O MN faz isso através da troca das mensagens Registration Request e Registration Reply via FA ou diretamente pela conexão com sua rede de origem. Obviamente, nessa última opção, há uma dupla conexão do $\mathrm{MN}$ em nível de camada de enlace.

- Tunelamento de Datagramas: neste momento, a fase de execução já foi terminada, porém o processo de handover ainda não está completo. Agora, será dado início à transmissão do primeiro pacote de dados, oriundo do $\mathrm{CN}$, para o $\mathrm{MN}$. No recebimento desse pacote, o processo do handover como um todo é considerado terminado. Os pacotes enviados para o endereço de origem do MN são interceptados pelo HA e enviados por ele para o FA através de um túnel IP. Ou seja, o pacote destinado ao endereço de origem do $\mathrm{MN}$ é encapsulado dentro de um pacote que tem como endereço de destino o CoA. O FA recebe esse pacote oriundo do HA, o desencapsula e entrega a carga útil dele (payload) ao MN. Nota-se que o $\mathrm{MN}$ recebe um pacote endereçado a ele com o seu IP de origem, ou seja, o encapsulamento e o desencapsulamento são totalmente transparentes para o MN. 
$\mathrm{Na}$ direção inversa, os pacotes enviados pelo $\mathrm{MN}$ são geralmente entregues ao destino através dos mecanismos tradicionais de roteamento IP através do FA sem a necessidade de passar pelo HA. Todo o processo é ilustrado na Figura B.2.

\subsubsection{2}

\section{Ineficiências do MIP e handover transparente}

Infelizmente, o protocolo IP móvel não elimina todos os problemas do gerenciamento de mobilidade na camada de rede. As duas ineficiências mais críticas, comentadas a seguir, são o roteamento triangular (Routing Triangle) e o tempo que ele acrescenta à latência do processo global de handover [27,28].

- Roteamento triangular: quaisquer pacotes enviados ao terminal móvel após o handover devem ser roteados primeiramente para o HA, presente em sua rede de origem, para serem, em seguida, reenviados para a rede de conexão atual do terminal móvel (isto é, a rede estrangeira) mesmo quando existir uma rota mais eficiente entre o $\mathrm{CN}$ e o terminal móvel. Um caso limite acontece quando o $\mathrm{CN}$ se encontra na própria rede estrangeira. Em vez de o FA enviar o pacote diretamente para o $\mathrm{CN}$, ele o enviará primeiramente para o HA.

- Latência: as mensagens de sinalização nas fases de anúncio de presença, a obtenção do CoA e o registro do terminal móvel na rede estrangeira inserem uma latência considerável ao processo de handover.

Em [28], encontra-se um estudo de alguns esforços que buscam minimizar estes e outros problemas presentes no MIP. Os protocolos FMIPv6 e HMIPv6, ambos baseados na versão mais recente do protocolo IP, o IPv6, constituem exemplos desses esforços.

Mesmo com as melhorias, a latência total do processo de handover ainda é grande e não atende às necessidades das aplicações de tempo real e sensíveis a atrasos. Devido à popularização de aplicações desse tipo, a busca pela redução dessa latência se tornou objeto de vários estudos. Assim surgiu o conceito de handover suave e transparente, ou Seamless Vertical Handover, cujo significado consiste em tornar o processo de handover vertical imperceptível para o terminal 
móvel, independentemente da aplicação que ele esteja utilizando, exatamente como ocorre no handover (horizontal) na rede de telefonia móvel celular.

Outra abordagem muito interessante $[26,29,30]$ na busca pela redução da latência é a utilização do protocolo mSCTP (mobile Stream Control Transmission Protocol). Essa abordagem consiste na resolução do problema de gerenciamento de mobilidade seja tratado também na camada de transporte ao invés de tratá-lo somente em nível de camada de rede. De maneira resumida, o mSCTP realiza uma espécie de soft handover na camada de transporte, ou seja, permite que mais de um endereço IP seja gerenciado em uma sessão TCP através da funcionalidade de multihoming. Assim, é possível realizar a troca de um endereço IP por outro sem que a conexão fim a fim entre $\mathrm{MN}$ e $\mathrm{CN}$ seja interrompida, o que não é possível fazer com os protocolos TCP e UDP.

Uma vez feitos os comentários acerca dos problemas e das soluções relacionados à camada de rede durante o processo de handover vertical, a atenção se volta agora para os problemas na camada de enlace durante o processo. Isto é, como tratar, de forma efetiva, a interoperabilidade entre tecnologias de RATs diferentes? Esse é o objetivo do próximo tópico.

\section{B.4}

\section{Principais propostas de interoperabilidade [23]}

\section{B.4.1}

\section{I-WLAN (Interworking WLAN)}

A I-WLAN é uma solução de integração entre redes 3G e WLANs proposta pelo 3GPP [29]. Neste modelo, um usuário tem acesso somente a serviços específicos de uma rede visitada, mas não realiza handover vertical. Por exemplo, um usuário portador de um smart card UMTS poderia acessar serviços IMS (Internet Multimedia Subsystem), com QoS oferecido pela rede de telefonia móvel, através de um hotspot 802.11 público cuja operadora fornecedora tenha contrato de roaming com a operadora de telefonia móvel [24,31].

Esta arquitetura de integração é comumente referida como levemente acoplada (loose coupling interworking) e uma ilustração dela é feita na Figura 
B.3, onde podem ser vistos os principais elementos da rede UMTS, de uma WLAN 802.11 e as novas funcionalidades necessárias marcadas com círculos.

Pelo lado da rede 3GPP, tem-se o GGSN executando as funções de gateway, o SGSN executando funções de servidores WNC pertencentes ao Plano de Controle da rede e as funções relacionadas à pilha de protocolos de rádio (RRM) distribuída entre o RNC e os NodeBs.

Já pelo lado da 802.11 , todas as funções de camada física e de enlace são executadas pelo AP, as funções de gateway são realizadas por roteadores genéricos quaisquer e algumas das funções de servidores WNC do Plano de Controle, por exemplo, controle de acesso e segurança, realizadas por servidores AAA que utilizam protocolos IETF como RADIUS e EAP (Extensible Authentication Protocol) ou 802.1x.

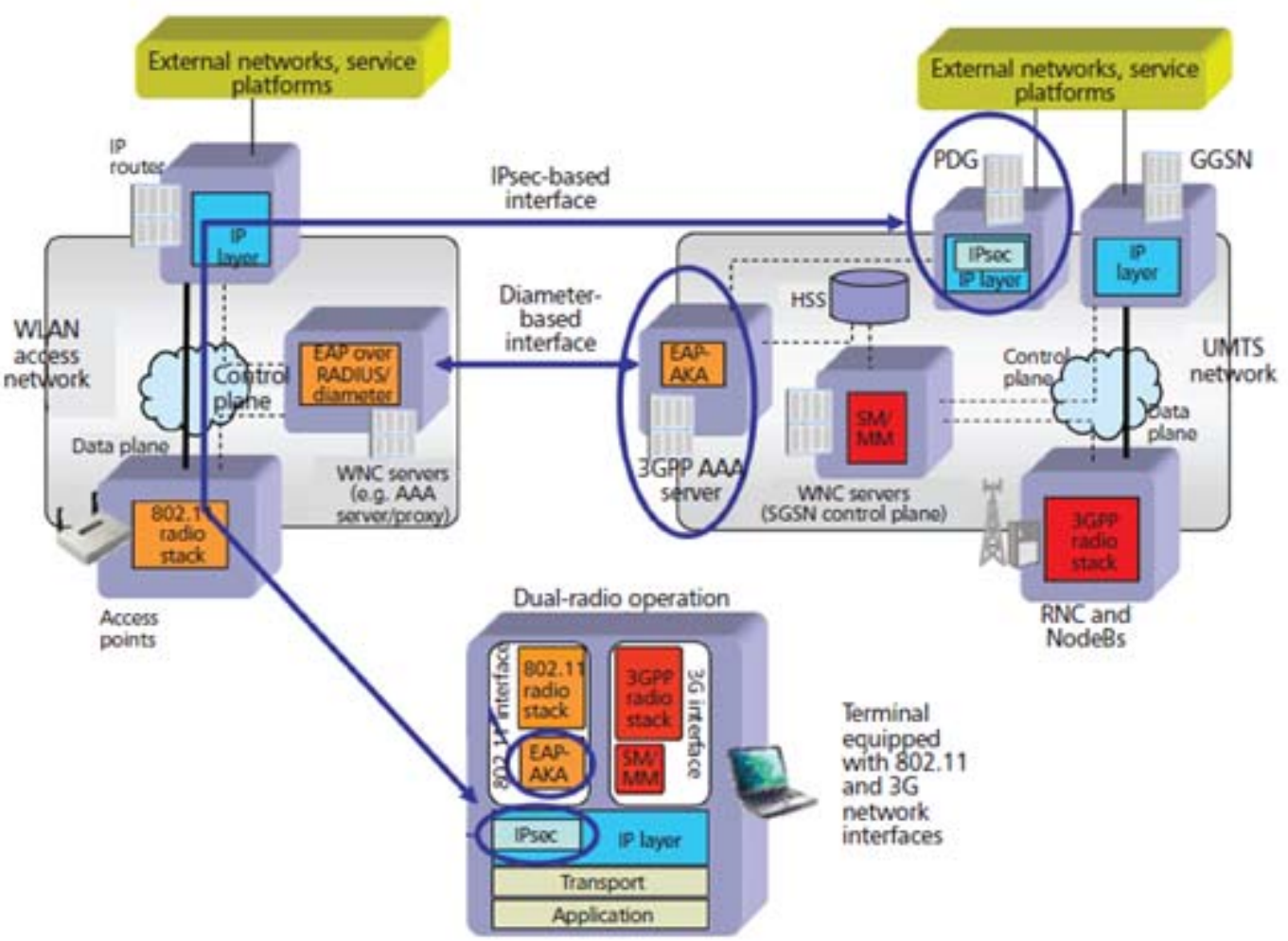

Figura B.3: Arquitetura de integração I-WLAN [23]

A interoperação fica por conta da adição de um servidor com funções AAA (Authorization, Authentication and Accouting) na rede 3GPP e de um servidor proxy na 802.11. A interface que liga os dois é baseada no protocolo DIAMETER, uma evolução do RADIUS, o qual também será responsável por 
transmitir mensagens EAP de autenticação e autorização. Algumas funções dos dois são apresentadas a seguir [29]:

- Servidor Proxy: realiza a retransmissão de informações AAA entre a WLAN e rede 3GPP e aplicação de políticas de acordos de roaming entre as operadoras WLAN e 3GPP;

- Servidor 3GPP AAA: realiza atualizações e acessos aos registros dos perfis dos usuários no HLR/VLR da rede UMTS para autenticação e autorização de serviços e fornece informações sobre a aplicação adequada de roteamento para a WLAN.

Em nível de camada de rede, tem-se o IPsec como provedor de túneis seguros entre o terminal móvel e uma nova entidade de rede chamada de PDG (Packet Data Gateway) que funciona, para usuários da WLAN, exatamente como o GGSN funciona para os usuários da rede UMTS. Ou seja, um usuário na WLAN tem acesso a serviços de redes externas através do PDG. Uma lista com as redes UMTS disponíveis é disponibilizada pela rede WLAN através de um mecanismo de descoberta de rede definido no RFC 4284.

No terminal móvel, a I-WLAN requer basicamente, interfaces convencionais das redes UMTS e 802.11 com suporte a autenticação EAP/802.1x (por exemplo, certificação WPA) e ao protocolo IPsec.

No que se refere a operações de billing and accouting, o acesso a informações de uso de recursos por parte do usuário é livre, ou seja, informações coletadas na WLAN podem ser comparadas com as da UMTS ou convertidas no formato CDR (Call Detail Record) utilizado por esta última [29].

\section{B.4.2}

\section{GAN (Generic Access Network)}

A proposta GAN tem como solução de integração estender os serviços de comutação de pacotes e de circuitos para que funcionem através de uma rede IP de banda larga. A rede IP não deve ser necessariamente a rede 802.11, embora essa seja a abordagem mais comum. 
A Figura B.4 abaixo mostra a arquitetura de integração GAN no mesmo cenário descrito para a I-WLAN. Seus três principais elementos são o GANC (GAN Controller) localizado na rede 3GPP/UMTS, um terminal móvel chamado UMA (Unlicensed Mobile Access) e uma nova interface entre elementos específicos do 3GPP.

O funcionamento do GANC é parecido com o do RNC uma vez que faz interface com o núcleo da rede, agindo como um gateway para serviços $3 \mathrm{GPP}$. É por esse motivo que abordagem GAN também é conhecida como interoperação rigidamente acoplada (tight coupling interworking).

O UMA é um terminal que possui uma interface 3GPP/UMTS e uma interface 802.11, sendo capaz de comunicação de forma dual-mode. A interface entre o GANC e o UMA deve possuir funções muito parecidas com as funções exercidas pelo RRC (Radio Resource Control) podendo ser chamada de GA-RRC (Generic Access - RRC). Nota-se o protocolo GA-RRC com um círculo em volta dentro do UMA na Figura B.4. A transferência de todo o tráfego entre o GANC e a WLAN pode utilizar mecanismos de tunelamento IP como o IPsec.

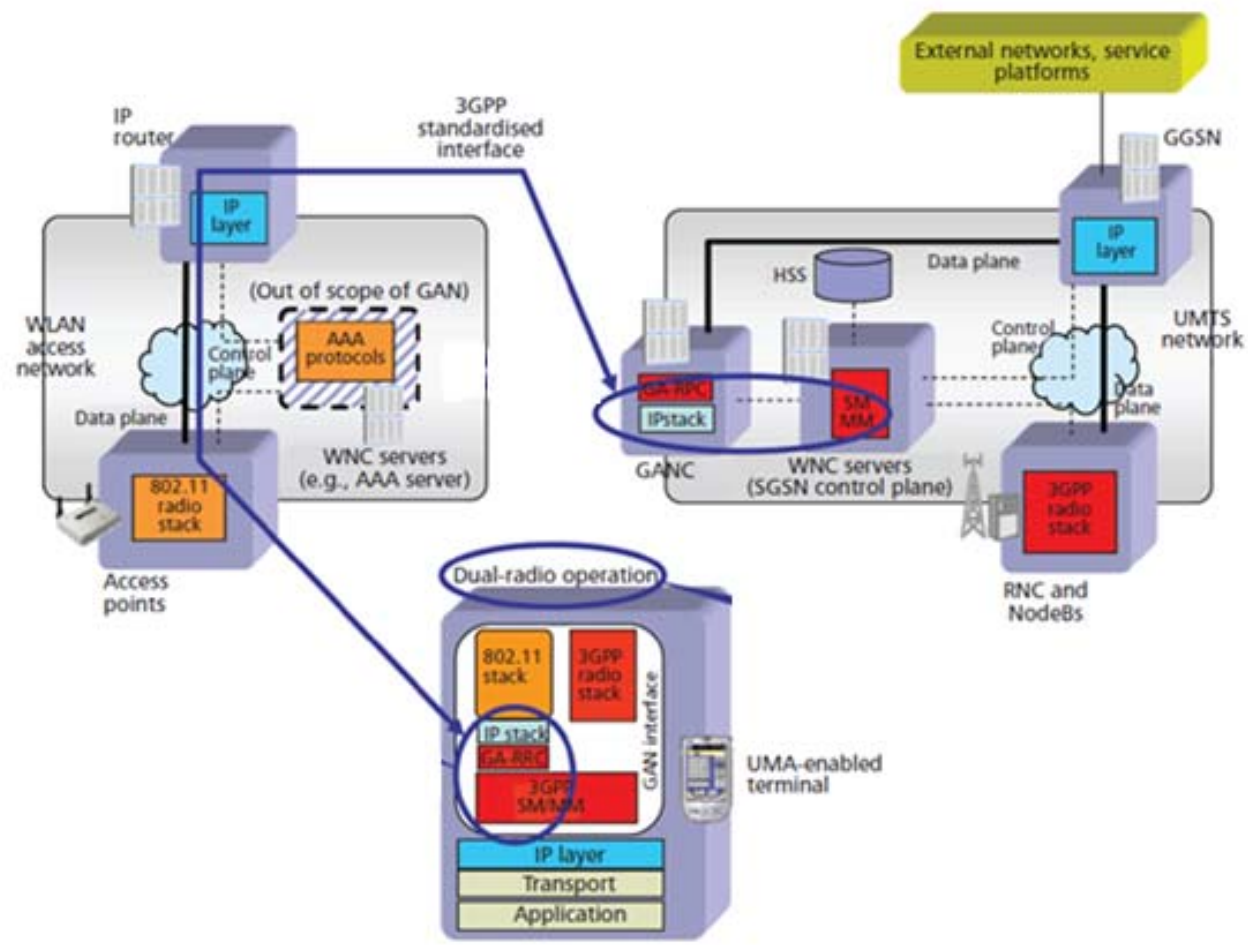

Figura B.4: Arquitetura de integração GAN [23] 
Operações de handover ocorrem aproveitando-se os mecanismos especificados pela rede UMTS. O GANC, assim como o RNC, pode redirecionar o fluxo de dados ou de chamadas para outros RNCs e, caso necessário, pode utilizar a mobilidade com um elemento âncora em níveis de hierarquia superior como descrito no tópico A.5 do Apêndice A.

Latências de handover vertical parecidas com as latências de handover horizontal da rede UMTS podem ser alcançadas pelo fato do terminal UMA dar suporte à comunicação dual-mode. Assim, o terminal UMA pode se conectar ao GANC através da WLAN mantendo sua conexão com a rede UMTS intacta, de modo que os mecanismos para a realização do handover em nível de camada de enlace não são necessários. Também em razão desse motivo, não há necessidade de servidores AAA na arquitetura GAN.

O modelo GAN de interoperação é também proposto pelo $3 \mathrm{GPP}$ e foi inicialmente desenvolvido com redes $2 \mathrm{G}$ e estendido posteriormente às redes $3 \mathrm{G}$, mas não há previsão para soluções LTE/SAE.

\section{B.4.3}

\section{IEEE 802.21 ou MIH (Media Independent Handover)}

A proposta do IEEE para interoperação de redes visa um tipo de solução genérica diferentemente das duas propostas anteriores. Entretanto, aplicá-las em um contexto de redes 3GPP não é uma tarefa tão harmoniosa como aplica-las no contexto das redes IEEE802 que já compartilham aspectos comuns de arquitetura.

A solução IEEE 802.21 deverá constituir, no futuro, outro capítulo na proposta do IEEE junto ao IMT-A em que as tecnologias 802.16 e 802.11 poderão ser integradas sob um único modelo de interoperabilidade. 